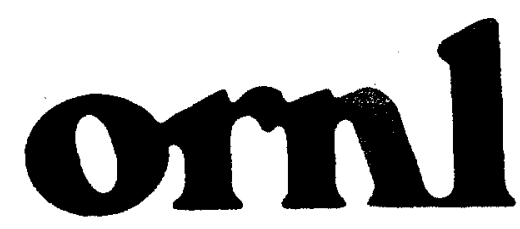

ORNL/TM-13689

OAK RIDGE

NATIONAL

LABORATORY

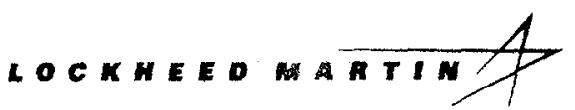

Evaluation of Improved

Techniques for the Removal of Fission

Products From Process

Wastewater and

Groundwater: FY 1998

and 1999 Status

D. T. Bostick

S. M. DePaoli 
Chemical Technology Division

\title{
EVALUATION OF IMPROVED TECHNIQUES FOR THE REMOVAL OF FISSION PRODUCTS FROM PROCESS WASTEWATER AND GROUNDWATER: FY 1998 AND FY 1999 STATUS
}

D. T. Bostick and S. M. DePaoli

Date Prepared-July 1999

Date Published -February 2000

Prepared for the

U.S. Department of Energy Office of Science and Technology Efficient Separations and Processing Crosscutting Program

\author{
Prepared by the \\ OAK RIDGE NATIONAL LABORATORY \\ Oak Ridge, Tennessee 37831-6285 \\ managed by \\ LOCKHEED MARTIN ENERGY RESEARCH CORP. \\ for the \\ U.S. DEPARTMENT OF ENERGY \\ under contract DE-AC05-96OR22464
}




\section{CONTENTS}

LIST OF TABLES $\ldots \ldots \ldots \ldots \ldots \ldots \ldots \ldots \ldots \ldots \ldots \ldots \ldots \ldots \ldots \ldots \ldots \ldots \ldots \ldots$

LIST OF FIGURES $\ldots \ldots \ldots \ldots \ldots \ldots \ldots \ldots \ldots \ldots \ldots \ldots \ldots \ldots \ldots \ldots \ldots \ldots \ldots \ldots$

EXECUTIVE SUMMARY $\ldots \ldots \ldots \ldots \ldots \ldots \ldots \ldots \ldots \ldots \ldots \ldots \ldots \ldots \ldots \ldots \ldots \ldots$

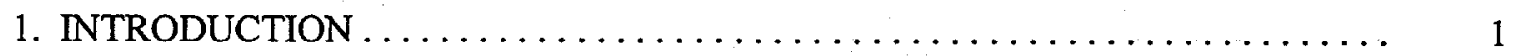

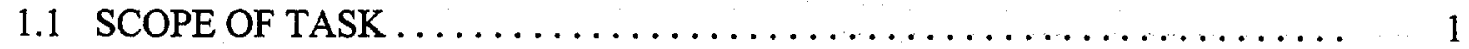

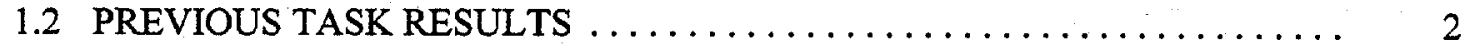

1.3 OVERVIEW OF FY 1998 TASKS $\ldots \ldots \ldots \ldots \ldots \ldots \ldots \ldots \ldots \ldots \ldots \ldots \ldots \ldots$

1.4 OVERVIEW OF FY 1999 TASKS $\ldots \ldots \ldots \ldots \ldots \ldots \ldots \ldots \ldots \ldots \ldots \ldots$

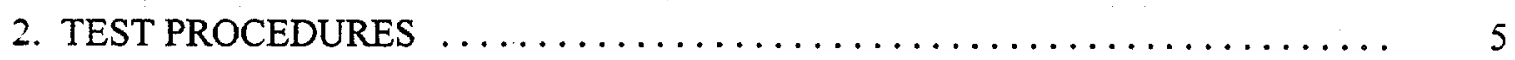

2.1 WASTEWATER FEED STREAMS FOR TESTS $\ldots \ldots \ldots \ldots \ldots \ldots \ldots \ldots \ldots$

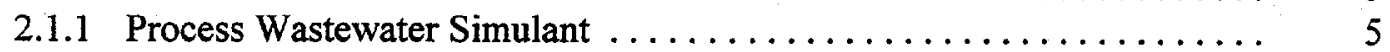

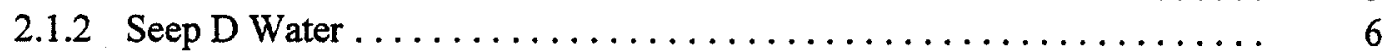

2.1 .3 Core Hole 8 Groundwater ...................... 6

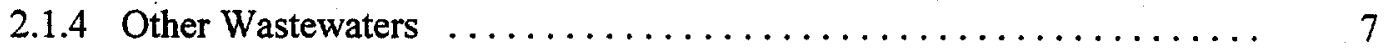

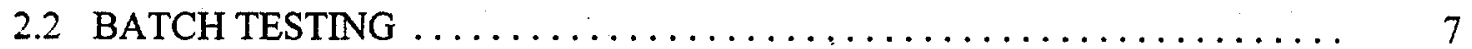

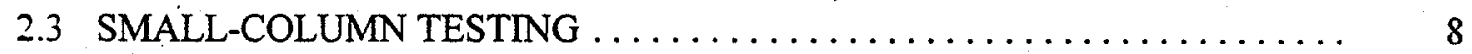

2.4 GAMMA SCANNING OF COLUMNS $\ldots \ldots \ldots \ldots \ldots \ldots \ldots \ldots \ldots \ldots \ldots$

3. CHEMISTRY OF CATION EXCHANGE ON SORBENTS IN PROCESS/SEEP/

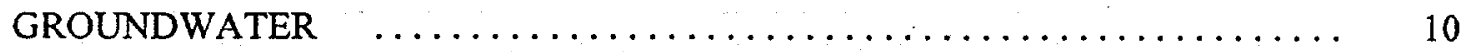

3.1 INTERACTION OF WASTEWATER CATIONS WITH SORBENTS ....... 10

3.2 PHYSICAL AND CHEMICAL CHARACTERISTICS OF ION

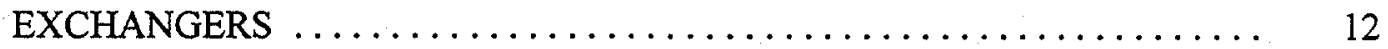

3.3 CATIONIC COMPOSITION OF SORBENTS $\ldots \ldots \ldots \ldots \ldots \ldots \ldots \ldots \ldots$

4. RESULTS OF BATCH TESTS USING ACTUAL WASTEWATERS $\ldots \ldots \ldots \ldots .14$

4.1 GAAT WASTEWATER BATCH STUDIES $\ldots \ldots \ldots \ldots \ldots \ldots \ldots \ldots \ldots \ldots \ldots$

4.2 CNF WASTEWATER BATCH STUDIES $\ldots \ldots \ldots \ldots \ldots \ldots \ldots \ldots \ldots \ldots \ldots$

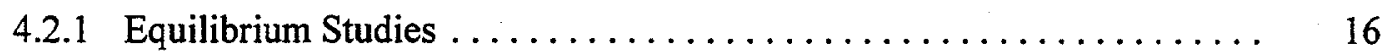

4.2.2 CNF Wastewater Isotherms . . . . . . . . . . . . . . 17

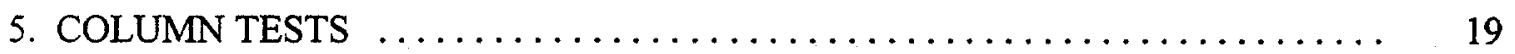

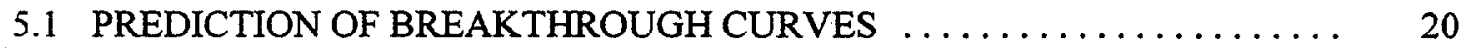

5.2 COLUMN TESTS WITH PWTP SIMULANT FEED $\ldots \ldots \ldots \ldots \ldots \ldots \ldots \ldots$

5.2 .1 Chabazite Zeolite ............................. 23

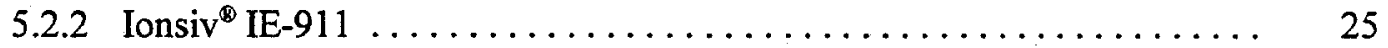

5.3 COLUMN TESTS WITH ACTUAL SEEP D WATER $\ldots \ldots \ldots \ldots \ldots \ldots \ldots$

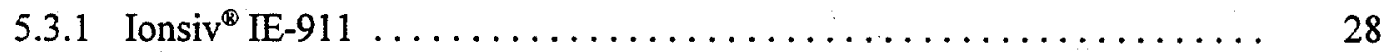

5.3.2 Chabazite Zeolite ............................. 29

5.4 CST COLUMN FIELD TEST WITH CORE HOLE 8 GROUNDWATER

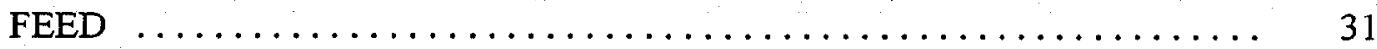

6. GAMMA SCANNING OF COLUMNS $\ldots \ldots \ldots \ldots \ldots \ldots \ldots \ldots \ldots \ldots \ldots$ 


\section{CONTENTS (Cont.)}

6.1 CST/PWTP SIMULANT COLUMN $\ldots \ldots \ldots \ldots \ldots \ldots \ldots \ldots \ldots \ldots \ldots . \ldots \ldots$

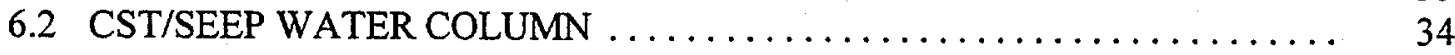

6.3 ZEOLITE/SEEP WATER COLUMN $\ldots \ldots \ldots \ldots \ldots \ldots \ldots \ldots \ldots \ldots \ldots$

7. CONCLUSIONS AND RECOMMENDATIONS $\ldots \ldots \ldots \ldots \ldots \ldots \ldots \ldots \ldots \ldots$

7.1 TREATMENT OF GAAT SCABBLING WATER AND CNF FEED

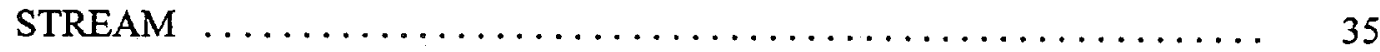

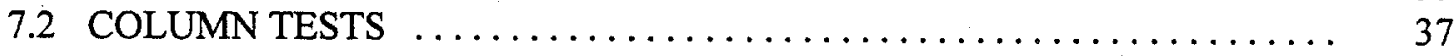

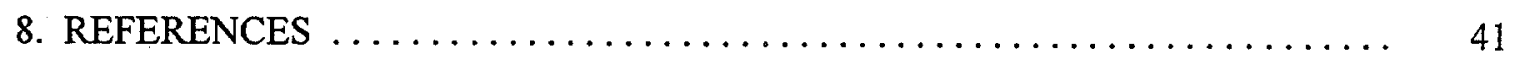




\section{LIST OF TABLES}

Table

Page

1 Composition of Process Waste Treatment Plant (PWTP) actual and simulant wastewater and Seep D water and groundwater from Core Hole 8 sump ... 43

2 Actual compositions of wastewaters used in batch studies $\ldots \ldots \ldots \ldots \ldots 43$

3 Atomic parameters of wastewater cations $\ldots \ldots \ldots \ldots \ldots \ldots \ldots \ldots . \ldots 4$

4 Physical and chemical parameters of sorbents $\ldots \ldots \ldots \ldots \ldots \ldots \ldots \ldots$

5 Cationic compositions of tested sorbents $\ldots \ldots \ldots \ldots \ldots \ldots \ldots \ldots \ldots$

6 Comparison of strontium and cesium removal by Ionsiv ${ }^{\otimes}$ IE-911 in different

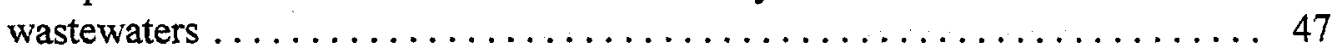

7 Decontamination factors and predicted distribution coefficients from batch isotherm studies in CNF wastewater $\ldots \ldots \ldots \ldots \ldots \ldots \ldots \ldots \ldots 48$

8 Cation $\mathrm{K}_{\mathrm{d}}$ values $(\mathrm{L} / \mathrm{kg})$ in actual $\mathrm{CNF}$ wastewater $\ldots \ldots \ldots \ldots \ldots \ldots$

9 Selectivity factors in actual $\mathrm{CNF}$ wastewater $\ldots \ldots \ldots \ldots \ldots \ldots \ldots \ldots$

10 Summary of variables in column experiments $\ldots \ldots \ldots \ldots \ldots \ldots \ldots$

11 Film Mass-transfer coefficients calculated for column breakthrough curve

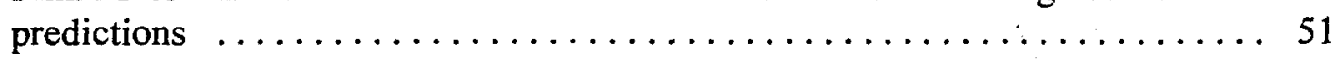

12 Liquid diffusivities calculated by the Nernst equation $\ldots \ldots \ldots \ldots \ldots \ldots 2$

13 Distribution coefficients $\left(\mathrm{K}_{\mathrm{d}}\right)$ at $50 \%$ breakthrough for cations during

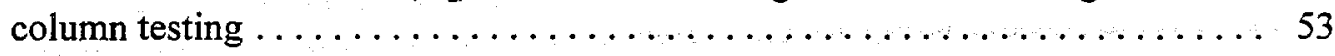

14 Selectivity factors among competing cations for CST and zeolite ....... 54 


\section{LIST OF FIGURES}

$\begin{array}{lll}\text { Figure } & \text { Page }\end{array}$

1 Flow diagram for column test $\ldots \ldots \ldots \ldots \ldots \ldots \ldots \ldots \ldots \ldots \ldots \ldots \ldots$

2 Schematic of gamma scan shielding configuration $\ldots \ldots \ldots \ldots \ldots \ldots \ldots$

3 Photo of gamma scanning equipment $\ldots \ldots \ldots \ldots \ldots \ldots \ldots \ldots \ldots \ldots$

4 Equilibrium time for strontium and cesium removal from actual CNF

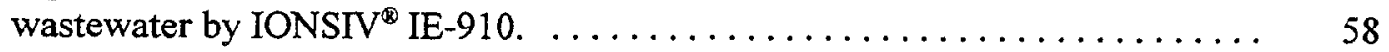

5 Equilibrium time for cesium removal from actual CNF wastewater by $\ldots \ldots$. .

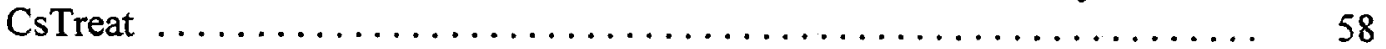

6 Sorption isotherms for strontium removal from CNF wastewater by various

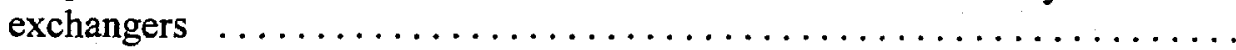

7 Sorption isotherms for cesium removal from CNF wastewater by various

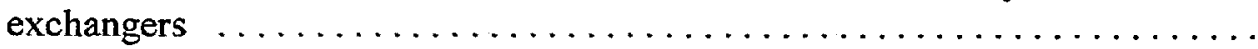

8 Experimental and theoretical breakthrough curves for (a) sodium,

(b) magnesium, and (c) calcium on chabazite zeolite in PWTP simulant .....

9 Experimental and theoretical strontium breakthrough on chabazite zeolite in PWTP simulant

10 Experimental and theoretical cesium breakthrough on chabazite zeolite in

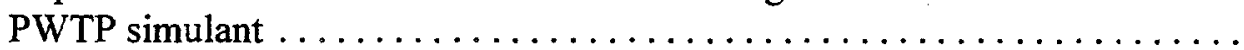

11 Experimental and theoretical breakthrough curves for (a) sodium, (b) calcium, (c) magnesium, and (d) potassium on Hydrogen 1-CST in PWTP simulant .....

12 Experimental and theoretical breakthroughs of strontium on Hydrogen1-CST in PWTP simulant . . . . . . . . . . . . . . . . . . . . . . . . .

13 Experimental and theoretical breakthroughs of cesium on Hydrogen 1-CST in PWTP simulant . . . . . . . . . . . . . . . . . . . . . . . .

14 Experimental and theoretical breakthrough curves for (a) sodium, (b) calcium, (c) magnesium, and (d) potassium in groundwater on Hydrogen2-CST in Seep D water . . . . . . . . . . . . . . . . . . . . . . . 
15 Experimental and theoretical breakthrough of strontium on Hydrogen2-CST in

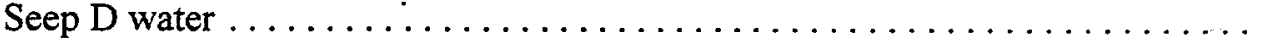

16 Experimental and theoretical cesium breakthrough on Hydrogen2-CST in Seep D water . . . . . . . . . . . . . . . . . . . . . . . . .

17 Experimental and theoretical breakthrough curves for (a) sodium, (b) calcium, (c) magnesium, and (d) potassium on chabazite zeolite in groundwater on chabazite zeolite in Seep D water . . . . . . . . . . . . . . . . . .

18 Experimental and theoretical breakthrough of strontium on chabazite zeolite in Seep D water . . . . . . . . . . . . . . . . . . . . . . . . . .

19 Experimental and theoretical breakthrough of cesium on chabazite zeolite in

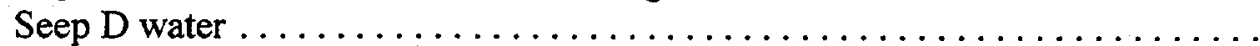

20 Experimental and theoretical curves for (a) sodium, (b) calcium, (c) magnesium, and $(d)$ potassium on CST in Core Hole 8 groundwater . . . . . . . . . . .

21 Experimental and theoretical breakthrough of strontium on CST in Core Hole 8

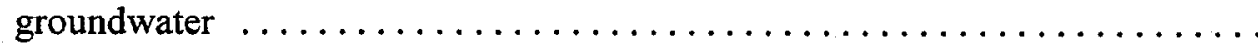

22 Experimental and theoretical breakthrough of cesium on CST in Core Hole 8

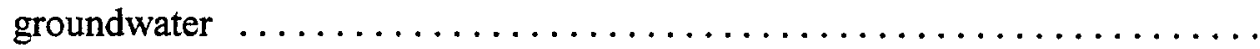

23 Gamma scan of columns showing cesium loading on (a) CST from PWTP simulant, (b) CST from Seep D water, and (c) chabazite zeolite from Seep D water

24 Selectivity coefficient ratios (selectivity factors) for strontium and competing cations on various sorbents in $10 \mathrm{~mL}$ of actual CNF wastewater:

(a) strontium/calcium, (b) strontium/sodium, (c) strontium/potassium, and

(d) strontium/magnesium

25 Selectivity coefficient ratios (selectivity factors) for cesium and competing cations on various sorbents in $10 \mathrm{~mL}$ of actual CNF wastewater:

(a) cesium/calcium, (b) cesium/sodium, (c) cesium/potassium, and

(d) cesium/magnesium 


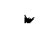

$-$

$-$ 


\section{EXECUTIVE SUMMARY}

The primary goal of this program is to test new materials for their capacity to remove fission products, namely ${ }^{90} \mathrm{Sr}$ and ${ }^{137} \mathrm{Cs}$, from near-neutral-pH wastewater and groundwater containing competing cations. In the past several years, many materials have been tested for their ability to meet these criteria. Testing has encompassed physical and chemical characterization of these materials; batch and column testing to quantify their uptake of strontium and cesium; and testing of the select materials on actual waste against the baseline sorbent, chabazite zeolite. Results and conclusions have been summarized yearly in status reports. This report summarizes the information obtained during fiscal years (FY) 1998 and 1999.

Milestones addressed during FY 1998 and 1999 include the completion of a column test using Ionsiv ${ }^{\circledR}$ IE-911 (a crystalline silicotitanate (CST) pellet) to remove strontium and cesium from a variety of waste water sources. Waste streams included process waste simulant reflecting the composition of the ORNL Process Waste Treatment Plant (PWTP); actual wastewater generated at the East Tennessee Technology Park (ETTP) and treated at the Central Neutralization Facility (CNF); operation of a column to treat actual Seep D water from Oak Ridge National Laboratory (ORNL) burial grounds; and actual groundwater collected at the $2016 \mathrm{C}$ sump area of Core Hole 8, ORNL. Testing results were augmented by gamma emission scans to locate sorption profiles of gamma emitters within the loaded columns.

Ionsiv ${ }^{\oplus}$ IE-911, obtained through UOP, selectively removed strontium and cesium from ORNL process wastewater simulant, with $50 \%$ breakthroughs of major cations ( $\mathrm{Ca}, \mathrm{Mg}$, and $\mathrm{Na}$ ) occurring at less than 1300 bed volumes (BV) and potassium at $15,000 \mathrm{BV}$. The column experiment was terminated at 120,000 $\mathrm{BV}$, at which time strontium breakthrough was at $15 \%$ of feed concentration. Incipient breakthrough of strontium occurred at $16,000 \mathrm{BV}$, as compared with $3000 \mathrm{BV}$ on a similarly sized zeolite column. Cesium was not present in the Ionsiv ${ }^{\otimes} \mathrm{IE}-911$ column effluent throughout the 10 months of column operation, whereas initial cesium breakthrough occurred at $6000 \mathrm{BV}$ on the zeolite column. The strontium and cesium distribution coefficients $\left(\mathrm{K}_{\mathrm{d}}\right)$ in PWTP water simulant were estimated to be $1.7 \times 10^{5}$ and $8 \times 10^{5} \mathrm{~L} / \mathrm{kg}$, respectively, or 30 and 100 times greater than those obtained for sorption on zeolite. Unlike the zeolite, the Ionsiv ${ }^{\circledR}$ IE-911 pellets did not break down over the extended length of the column test; no fines or column plugging was encountered.

A similar comparison test was performed using actual Seep D water, a water source with a calcium concentration nearly twice $(75 \mathrm{ppm})$ that of the process water simulant. The seep water is contaminated with approximately $20,000 \mathrm{~Bq} / \mathrm{L}{ }^{90} \mathrm{Sr}$; both ${ }^{85} \mathrm{Sr}$ and ${ }^{137} \mathrm{Cs}$ were subsequently added to the water so that strontium and cesium breakthrough from the Ionsiv ${ }^{\oplus} \mathrm{IE}-911$ and zeolite columns could be followed by gamma spectroscopy. Over 30,000 BV and 60,000 BV were processed through the zeolite and CST columns, respectively. Because of the elevated concentration of calcium in groundwater, all competing cations, with the exception of potassium, reached $50 \%$ breakthrough at $350 \mathrm{BV}$ on both columns. Incipient breakthrough of strontium occurred at 2000 and $6500 \mathrm{BV}$ on the zeolite and Ionsiv ${ }^{\otimes} \mathrm{IE}-911$ columns, respectively. At the completion of the CST column run, strontium breakthrough was 50\%; no cesium was present in the column effluent. At half the column throughput of CST, strontium had completely broken through and began to desorb from the zeolite column. Cesium breakthrough was at 
$70 \%$. These results indicate that maximum strontium loading on CST is greater than three times higher than on zeolite, and that strontium is retained on CST while processing much higher volumes of seep water.

A field demonstration using a small CST column to treat ${ }^{90} \mathrm{Sr}$ contaminated groundwater collected at Core Hole 8 was completed after five months of continuous operation. This particular source of water has the highest calcium concentration $(85 \mathrm{ppm})$ of the waste streams tested thus far. Approximately $42,000 \mathrm{BV}$ of Core Hole 8 groundwater were treated. Breakthrough profiles of competing water cations are similar to those observed in the treatment of Seep D water. Incipient column breakthrough (at $0.1 \%$ $\mathrm{C} / \mathrm{Co}$ ) for strontium was noted at $3200 \mathrm{BV}$ of Core Hole 8 feed. Beyond incipient breakthrough, the strontium profile exhibited a slow, unsteady increase in ${ }^{90} \mathrm{Sr}$ content in the column effluent. The gradual breakthrough profile is indicative of the slow kinetics of sorption between strontium and CST. Peak ${ }^{90} \mathrm{Sr}$ breakthrough reached $25 \%$ at 22,000 bed volumes (BV), concurrent with potassium displacement from the column. Once potassium concentration in the column effluent returned to feed stream levels, ${ }^{90} \mathrm{Sr}$ levels decreased and average $24(+/-4) \%$ of influent concentration for the remainder of the column run. Data available to date indicate the ${ }^{90} \mathrm{Sr}$ activity in the $2016 \mathrm{C}$ sump area of Core Hole 8 plume is about $170 \mathrm{~Bq}$ L. CST column data thus suggest that at least $30,000 \mathrm{BV}$ of $2016 \mathrm{C}$ sump water can be treated before the column effluent activity level exceeds the DOE 5400.5 Derived Concentration Guide of 37 $\mathrm{Bq}{ }^{*} \mathrm{Sr}$.

As noted in previous CST column studies, the sorption capacity for cesium is so great that no ${ }^{137} \mathrm{Cs}$ was found in the effluent, even after treating $42000 \mathrm{BV}$ of groundwater containing high levels of calcium. A gamma counting system was assembled so that the ${ }^{137} \mathrm{Cs}$ loading profile from the above experimental runs could be determined. The two CST and zeolite columns loaded from the treatment of process u asteu ater simulant and Seep D groundwater were scanned. Results indicated good run-to-run reproducibility. The gamma data were used to calculate the distribution coefficient $\left(\mathrm{K}_{\mathrm{d}}\right)$ and loading capacity of ${ }^{137} \mathrm{Cs}$. The $\mathrm{K}_{d}$ for $\mathrm{Cs}$ removal from process water is $850,000(\mathrm{~L} / \mathrm{kg})$ on CST as compared to $90,000(\mathrm{~L} / \mathrm{kg})$ on zeolite. The cesium $\mathrm{K}_{\mathrm{d}}$ in the Seep $\mathrm{D}$ groundwater matrix was also significantly higher than that of zeolite, $150,000(\mathrm{~L} / \mathrm{kg})$ versus $50,000(\mathrm{~L} / \mathrm{kg})$, respectively. If funding is available at the end of FY 99 , a request will be made to scan the CST column used to treat Core Hole 8 groundwater so that a $\mathbf{K}_{\mathbf{s}}$ for cesium in this matrix can also be determined.

Batch studies were also completed to determine the strontium and cesium removal efficiencies of several sorbents for two additional waste streams: (1) wastewater resulting from the washdown of the inactive low-level waste tanks at ORNL (only tested with engineered CST) and (2) wastewater normally treated at the CNF at ETTP. The challenge in treating these two waste streams is the significantly higher concentrations of competing cations: $400-7000 \mathrm{ppm} \mathrm{Na}$; up to $400 \mathrm{ppm} \mathrm{Ca}$; and $10-20 \mathrm{ppm} \mathrm{K}$.

Batch uptake tests were performed to determine how effective Ionsiv ${ }^{\circledR}$ IE-911 would be in treating ORNL tank wastewater. Initial results indicated that the ${ }^{90} \mathrm{Sr}$ was not removed to a significant extent from the waste, but the decontamination factor for ${ }^{137} \mathrm{Cs}$ was greater than 1200 . The presence of trace complexing agents and the relatively high concentration of potassium ion $(20 \mathrm{ppm})$ in the waste suppressed ${ }^{90} \mathrm{Sr}$ removal. Therefore, at this time, treatment of this waste stream by CST will not remove ${ }^{90} \mathrm{Sr}$ to levels that will allow for treatment of the wastewater in a more cost-effective manner.

The driver for additional treatment at $\mathrm{CNF}$ appears to be defined by the source of waste burned at the Toxic Substance Control Act (TSCA) incinerator. If the waste is derived from ORNL, TSCA blowdown may contain sufficient ${ }^{90} \mathrm{Sr}$ and ${ }^{137} \mathrm{Cs}$ to require an additional decontamination operation at $\mathrm{CNF}$ for these 
determine the decontamination achievable with various sorbents. The sorbents in these batch tests included: (a) Ionsiv ${ }^{\circledR}$ IE-911 and IE-910 (engineered and powdered CST), (b) SrTreat ${ }^{\circledR}$ powder, (c) CsTreat ${ }^{\circledR}$ powder, and (d) the baseline sorbent, chabazite zeolite. CsTreat ${ }^{\circledR}$, followed closely by Ionsiv ${ }^{\otimes}$ IE-910, has the highest capacity for cesium in the waste. Zeolite did not compete well against the other sorbents for either cesium or strontium. Ionsiv ${ }^{\mathbb{D}}$ IE-910 removed the strontium much more effectively than either the SrTreat ${ }^{\otimes}$ or the zeolite. Strontium is expected to be present in solid particulates in the TSCA blowdown water and therefore could be removed primarily by physical means. It is the cesium, present as a soluble cation, that must be removed chemically from CNF waste. At the cesium concentrations tested here, a minimum DF of 1000 would be necessary to reduce the cesium in the wastewater to an acceptable level. The CsTreat ${ }^{\circledR}$ does not sorb primary wastewater cations and hence has a greater selectivity for ${ }^{137} \mathrm{Cs}$ than does Ionsiv ${ }^{\otimes} \mathrm{IE}-910$. However, if strontium must be removed also, the CsTreat ${ }^{\mathbb{D}}$ will have to be used in conjunction with a strontium-selective sorbent. CNF batch processing time places an additional demand on sorbent selection for waste treatment. Sixteen thousand gallons of waste are currently processed within a 4-h period. In the review of the above sorbents, it appears that equilibration times are more a function of the radionuclide rather than the sorbent. Only $50 \%$ of maximum cesium removal is achieved in $4 \mathrm{~h}$ relative to the 24-h equilibration time required on either Ionsiv ${ }^{\circledR}$ IE-910 or CsTreat ${ }^{\circledR}$. Less than $20 \%$ strontium is removed at $4 \mathrm{~h}$ as compared with that removed at an equilibration time approaching $100 \mathrm{~h}$. Under this time constraint, it may be advisable to post-process the CNF waste using column technology.

The overall conclusions that can be drawn from FYs 1998 and 1999 data are: (a) Ionsiv IE-910 and IE-911 demonstrate the best selectivity for strontium, particularly in high-salt media; (b) CsTreat ${ }^{\circledR}$ has a slightly greater loading capacity and selectivity for cesium over CST, although strontium removal must still be addressed; and (c) the engineered form of CST is more selective for either radionuclide and is mechanically more stable when compared with zeolite for processing wastewater using column technology. It is hoped that with more extensive use of the Ionsiv ${ }^{\otimes}$ products, the initial cost of the CST will decrease to make it more competitive economically with other commercial products. 


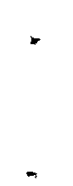

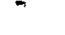

-

. 


\section{INTRODUCTION}

\subsection{SCOPE OF TASK}

The objectives of this task are to adequately understand the needs of those responsible for wastewater treatment, to evaluate emerging treatment materials, and then to provide the end users with pertinent information required to select and scale up these new technologies for a given waste stream. A survey of customers within the Oak Ridge Reservation was performed in FY 1997 to define the critical parameters required by the user to implement a technology to remove ${ }^{90} \mathrm{Sr}$ and ${ }^{137} \mathrm{Cs}$ from wastewater. Findings from this survey were used to direct the FY 1998 and FY 1999 studies that are summarized in this report. Technical issues specific to the removal of ${ }^{90} \mathrm{Sr}$ and ${ }^{137} \mathrm{Cs}$ from groundwater and process wastewater using novel sorbents are addressed through specific laboratory testing and data evaluation.

Materials/processes that have been investigated in the course of this task include (a) ion exchange on . resorcinol-formaldehyde (R-F) resin, an organic exchanger developed at Savannah River Laboratory and manufactured by the Boulder Scientific Company; (b) strontium sorption on sodium nonatitanate, an inorganic exchanger developed by Texas A\&M University and Allied Signal Corporation; (c) strontium and cesium sorption on crystalline silicotitanate (CST); and (d) strontium and cesium sorption on the baseline material, chabazite zeolite..$^{1-5}$ Studies during the past two years have concentrated on CST, an ion-exchange material developed at Sandia National Laboratory and Texas A\&M for the remediation of highly alkaline tank waste and available commercially from UOP in powder and pellet forms. Ionsiv ${ }^{\otimes}$ IE-911, the engineered form of CST, was used to remove both strontium and cesium from near-neutral$\mathrm{pH}$ wastewaters in batch and column studies. The powder form (Ionsiv IE-910) of CST was used for batch testing only. In this report, data acquired during FY 1998 and FY 1999 are presented and evaluated, including strontium and cesium removal from (1) a process wastewater simulant using Ionsiv ${ }^{\otimes}$ IE-911 in a column configuration; (2) an actual wastewater generated at the East Tennessee Technology Park (ETTP) using CST, chabazite zeolite, cobalt hexacyanoferrate (CsTreat ${ }^{\circledR}$; IVO); and titanium dioxide (SrTreat; IVO) in batch testing; (3) an actual seep water from ORNL using Ionsiv ${ }^{\circledR}$ IE-911 and the baseline material (chabazite zeolite) in columns; and (4) a groundwater obtained from Core Hole 8 sump near Bldg. 2016 using Ionsiv ${ }^{\circledR}$ IE-911 in a column field test. A gamma counting system was assembled to obtain radioisotopic profiles of loaded columns both longitudinally and axially. Scanning results from the CST column used to treat Process Wastewater Treatment Plant (PWTP) 
simulant, and from the zeolite and CST columns used for Seep D water treatment are presented and discussed as well.

\subsection{PREVIOUS TASK RESULTS}

Laboratory studies have been carried out in an effort to obtain a quantitative understanding of the behavior of the new materials and to evaluate their sorption efficiency with reference to a standard benchmark treatment technique. Scoping tests have been performed in which new treatment materials were compared with the baseline sorbent, chabazite zeolite, in batch shaker tests. ${ }^{1}$ Equilibrium tests have been conducted under various treatment conditions ( $\mathrm{pH}$, temperature, waste composition). After batch testing of a treatment method has been completed, dynamic column tests are performed to obtain the defining column operating parameters for scaling up the technology.

The primary effort during FY 1994 and a portion of FY 1995 was characterization of the baseline treatment technology - that is, radionuclide sorption on natural chabazite zeolite. Cesium and strontium sorption characteristics on zeolite were determined for batchwise treatment of both a wastewater simulant and the corresponding actual wastewater. A test with a small zeolite column was completed in FY 1995 to observe ${ }^{90} \mathrm{Sr}$ and ${ }^{137} \mathrm{Cs}$ breakthrough characteristics under dynamic flow conditions. The performance of the chabazite zeolite for the treatment of process/groundwater samples has been summarized in ORNL topical reports. ${ }^{1,2,4}$

In lieu of an available new inorganic exchanger, R-F resin was selected in FY 1995 as the first in a series of new sorbents to be tested under this task. A portion of FY 1996 was used to complete this effort. Studies performed in FY 1995 used radioanalytical data to determine the fate of cesium and strontium in solutions treated with the resin. Supporting inductively coupled plasma (ICP) spectrometric data were acquired during FY 1996 to help interpret the nonlinear isotherms observed in strontium sorption tests conducted during FY 1995. Strontium and cesium sorption characteristics on the resin were also observed in a small-column test run in FY 1996. Comparison of natural chabazite zeolite sorption data with those for R-F resin demonstrated that, in a near-neutral-pH wastewater matrix, the sodium form of the zeolite had a greater sorption capacity for both strontium and cesium. Additionally, the 
preconditioned zeolite demonstrated a greater selectivity for both of these radionuclides over competing cations common in process wastewater. ${ }^{3,4}$

The first new inorganic sorbent selective for strontium became available for evaluation in late FY 1996. Two samples of sodium nonatitanate $\left(\mathrm{Na}_{4} \mathrm{Ti}_{9} \mathrm{O}_{20} \cdot x \mathrm{H}_{2} \mathrm{O}\right)$, in the form of a fine powder and as cylindrical pellets, were received from Allied Signal Research and Technology. Pretreatment options for the nonatitanate powder were explored; the cation content and ion-exchange capacity of this material were also determined. Equilibrium studies were completed to determine the optimum contact time for nonatitanate powder in $10 \mathrm{~mL}$ of either simulant or actual wastewater. Final testing in FY 1996 focused on the competition of other cations for strontium sorption sites on the nonatitanate. The nonatitanate w as found to sorb $\mathrm{Mg}$ and $\mathrm{Ca}$, in addition to $\mathrm{Sr}$; selectivity of the sorbent over competing cations was lime dependent. Due to the projected time required to understand the complexity of cationic interactions on nonatitanate, further studies of this particular sorbent were postponed. Therefore, the applicability of nonatitanate to wastewater treatment still needs to be more fully defined. Again, detailed results of these findings can be found in previous reports. ${ }^{3,5}$

A sample of a commercial treatment reagent for cesium removal was received in FY $1996 .^{5}$ This matcrial. referred to as FEZHEL (or ANFEZH), is available through JSC "Compomet Cantec" of Ychaternburg, Russia. It consists of wood cellulose fibers coated with potassium ferrous hevas anoferrate. At the request of the DOE Efficient Separations and Processing Crosscutting Program (ISP). a limited evaluation of this sorbent was performed to determine whether it might have applications for wastewater treatment in the United States. In a short scoping study, the as-received material was sized, the equilibration mixing time was determined, and a single batch isotherm profile was developed. As this sorbent was still undergoing development, further testing was postponed until a final product becomes available.

Engineered CST (Ionsiv ${ }^{\circledR}$ IE-911) was received from UOP in early FY 1997. Preliminary experimental efforts included determining the average particle size, surface water content, total sodium content, ionexchange capacity, and equilibration mixing time. A small-column test using the hydrogen form of Ionsiv ${ }^{\otimes}$ IE-911 was initiated within the first week of May 1997. The final report for FY 1997 summarized the physical features of engineered CST and presented limited batch-testing data as well as a portion of the data from the column test using CST to treat a process wastewater simulant. The final 
results of this column test, which was not completed until February 1998, are presented in some detail in this report; they have also been included in other recently published reports. ${ }^{5,6}$

\subsection{OVERVIEW OF FY 1998 TASKS}

During FY 1998, the CST column test using PWTP simulant was completed. Batch tests were performed on actual wastewaters using up to five different sorbents, including the engineered and powder forms of CST, potassium cobalt hexacyanoferrate and modified titanium dioxide (CsTreat ${ }^{\circledR}$ and SrTreat ${ }^{\circledR}$, respectively, from SELION OY of Finland), and chabazite zeolite. Two actual wastewaters, one generated during the cleanup of inactive low-level waste tanks at Oak Ridge National Laboratory (ORNL) and the other a process wastewater from the ETTP, were treated in the batch tests. Two separate column tests using Ionsiv ${ }^{\circledR E}$ IE 911 and chabazite zeolite were begun in FY 1998 to define the capacities of the sorbents for strontium and cesium removal from actual seep water containing significant quantities of competing cations. The seep water was obtained from Waste Area Grouping (WAG) 5 , Seep D, at ORNL.

Batch testing of a decontamination wastewater from the cleanup of ORNL tanks, and the second column test using chabazite zeolite in the cleanup of seep water, were beyond the scope of work initially outlined for FY 1998. However, the prospect of reducing the volumes of wastewater transferred to radioactive waste tanks for further storage and treatment prompted a short-term scoping study of this waste stream.

The second zeolite column was funded late in FY 1998 to provide an efficacious comparison with CST results. Further, gamma scanning equipment was designed to pinpoint the location of gamma emitters along loaded CST columns used to treat process wastewater simulant and actual seep water. Such a counting system might identify the position of the cesium mass transfer zone within the CST column and allow an accurate extrapolation of cesium breakthrough parameters. Additional funds were acquired late in the fiscal year to complete these extra experiments. This report summarizes the results obtained in the work completed during FY 1998. 


\subsection{OVERVIEW OF FY 1999 TASKS}

Early in FY 1999 the column experiment using Ionsiv ${ }^{8}$ IE-911 to define the sorbent's capacity for strontium and cesium removal from actual Seep D water was completed. Also completed during FY 1999 were tasks funded late in FY 1998, namely the zeolite/Seep D water column test and the gamma scanning of Cs and Sr-loaded columns from the three column tests: (1) CST/PWTP simulant, (2) CST/Seep D water, and (3) chabazite zeolite/Seep D water. In addition, a field test of Ionsiv ${ }^{\otimes} \mathrm{IE}-911$ was begun and completed in FY 1999 . The test was run for approximately $41 / 2$ months using feed from the Bldg. 2016 Core Hole 8 (groundwater) sump that was traced with ${ }^{85} \mathrm{Sr}$ and ${ }^{137} \mathrm{Cs}$.

\section{TEST PROCEDURES}

\subsection{WASTEWATER FEED STREAMS FOR TESTS}

\subsubsection{Process Wastewater Simulant}

Accurate comparative testing of new sorbent materials requires that experimentation be performed under defined, consistent conditions. To accomplish this need, each of the sorbent materials was tested by treating a synthetic wastewater of standard composition using a specific experimental protocol detailed in the following discussion. The formulation of the PWTP simulant, as presented in Table 1, is based on reviews $\mathrm{s}^{1,2}$ of the compositions of local groundwater and DOE wastewater. The chemical makeup of the ORNL PWTP feed was found to be representative of waste streams of local DOE sites and also falls within the ranges of concentration for the general description for groundwater composition. ${ }^{7}$ The chemical composition of the simulant, therefore, is derived from the actual composition of this particular feed stream; the actual composition of a grab sample is also shown in Table 1.

One-hundred-liter volumes of simulant were prepared at a time as process wastewater feed for column testing. After addition of reagent chemicals, the solution was filtered with a $0.45-\mu \mathrm{m}$ Supor ${ }^{\mathrm{TM}}$ filter membrane. Stable strontium and cesium were added to $20-\mathrm{L}$ aliquots of the simulant at this point, as were tracer ${ }^{85} \mathrm{Sr}$ and ${ }^{137} \mathrm{Cs}$ isotopes; $2-\mathrm{mL}$ samples from each aliquot were retained to determine the initial activity of the feed solution. Strontium was included in the simulant at a level of $0.1 \mathrm{mg} / \mathrm{L}$ (which included a $1 \times 10^{6} \mathrm{~Bq} / \mathrm{L}{ }^{85} \mathrm{Sr}$ tracer) to reflect the average concentration of total strontium in the PWTP 
feed. This strontium concentration is also typical of process water in the local DOE area and represents a midrange value for groundwater. Cesium was added to the simulant at a concentration of $1.12 \times 10^{6}$ $\mathrm{Bq} / \mathrm{L}$. Table 1 gives the concentrations of the cations in the simulant.

\subsubsection{Seep D Water}

In FY 1997 the scope of the evaluation program was broadened to encompass the treatment of contaminated seep water that is specific to the ORNL site. A test was initiated in FY 1998 to remove strontium from Seep D water using CST, and late in FY 1998 a comparative column test utilizing the baseline chabazite zeolite for the same treatment was begun. The composition of this water collected from Seep D, located at the down-gradient perimeter to the WAG 5 on the Oak Ridge Reservation is shown in Table 1 . Note that the calcium concentration is approximately twice that found in PWTP wastewater and is contaminated with radiostrontium, as shown in the table. Both ${ }^{134} \mathrm{Cs}$ and ${ }^{137} \mathrm{Cs}$ are normally absent in the local on-site groundwater, but ${ }^{137} \mathrm{Cs}$ was added to the actual seep water to provide data for DOE sites in which radiocesium is present. To test the capacity of each sorbent in the presence of elevated calcium, this radionuclide was added to the seep water at a tracer level of $1.12 \times 10^{6} \mathrm{~Bq} / \mathrm{L}$ and reflects the upper limit for cesium activity typical of process wastewater.

\subsubsection{Core Hole 8 Groundwater}

A column study using CST in the field was completed in FY 1999. ORNL Core Hole 8 groundwater was used as the feed to the column. A plume of groundwater within Bethel Valley at ORNL has been contaminated by an underground waste tank; this plume has been called Core Hole 8 . Core Hole 8 groundwater was chosen as a treatment medium since it is contaminated with ${ }^{90} \mathrm{Sr}$. The levels of contamination exceed discharge limits set forth in DOE Order 5400.5 (limit of $37 \mathrm{~Bq} / \mathrm{L}{ }^{90} \mathrm{Sr}$ ). Levels of

${ }^{90} \mathrm{Sr}$ in the groundwater decrease as you move away from the contamination source. A site near Building 2016, where a sump is located, was chosen as the field demonstration site. Excessive levels of ${ }^{233} U$ are also present in the Core Hole 8 groundwater, but at this location they were below ICP detection limits and therefore not analyzed in this field test. Table 1 gives the cation content of the groundwater at Building 2016 Core Hole 8 sump. The cesium was added as a tracer to the Core Hole 8 wastewater to determine its removal efficiency by CST in this particular matrix. 


\subsubsection{Other Wastewaters}

Two actual wastewaters were tested in batch studies to determine the strontium and cesium removal efficiency of several sorbents. Wastewater resulting from the washdown of the inactive Gunite-walled tanks (referred to as the GAATs) at ORNL and wastewater normally treated at the Central Neutralization Facility (CNF) at ETTP were obtained during FY 1998 for tests completed this same fiscal year. The cationic compositions of these two waste streams are given in Table 2. The potassium(18 ppm) and sodium concentrations ( $400 \mathrm{ppm}$ ) of the GAAT waste given in Table 2 are significantly greater than those in the other wastewaters (1-8 ppm for potassium and 9-220 ppm for sodium). All the cations in the CNF wastewater, with the exception of magnesium, are elevated in comparison to the other treated wastewaters (Tables 1 and 2). Both radioactive strontium and ${ }^{137} \mathrm{Cs}$ were present in the GAAT wastewater. The CNF wastewater was traced with these radioactive species (to the levels shown in the table) to simulate the possible presence of these isotopes derived from the incineration of ORNL waste at ETTPs TSCA mixed waste incinerator.

\subsection{BATCH TESTING}

Sorption measurements were made in long-term batch equilibrium tests. The solutions and exchanger were contacted in screw-cap polycarbonate centrifuge tubes by mixing on a Labquake ${ }^{\mathrm{TM}}$ shaker, which rocks the samples from $-45^{\circ}$ to $+45^{\circ}$ from horizontal at 20 cycles per minute. Three samples were included in each data point. Solution volumes were determined from the weight and density of the PWTP simulant or the actual wastewater samples. The sorbent was weighed directly and added to the tubes. The tubes were weighed at the beginning and at the end of the equilibration periods to determine any solution loss. At the conclusion of the equilibration period, the tubes were centrifuged for $30 \mathrm{~min}$ at 5000 relative centrifugal force (rcf). The solutions studied were clarified further by filtering the centrifuged supernatant using a plastic syringe fitted with either a 0.20 - or 0.45 - $\mu \mathrm{m}$-pore nylon membrane filter. Due to the finer particle size of the sorbent, the solutions generated in the nonatitanate and Ionsiv ${ }^{\oplus}$ IE-910 studies were filtered with a $0.2-\mu \mathrm{m}$-pore polyethersulfone membrane filter.

The ${ }^{85} \mathrm{Sr}$ and ${ }^{137} \mathrm{Cs}$ count rates were determined with a Canberra Series 90 gamma spectrometer. Twomilliliter samples were counted for $1000 \mathrm{~s}$ in a germanium well detector. Data for ${ }^{85} \mathrm{Sr}$ were corrected for 
the interference of ${ }^{137} \mathrm{Cs}$ at the $514-\mathrm{keV}$ peak by using a linear regression line developed with ${ }^{137} \mathrm{Cs}$ standards. Test data were used in the following calculations:

$$
\begin{gathered}
\text { Decontamination factor, } D F:=\frac{G_{i}}{G_{f}}, \\
\text { Sorption ratio, } \mathrm{R}_{\mathrm{s}}(\mathrm{L} / \mathrm{kg}):=\frac{\left(G_{i}-G_{f}\right) V}{G_{f} W},
\end{gathered}
$$

Final solution concentration, $C_{f}(\mathrm{meq} / \mathrm{L}):=\frac{C_{i} G_{f}}{G_{i}}$,

Final concentration on exchanger, $C_{x}(\mathrm{meq} / \mathrm{kg}):=C_{f} R_{s}$,

where

$$
\begin{aligned}
& G_{i}=\text { count rate of the initial solution; } \\
& G_{f}=\text { count rate of the final solution; } \\
& V=\text { initial volume of the solution, } \mathrm{mL} ; \\
& W=\text { exchanger weight, } \mathrm{g} ; \\
& C_{i}=\text { concentration in initial solution, meq } / \mathrm{L} ; \\
& C_{f}=\text { concentration in final solution, meq } / \mathrm{L} .
\end{aligned}
$$

The sorption ratio $\left(R_{\mathrm{s}}\right)$ is equivalent to the distribution coefficient $\left(K_{\mathrm{d}}\right)$ if equilibrium conditions are assumed. The exchanger weight is reported on a dry-weight basis by correcting for the moisture content of the sorbent in order to make direct comparison of sorption efficiency among sorbent materials. The fate of competing cations in treated solutions was determined using a Thermo Jarrel Ash ICAP 61E Trace ICP spectrophotometer.

\subsection{SMALL-COLUMN TESTING}

Column testing was used to define the sorption characteristics of a material under dynamic flow conditions. The dimensions of a sorbent column were selected primarily on the basis of the diameter of the average sorbent particle, ${ }^{8}$ although results of previous small-column experiments were used to modify 
Strontium sorption by three materials (powdered CST-Ionsiv ${ }^{\circledR}$ IE-910, SrTreat ${ }^{\circledR}$, and chabazite zeolite) is shown in the isotherms in Fig. 6. The plot displays the relative difference between the sorbents; the Ionsiv ${ }^{\circledR}$ IE-910 removed the strontium much more effectively than either the SrTreat ${ }^{\circledR}$ or the zeolite at higher solution concentrations (i.e., low sorbent loading). At lower strontium concentrations, the $\mathrm{SrTreat}^{\circledast}$ and CST appear to be competitive; however, the reader must be cautioned that the $\mathrm{K}_{\mathrm{d}}$ value in the lower portion of the curve may be overestimated for either one of these sorbents because equilibrium concentrations of competing cations in samples treated with large amounts of a nonselective sorbent are lower than the initial waste concentrations. The measured $K_{d}$ in this case may be representative of that which might be obtained only in a much cleaner feed stream. It is, therefore, important to validate batch results with a small-column study so that $\mathrm{K}_{d}$ values can be determined under actual feed stream compositions. From Fig. 6, it is obvious that the zeolite does not have the capacity to remove strontium in this waste matrix to the same degree that the other two sorbents do. Earlier column studies with zeolite support these batch-test results. ${ }^{12}$

Decontamination factors at the different loadings are given in Table 7. Again, the strontium DFs in the CNF wastewater are much larger for the CST than for either SrTreat ${ }^{\circledR}$ or zeolite at a 5-mg loading, which probably reflects values that would be obtained in actual CNF treatment. At the strontium concentrations tested here, a minimum DF of 10 would be necessary to reduce the strontium in the wastewater to a level acceptable for discharge from CNF. The DFs in Table 7 show that the zeolite would not meet the minimum requirements for strontium removal at CNF.

Cesium sorption isotherms for three materials (Ionsiv ${ }^{\circledR}$ IE-910, CsTreat ${ }^{\circledR}$, and chabazite zeolite) are shown in Fig. 7. These isotherms display the relative capacities of the sorbents for cesium. The CsTreat ${ }^{\circledR}$ has the highest capacity for cesium at higher solution concentrations, while at lower cesium solution concentrations, the CST and CsTreat ${ }^{\circledR}$ are comparable. Again, the uppermost sample data probably reflects $\mathrm{K}_{\mathrm{d}}$ values under actual process conditions. For cesium removal, as with strontium removal, the zeolite does not compete well against the other sorbents, as seen in Fig. 7. Cesium decontamination factors at the different loadings are given in Table 7. Again, the cesium DFs in the CNF wastewater are much larger for the CST and CsTreat ${ }^{\circledR}$ than for the zeolite. At the cesium concentrations tested here, a minimum DF of 1000 would be necessary to reduce the cesium in the wastewater to an acceptable level. The DFs in Table 7 show that the zeolite would not meet the minimum requirements for cesium removal at $\mathrm{CNF}$. 
Determination of the capacity of a sorbent for the radioactive species of interest must also include a measure of its selectivity for that sorbent over other competing cations. A ratio of the cationic distribution coefficients $\left(\mathrm{K}_{\mathrm{d}}, \mathrm{L} / \mathrm{kg}\right)$ of two cations, or selectivity factor, can allow a quantitative comparison to be made. The distribution coefficients and selectivity factors for the cations in CNF wastewater, at the lowest sorbent loading $(5 \mathrm{mg})$ tested, are given in Tables 8 and 9 . At this sorbent loading, the equilibrium concentrations of competing cations are close to that of CNF waste and, therefore, represent a good estimate of $\mathrm{K}_{d}$ values to be expected in actual waste processing. These results indicate that both zeolite and CST sorb strontium and cesium, although the Ionsiv ${ }^{\circledR}$ IE-910 distribution coefficients are greater by a factor of approximately 100 over those of the zeolite. The Ionsiv IE-910 has a slightly greater selectivity for strontium over competing cations as compared with the SrTreat ${ }^{\circledR}$ and is significantly better than zeolite. The CsTreat ${ }^{\circledR}$ does not sorb primary wastewater cations and, therefore, has a greater selectivity for cesium than either the Ionsiv ${ }^{(}$IE-910 or the zeolite. However, the CsTreat ${ }^{2}$ must be used in conjunction with a strontium-selective sorbent to meet the waste-treatment needs of the CNF.

\section{COLUMN TESTS}

Several column tests have been completed under this program. In the first test, the baseline material, chabazite zeolite, was used to remove strontium and cesium from process wastewater simulant (see Table 1 for the composition of the simulant). A brief summary of this test, along with breakthrough cunces, is presented in Sect. 5.2.1. A second column test was run using R-F resin in the same configuration; however, the resin did not perform satisfactorily as compared with the zeolite. During FY 1997, a column test using engineered CST to treat process wastewater simulant was initiated. The material performed so well that the test was allowed to continue into FY 1998. Thus, the final results of the test are presented here, although preliminary results were distributed during the last fiscal year. A column test using CST to remove strontium and cesium from Seep D water and an identical test using chabazite zeolite were also begun in FY 1998 and completed in FY1999. Table 1 lists the cationic compositions of the Seep D water. The seep water is contaminated with ${ }^{90} \mathrm{Sr}$, however, cesium was added to the feed so that the efficiencies of the materials for cesium removal might also be observed. A final column test actually located in the field was run in FY 1999 using CST to treat Core Hole 8 groundwater for ${ }^{90} \mathrm{Sr}$ removal; again, the feed was spiked with ${ }^{137} \mathrm{Cs}$ to note the efficiency of removal for this species. 


\subsection{PREDICTION OF BREAKTHROUGH CURVES}

The results from the column tests are summarized in Sects. 5.2-5.4. This section discusses the theoretical treatment of the breakthrough curves applied to each of the experimental results and summarizes the material-specific parameters determined by the tests such as loading capacities, mass transfer coefficients, and distribution coefficients.

All column experimental data were fit to the Rosen solution ${ }^{13}$, which is valid for long-bed systems. ${ }^{14}$ Both the film- and the particle-side resistances to mass transfer are accounted for in the model. Rosen began with two basic assumptions: (1) the diffusional parameters for both the film and particle are independent of concentration and position in the column, and (2) adsorption of the solute(s) can be represented by a linear isotherm. The linear representation of equilibrium is written as

$$
q_{s}=K_{d} c
$$

where

$$
\begin{aligned}
& q_{s}=\text { the concentration on the solid, meq } / \mathrm{kg} \\
& K_{d}=\text { the equilibrium constant, or distribution coefficient, } \mathrm{L} / \mathrm{kg} \\
& c=\text { the concentration in the liquid, meq } / \mathrm{L} .
\end{aligned}
$$

Based on these assumptions, Rosen presented an analytic solution to the mass balance equation

$$
v \frac{\partial \mathrm{c}}{\partial \mathrm{z}}+\frac{\partial \mathrm{c}}{\partial \mathrm{t}}=-\frac{1}{\mathrm{~m}} \frac{\partial \mathrm{q}_{\mathrm{s}}}{\partial \mathrm{t}}
$$

as:

$$
\frac{C}{C_{0}}=\frac{1}{2}\left(1+\operatorname{erf}\left(\frac{(3 Y / 2 x)-1}{2 \sqrt{y / x}}\right)\right)
$$

where

$$
X=\frac{3 D_{p} K_{d} \rho_{s}(1-\varepsilon) Z}{\varepsilon U_{z} R^{2}} \text { (bed-length parameter) }
$$


and

$$
\begin{gathered}
v=\frac{D_{p} K_{d} \rho s}{R k_{f}} \text { (film-resistance parameter), } \\
Y=\frac{2 D_{p}}{R^{2}}-\left(t-\frac{Z}{U_{z}}\right) \text { (contact-time parameter). }
\end{gathered}
$$

The variables in the above equations are defined as follows:

$D_{p}=$ effective diffusivity in the particle, $\mathrm{cm}^{2} / \mathrm{s}$;

$R^{p}=$ radius of the particle, $\mathrm{cm}$;

$U_{z}=$ interstitial liquid velocity, $\mathrm{cm} / \mathrm{s}$;

$t=$ time, s;

$k_{f}=$ film mass transfer coefficient, $\mathrm{cm} / \mathrm{s}$;

$C=$ concentration of solute at time $t, \mathrm{meg} / \mathrm{L}$;

$C_{0}=$ concentration of solute in feed, meq/L;

$\mathcal{\varepsilon}=$ void fraction in column;

$Z$ = bed length, $\mathrm{cm}$;

$\rho_{s}=$ density of solid, $\mathrm{kg} / \mathrm{L}$.

This solution was used to predict strontium and cesium breakthrough profiles for the CST column experiments. All the measured material and column variables (exchanger weights, bed length, flow rates, etc.) used in the predictions are summarized in Table 10.

The validity of the simplified Rosen solution requires that the bed-length parameter, $X$, be greater than $40 .{ }^{14}$ Material-specific, adjustable parameters needed to complete the above solution include the effective diffusivity in the particle and the film mass transfer coefficient. In order for $X$ to be greater than 40, the effective diffusivities must exceed a given value. An effective particle diffusivity of $2.7 \times 10^{-7}$ $\mathrm{cm}^{2} / \mathrm{s}$ was assumed for cesium diffusing into the particle. This assumption is supported by researchers at Texas A\&M, ${ }^{15}$ who have calculated and verified this effective diffusivity for cesium in CST. Using this value, $X$ exceeds 40 . An effective diffusivity of $5.0 \times 10^{-5} \mathrm{~cm}^{2} / \mathrm{s}$ was assumed for strontium. ${ }^{16}$ 
The film mass-transfer coefficients for each cationic species were calculated from empirical relationships presented in The Chemical Engineers' Handbook, by Perry and Chilton, ${ }^{17}$ as

$$
k_{f}=\frac{10.9 V(1-\varepsilon)}{d_{p} a_{p}}\left[\frac{D_{f}}{d_{p} V}\right]^{0.51}\left(\frac{D_{f} \rho_{f}}{\mu}\right)^{0.16}
$$

or

$$
k_{f}=\frac{4.367(1-\varepsilon)\left(D_{f} V\right)^{0.5}}{d_{p}{ }^{1.5} a_{p}}
$$

where

$V=$ volumetric flow rate, $\mathrm{cm}^{3} / \mathrm{s}$

$D_{f}=$ fluid-phase diffusivity, $\mathrm{cm}^{2} / \mathrm{s}$;

$d_{p}=$ diameter of particle, $\mathrm{cm}$;

$a_{p}=$ outer surface area of particles per unit volume of contacting system, $6(1-\varepsilon) / d_{p}, \mathrm{~cm}^{-1}$;

$\mu=$ fluid viscosity, poises.

The coefficients were then adjusted to predict the actual experimental data more accurately. For strontium, the addition of a term to account for longitudinal dispersion was necessary. ${ }^{17}$ For cesium, the film coefficient had to be increased to account for the slower mass transfer mechanism. Table 11 summarizes the calculated film mass-transfer coefficients for each experiment, and Table 12 gives the liquid diffusivities for each cation as calculated from the Nernst equation. ${ }^{18}$

Figures 8 through 19 show this prediction of the experimental data. Prediction of the breakthrough curves for the zeolite studies (Figs. 8, 9, and 10) followed the experimental data closely but do not predict the desorption shown by the experimental data (i.e., $C / C_{0}$ decreasing). The experimental CST breakthrough curves showed significant tailing where the approach to complete breakthrough (100\%) was significantly drawn out. This is probably due to slow and complex intraparticle mass transfer mechanisms occurring in the CSTs, which would be modeled more accurately by rigorous numerical solutions. 


\subsection{COLUMN TESTS WITH PWTP SIMULANT FEED}

\subsubsection{Chabazite Zeolite}

Laboratory results identified several sorbent characteristics that might impact the selection of chabazite zeolite by end users. Natural zeolite has a significant heat of hydration. Consequently, steam is initially generated when water is added to a column of fresh, dry zeolite and may produce voids in the column packing. Natural zeolite is friable; fines are created during the transportation to and charging of a column. With continued column use, zeolite fines and algae cement the column packing so that spent zeolite cannot be easily sluiced from the column. ${ }^{2}$ If it is found to be cost-effective, the natural zeolite should be charged with concentrated saline to displace the natural strontium already present on the sorbent. Care must be taken to remove any excess sodium entrained in the column packing by this pretreatment process so that it will not affect column performance; in this way, the lifetime of the zeolite column will be enhanced by about $30 \%$. Some of the positive operational features of this particular sorbent are (1) the inorganic material does not swell significantly when wetted and (2) the particle size does not change with compositional fluctuations in the waste matrix. Because the material is relatively dense, the column packing is not easily disturbed with changes in column operating pressures. Finally, waste immobilization procedures using grout/cement have already been defined for the final disposal of spent zeolite and the zeolite cost is extremely low as compared with the costs of other, new sorbents.

A test with a small zeolite column was completed in order to observe ${ }^{90} \mathrm{Sr}$ and ${ }^{137} \mathrm{Cs}$ breakthrough characteristics under dynamic flow conditions. The performance of the chabazite zeolite for the treatment of process/groundwater samples has been summarized in ORNL topical reports. ${ }^{1-5}$ The combination of sorption data and column performance served to define zeolite characteristics, as well as 
to establish standardized testing procedures for the direct comparison of the baseline treatment with emerging sorbent technology in the future. A 1-cm-ID column containing about $2 \mathrm{~g}$ of sodium-modified zeolite was used to treat PWTP wastewater simulant, the composition of which is given in Table 1. Cation breakthrough was followed by ICP analysis of the effluent, and the strontium and cesium breakthroughs were monitored using gamma spectrometry. The zeolite bed in the column was $4.9 \mathrm{~cm}$ deep, and the bed volume was $3.85 \mathrm{~mL}$. At a nominal simulant flow rate of $1.25 \mathrm{~mL} / \mathrm{min}$ [ 19 bed volumes $(\mathrm{BV}) / \mathrm{h}]$, the superficial velocity through the bed was $1.6 \mathrm{~cm} / \mathrm{min}$. The void volume was 2.52 $\mathrm{mL}$, and the nominal solution residence time in the column was about $3 \mathrm{~min}$. Details of the test can be found in previous reports. ${ }^{1,2}$ The column test, which was conducted for a period of $120 \mathrm{~d}$, was terminated after $59,000 \mathrm{BV}$ because the cementation of fractured zeolite particles plugged the column.

The experimental and modeled breakthrough curves for the major cations are presented in Fig. 8 , where the fractional breakthrough $\left(C / C_{0}\right)$, defined as the ratio of the cation concentration in the column effluent to the concentration in the feed, is plotted as a function of the volume of solution passed through the column. The initial effluent fractions (about $2500 \mathrm{BV}$ ) were analyzed by ICP spectrometry to determine the breakthrough behavior of $\mathrm{Na}, \mathrm{Mg}$, and $\mathrm{Ca}$. At that time, the sorption behavior of potassium could not be determined because the potassium concentration in each of the feed and effluent samples was at or below the ICP detection limit of $0.1 \mathrm{mg} / \mathrm{L}$. Figure 8(a) illustrates the initial displacement of sodium ion from the prepared zeolite as the cations in the feed were sorbed onto the column. Continued sorption of $\mathrm{Sr}$ and $\mathrm{Cs}$ onto the zeolite resulted in the displacement of $\mathrm{Mg}$ beginning at $250 \mathrm{BV}$ and displacement of $\mathrm{Ca}$ beginning at $500 \mathrm{BV}$. These curves imply that the cation selectivity of the treated zeolite is as follows: $\mathrm{Ca}>\mathrm{Mg}>\mathrm{Na}$. The fractional breakthrough of these cations stabilized at a value of 1.0 at approximately 800 to $1400 \mathrm{BV}$. 
The ${ }^{85} \mathrm{Sr}$ and ${ }^{137} \mathrm{Cs}$ count rates of the effluent fractions were compared with those of the feed solutions to determine breakthrough points, which are shown in Figs. 9 and 10, along with the breakthrough curves predicted by the Rosen model. Strontium was first observed in the column effluent at approximately $3000 \mathrm{BV}$. Fractional breakthroughs of 10 and $50 \%$ occurred at 6600 and $15,000 \mathrm{BV}$, respectively. Under these conditions, cesium breakthrough was $1 \%$ after about $15,000 \mathrm{BV}, 10 \%$ after about 30,000 BV, and $50 \%$ after about 50,000 BV. Toward the end of the column test the zeolite began to break down, creating fines that cemented together and resulting in channeling and scatter in the cesium breakthrough data, as seen in Fig. 10.

The strontium loading for the zeolite was about $60 \mathrm{meq} / \mathrm{kg}$ at $50 \%$ strontium breakthrough; the cesium loading was $0.2 \mathrm{meq} / \mathrm{kg}$ at $50 \%$ cesium breakthrough. These loadings, particularly the strontium loading, are higher than the saturation loadings of about 24 and $0.17 \mathrm{meq} / \mathrm{kg}$ measured previously for strontium and cesium respectively in batch sorption isotherms. ${ }^{!}$

\subsubsection{Ionsiv ${ }^{\circledR}$ IE-911}

Engineered CST (Ionsiv ${ }^{\circledR}$ IE-911) was received from UOP. A small-column test using the Hydrogen1form of Ionsiv ${ }^{\infty E}$ IE-911 was carried out over a period of 10 months in order to compare its performance with that of the baseline zeolite in removing strontium and cesium from a process wastewater simulant. Physically, the CST performed in an outstanding manner; after an operational period of 10 months, no visual change in the appearance of the pellets was noticed, whereas the zeolite began to break down after only 5 months. In terms of removal, again the CST outperformed the baseline material. Performance of the Ionsiv ${ }^{\otimes}$ IE-911 under dynamic flow conditions for wastewater treatment is described in the paragraphs that follow. 
The column experiment was run with the PWTP simulant feed stream (see Table 1). The column properties, flow rates, and cation concentrations were identical to those used in the zeolite column test, in order to make possible direct comparisons of the two ion-exchange materials.

A 1-cm-ID column containing $3.81 \mathrm{~g}$ of Hydrogen 1-CST was used to treat wastewater simulant. Cation breakthrough was followed by analysis of the effluent by ICP spectrometry, and the radiostrontium and cesium breakthroughs were monitored using gamma spectrometry. The height of the CST bed in the column was $4.85 \mathrm{~cm}$, and the bed volume was $3.81 \mathrm{~mL}$. At a nominal simulant flow rate of $1.2 \mathrm{~mL} / \mathrm{min}$ (19 BV/h), the superficial velocity through the bed was $1.53 \mathrm{~cm} / \mathrm{min}$. The nominal solution residence time in the column was about $3.2 \mathrm{~min}$. A column void fractional volume of 0.47 was assumed.

The system was operated for a total of 10 months, processing $120,000 \mathrm{BV}$ during this time. Only limited maintenance of the system was required. This included the replacement of worn peristaltic tubing, flow lines, and the prefilter that had evidence of algae growth.

Figure 11 shows the breakthrough curves of the cations $\mathrm{Na}, \mathrm{Ca}, \mathrm{Mg}$, and $\mathrm{K}$. All, with the exception of $\mathrm{K}$, reached $50 \%$ breakthroughs at less than $1300 \mathrm{BV}: 200,800$, and $1200 \mathrm{BV}$ for $\mathrm{Mg}, \mathrm{Ca}$, and $\mathrm{Na}$, respectively. Figure 11 also shows the potassium breakthrough curve, where $50 \%$ breakthrough occurred at close to $16,000 \mathrm{BV}$. All cation breakthrough curves have a sharp front (i.e., initial part of the breakthrough curve) and a diffuse, or drawn-out, tail. The shapes of the curves are indicative of a slow approach to equilibrium concentration, which may signify that the rate-controlling step is diffusion of the species in the solid, particle phase as opposed to a rate-controlling step in the liquid phase. ${ }^{19}$ 
The CST selectivity of cesium over strontium is demonstrated in Fig. 12 and 13, which show the beginning of strontium breakthrough. Cesium breakthrough was not observed (Fig. 13), even up to $120,000 \mathrm{BV}$ (operational period of 10 months). The strontium breakthrough curve is very atypical, where $C / C_{0}$ increases, as expected, up to 0.28 , then decreases, but increases again, and then decreases to approximately 0.15 at $120,000 \mathrm{BV}$. This phenomenon was also noted in the CST column tests in which groundwater was treated for strontium and cesium removal. A complex mechanism for strontium sorption and ion exchange is obviously occurring, and while multicomponent sorption and desorption may account for some of these phenomena, perhaps the availability of sites within the sorbent is also changing during the diffusion process. A linear extrapolation of the breakthrough curve from the point at which the column test was terminated would give $50 \%$ breakthrough of strontium at $175,000 \mathrm{BV}$.

The $\mathrm{pH}$ was tracked throughout the column test. Based on the effluent $\mathrm{pH}$ and sodium concentration, the functionality of the Hydrogen1-CST in the column was calculated on the basis of the column throughput. Equilibrium calculations indicate that the Hydrogen I-CST is initially in the form of $\mathrm{H}_{3}$-CST. In continuous contact with a sodium-bearing feed stream, the CST is completely converted to $\mathrm{H}_{2} \mathrm{Na}-\mathrm{CST}$ by $1100 \mathrm{BV}$. Therefore, sorption of $\mathrm{Ca}, \mathrm{Mg}$, and $\mathrm{Na}$ is accomplished when the column is primarily in the trihydrogen form. Sorption of $\mathrm{K}, \mathrm{Sr}$, and Cs takes place when the CST is present as the monosodium form. 


\subsection{COLUMN TESTS WITH ACTUAL SEEP D WATER}

\subsubsection{Ionsiv $^{\circledR}$ IE-911}

Engineered CST was again used in a column test, this time with a feed stream consisting of actual seep water from ORNL Seep D from the WAG 5 burial grounds. The seep D water composition is shown in Table $1 ;{ }^{90} \mathrm{Sr}$ is present in the water, while the cesium was added for observational purposes. Note that the calcium concentration is almost two times higher than the PWTP simulant column feed. The column processed 61,400 bed volumes.

Column variables, such as flow rate and bed length, were similar to those in previous column tests, in order to make direct comparisons in experimental data. Two column experiments were completed, the first being terminated due to operational difficulties. From the first test, breakthrough data for calcium, magnesium, and sodium were obtained from the processing of $20 \mathrm{~L}$ of feed. The 1-cm-ID column was packed with $3.35 \mathrm{~g}$ of Hydrogen2-CST, and had a bed length of $4.9 \mathrm{~cm}$. The second column contained $3.85 \mathrm{~g}$ of Hydrogen2-CST in a bed length of $5.2 \mathrm{~cm}$. Flow rates were maintained at about $1.2 \mathrm{~mL} / \mathrm{min}$ $(17-19 \mathrm{BV} / \mathrm{h})$. Cation breakthrough was followed by ICP analysis of the effluent, and the radiostrontium and cesium breakthroughs were monitored using gamma spectrometry. The nominal solution residence time in the column was about $3.2 \mathrm{~min}$. A column void fractional volume of 0.47 was assumed.

The 4.1-mL column system was operated for a total of 6 months; a total of $61,400 \mathrm{BV}$ was processed during this time. Only limited maintenance of the system, which included the replacement of worn peristaltic pump tubing, flow lines, and the prefilter that had evidence of algae growth, was required. 
Figure 14 shows the breakthrough curves of the cations $\mathrm{Na}, \mathrm{Ca}, \mathrm{Mg}$, and $\mathrm{K}$. All, with the exception of $\mathrm{K}$, reached $50 \%$ breakthroughs at less than $800 \mathrm{BV}: 120,380$, and $750 \mathrm{BV}$ for $\mathrm{Mg}, \mathrm{Ca}$, and $\mathrm{Na}$, respectively. Figure $14(d)$ shows the potassium breakthrough curve, where $50 \%$ breakthrough occurred at $14,600 \mathrm{BV}$. The potassium breakthrough is not significantly different from that observed during the PWTP simulant test; however, the other cations broke through much more quickly, i.e., in approximately half the time). Strontium breakthrough appears to be occurring at a more rapid pace; $50 \%$ breakthrough might occur by $45,000 \mathrm{BV}$, whereas the predicted $50 \%$ breakthrough during the treatment of the PWTP simulant was $175,000 \mathrm{BV}$. Once the potassium effluent concentration returned to feed levels, strontium breakthrough decreased. At $60,000 \mathrm{BV}$, strontium $\mathrm{C} / \mathrm{C}_{\circ}$ was only $42 \%$. Based on the $50 \%$ breakthrough point, the strontium loading capacity and $K_{d}$ are $75 \mathrm{meq} / \mathrm{kg}$ and $36,000 \mathrm{~L} / \mathrm{kg}$, respectively.

Again, the CST selectivity of cesium over strontium is demonstrated in Figs. 15 and 16, which show no cesium breakthrough, up through the column test completion at $61,400 \mathrm{BV}$. The strontium breakthrough curve is very unusual, but similar to the strontium breakthrough for the PWTP simulant column test (see Fig. 12).

\subsubsection{Chabazite Zeolite}

A column test comparable to the CST/Seep D water column experiment (Sect. 5.3.1) was performed using chabazite zeolite with the Seep D water feed (Table 1). As mentioned before, this seep water contains ${ }^{90} \mathrm{Sr}$, and cesium was added for observational purposes.

The 1-cm-ID column was packed with $2.30 \mathrm{~g}$ of chabazite zeolite and had a bed length of $4.8 \mathrm{~cm}$. The flow rate was maintained at about $1.2 \mathrm{~mL} / \mathrm{min}(17-19 \mathrm{BV} / \mathrm{h})$. Cation breakthrough was followed by ICP 
analysis of the effluent, and the radiostrontium and cesium breakthroughs were monitored using gamma spectrometry. The nominal solution residence time in the column was about $3.2 \mathrm{~min}$. A column void fractional volume of 0.48 was assumed.

The 3.8-mL column system was operated for a total of $31 / 2$ months; $34,500 \mathrm{BV}$ were processed during this time. Only limited maintenance of the system, including the replacement of worn peristaltic tubing, flow lines, and the prefilter that had evidence of algae growth, was required.

Figure 17 shows the breakthrough curves of the cations $\mathrm{Na}, \mathrm{Ca}, \mathrm{Mg}$, and $\mathrm{K}$. Fifty percent breakthroughs of $\mathrm{Ca} . \mathrm{Mg}$, and $\mathrm{Na}$ occurred at 350,200 , and $<30 \mathrm{BV}$, respectively. In comparison, the breakthroughs for these three cations on the CST were 380,120 , and $750 \mathrm{BV}$. Potassium broke through at $50 \%$ of its initial concentration by $6700 \mathrm{BV}$. In the potassium plot [Figure 17 (d)], it appears that some potassium is eluted from the sorbent initially. Sodium [Fig. 17(a)] was exchanged and eluted from the column almost immediately. Magnesium was displaced in the zeolite as seen in Fig. 17(c). Desorption from the sorbent $(C C$. cxceeds 1.0$)$ is not predicted by the Rosen solution; hence the theoretical curves do not follow the experimental data past a value of 1.0 .

Figure 18 shows breakthrough of strontium on zeolite in Seep D water. Incipient (1\%) strontium breakthrough occurred at $2000 \mathrm{BV}, 50 \% \mathrm{Sr}$ breakthrough at $10,100 \mathrm{BV}$. In most zeolite column studies reported in literature, the run has been terminated at this point and a strontium $\mathrm{K}_{\mathrm{d}}$ calculated based on the quantity of strontium sorbed on the column to this point. However, continuation of the column run shows that sorbed strontium is not retained on the column, but rather is displaced from the zeolite as $C / C_{o}$ rises above 1.0 . By $22,000 \mathrm{BV}$, more than half the strontium originally sorbed onto the column was displaced from the zeolite by competing water cations. No cation displacement was observed from the 
comparable CST column test, even at a throughput of $60,000 \mathrm{BV}$ seep water. Again, this displacement is not modeled by the Rosen solution; however, breakthrough to $100 \%$ is predicted well by the model.

Cesium breakthrough on zeolite was modeled by the Rosen solution as shown in Fig. 19. Breakthrough at $50 \%$ occurred by about $30,000 \mathrm{BV}$ for cesium on zeolite. In comparison, no breakthrough of cesium was seen in the same Seep D water on the CST even at $61,400 \mathrm{BV}$.

\subsection{CST COLUMN FIELD TEST WITH CORE HOLE 8 GROUNDWATER FEED}

A column test was demonstrated as a field study in FY 1999. Core Hole 8 (CH 8) groundwater at ORNL was the feed to the column containing Ionsiv ${ }^{1 E-911}$ in the hydrogen form. About 20-25 L per batch were pumped and passed through a $0.45-\mu \mathrm{m}$ filter from the $\mathrm{CH} 8$ sump at Building 2016. This "batch" was then traced with ${ }^{85} \mathrm{Sr}$ and ${ }^{137} \mathrm{Cs}$ in the portable building utilized for the field test. Approximately 8 batches were run through the column during its $4 \frac{1}{2}$-month operation, amounting to $36,500 \mathrm{BV}$ of groundwater treated. Table 1 summarizes the groundwater cation concentrations at this location of the CH 8 plume.

The $1-\mathrm{cm}-\mathrm{ID}$ column was packed with $3.89 \mathrm{~g}$ of Ionsiv ${ }^{\circledR} \mathrm{IE}-911$ to a bed length of $4.8 \mathrm{~cm}$. The flow rate was maintained at about $1.2 \mathrm{~mL} / \mathrm{min}(17-19 \mathrm{BV} / \mathrm{h})$. Cation breakthrough was followed by ICP analysis of the effluent, and the radiostrontium and cesium breakthroughs were monitored using gamma spectrometry. The nominal solution residence time in the column was about $3.1 \mathrm{~min}$. A column void fractional volume of 0.48 was assumed. 
During its $4 \frac{1}{2}$-month operation, January through May, only limited maintenance of the column system was required. This included the replacement of worn peristaltic tubing, flow lines, and the prefilter that had evidence of algae growth. A portable, thermostatically-controlled heater was used in the building to keep the lines in the system from freezing.

Figure 20 shows the breakthrough profiles for pertinent cations present in Sump 2016C groundwater. The $50 \%$ breakthrough points for the major groundwater cations were: less than $110 \mathrm{BV}$ for $\mathrm{Mg} ; 900 \mathrm{BV}$ for $\mathrm{Na} ; 450 \mathrm{BV}$ for $\mathrm{Ca}$ and $14,000 \mathrm{BV}$ for $\mathrm{K}$. The slow breakthrough of potassium reflects the strong competition for CST sorption sites between this particular cation and strontium and cesium.

Breakthrough profiles of competing water cations are similar to those observed in the treatment of Seep D water collected at the ORNL WAG 5 site. However, elevated concentrations of calcium $(85 \mathrm{ppm})$, leached from limestone formations at the Core Hole, accelerate the strontium breakthrough point in the field test. Incipient column breakthrough (at $0.1 \% \mathrm{C} / \mathrm{C}_{\mathrm{o}}$ ) for strontium was noted at $3200 \mathrm{BV}$ of Core hole 8 feed, as compared with 5000 BV noted in the treatment of Seep D water, for which the calcium concentration is $10 \mathrm{ppm}$ lower. In comparison, incipient breakthrough occurred at $16,000 \mathrm{BV}$ when CST was used to treat process wastewater containing about $40 \mathrm{ppm}$ calcium.

Beyond incipient breakthrough, the strontium profile (Fig. 21) exhibits a slow, unsteady increase in ${ }^{90} \mathrm{Sr}$ content in the column effluent. The gradual breakthrough profile is indicative of the slow kinetics of sorption between strontium and CST. Peak ${ }^{90} \mathrm{Sr}$ breakthrough reached $25 \%$ at 22,000 bed volumes (BV), concurrent with potassium displacement from the column. Once potassium concentration in the column effluent returned to feed stream levels, ${ }^{90} \mathrm{Sr}$ levels decreased to $16 \%$ of influent concentration and then slowly increased to $28 \%$ by $42,000 \mathrm{BV}$. An estimate of $\mathrm{K}_{\mathrm{d}}$, made by extrapolating the breakthrough profile to $50 \%$, yields a value of $89,000 \mathrm{~L} / \mathrm{kg}$ and a loading capacity of $180 \mathrm{meq} / \mathrm{kg}$. Data available to 
date indicate the ${ }^{90} \mathrm{Sr}$ activity in the $2016 \mathrm{C}$ sump area of Core Hole 8 plume is about $170 \mathrm{~Bq} / \mathrm{L}$. CST column data thus suggest that at least $30,000 \mathrm{BV}$ of $2016 \mathrm{C}$ sump water can be treated before the column effluent activity level exceeds the DOE 5400.5 Derived Concentration Guide of $37 \mathrm{~Bq} / \mathrm{L}{ }^{90} \mathrm{Sr}$.

As noted in previous CST column studies, the sorption capacity for cesium is so great that no ${ }^{137} \mathrm{Cs}$ is found in the effluent, even after treating $42000 \mathrm{BV}$ of groundwater containing high levels of calcium (Fig. 22). At the completion of the field demonstration, a total of 0.0004 meq cesium had sorbed on the CST. suggesting that the cesium loading capacity and $\mathrm{K}_{\mathrm{d}}$ are greater than $0.11 \mathrm{meq} / \mathrm{kg}\left(3.6 \times 10^{10} \mathrm{~Bq} / \mathrm{kg}\right)$ and $64.000 \mathrm{~L} / \mathrm{kg}$, respectively. A gamma counting system described below, assembled to obtain the ${ }^{137} \mathrm{Cs}$ loading profile on CST columns from previous experimental runs, was used to calculate the ${ }^{137} \mathrm{Cs}$ loading capacin on this particular column.

\section{GAMMA SCANNING OF COLUMNS}

\subsection{CSTPWTP SIMULANT COLUMN}

Figure 23(a) shows the gamma scan profile of the CST column test using PWTP simulant feed. Approximately $300 \mathrm{meq} / \mathrm{kg}$ strontium and $0.3 \mathrm{meq} / \mathrm{kg}$ cesium had been sorbed onto the column when the

test was terminated in February 1998. Accounting for the decay of ${ }^{85} \mathrm{Sr}, 3 \mu \mathrm{Ci}^{85} \mathrm{Sr}$ and $13 \mu \mathrm{Ci}^{137} \mathrm{Cs}$ were present in the column when the scan was taken; the dose rate of the column was $50 \mathrm{mR} / \mathrm{h}$ at contact.

Each data point in the figure represents the count rate of $0.25-\mathrm{cm}$ lengths, starting from the head of the column. The ${ }^{137} \mathrm{Cs}$ profile indicates that the mass transfer zone is $\sim 1 \mathrm{~cm}$ long; therefore, less than $25 \%$ of the sorbent bed is saturated with cesium. The gamma data have been used to calculate the distribution 
coefficient $\left(\mathrm{K}_{d}\right)$ and loading capacity of ${ }^{137} \mathrm{Cs}$ on CST. The $\mathrm{K}_{d}$ for Cs removal from process water is $850,000(\mathrm{~L} / \mathrm{kg})$ on CST as compared to $90,000(\mathrm{~L} / \mathrm{kg})$ on zeolite. The calculated CST loading capacity; based on the gamma results indicated the point of $50 \%$ cesium saturation is $2.1 \mathrm{meq} / \mathrm{kg}$. Strontium detection is hampered both by the lower energy gamma ( $514 \mathrm{keV})$ that is moderated by the CST and shielding from the glass column, and also by the interference of a secondary ${ }^{137} \mathrm{Cs}$ emission at this same energy. Therefore, the signal-to-noise ratio in ${ }^{85} \mathrm{Sr}$ detection is limited relative to that of ${ }^{137} \mathrm{Cs}$. Nonetheless, the ${ }^{85} \mathrm{Sr}$ profile indicates that the strontium mass transfer zone is nearly the full length of the column $(3.8 \mathrm{~cm})$, suggesting full utilization of the column bed. This value conforms to a $\mathrm{C} / \mathrm{C}_{\circ}$ of $15-20 \%$ determined by the analysis of column effluent.

\subsection{CST/SEEP WATER COLUMN}

Figure 23(b) illustrates radionuclide loading profiles on CST using Seep D water as the column feed. Evident in the figure is the excellent reproducibility in gamma profiles of the column in triplicate scanning runs. The cesium $K_{d}$ in the Seep $D$ water matrix is $150,000(\mathrm{~L} / \mathrm{kg})$, indicating a reduction in cesium loading capacity on CST at a calcium concentration twice that present in PWTP simulant.

\subsection{ZEOLITE/SEEP WATER COLUMN}

Gamma scan results also identified significant displacement of radionuclides in the upstream portion of the zeolite column [Fig. 23(c)], and to a much smaller extent from the CST column [Fig. 23(b)], during the treatment of actual seep water. Although effluent activity indicated that strontium was desorbed from zeolite, the gamma scan indicates that both cesium and strontium in the saturated zone of the zeolite column are displaced by the higher levels of water cations and are resorbed further down the column. 
The cesium $K_{d}$ in the Seep D water matrix was a factor of three lower on zeolite $(50,000 \mathrm{~L} / \mathrm{kg})$ than that observed with CST in the same water matrix.

\section{CONCLUSIONS AND RECOMMENDATIONS}

\subsection{TREATMENT OF GAAT SCABBLING WATER AND CNF FEED STREAM}

Batch studies were performed on water generated during scarification of inactive waste tanks at the ORNL site, which represents a waste stream that is produced throughout the DOE complex as waste tanks are removed from service. The water contains both ${ }^{90} \mathrm{Sr}$ and ${ }^{137} \mathrm{Cs}$ in the presence of high levels of $\mathrm{Na}(402 \mathrm{ppm})$ and $\mathrm{K}(20-80 \mathrm{ppm})$ at $\mathrm{pH} 9-10$. If the ${ }^{90} \mathrm{Sr}$ and ${ }^{137} \mathrm{Cs}$ could be reduced by factors of 500-1000 using CST, the ORNL waste remediation staff could transfer the scabbling water directly to the PWTP for final treatment. A number of inactive tanks are scheduled in the near future for scarification so that the benefit would be significant. Batch-uptake tests were performed to determine how effective Ionsiv ${ }^{\circledR}$ IE-911 would be in treating this waste stream. Initial results indicated that the

${ }^{90} \mathrm{Sr}$ was not removed to a significant extent from the waste, but the decontamination factor for ${ }^{137} \mathrm{Cs}$ was greater than 1200 . The presence of trace complexing agents and the relatively high concentration of potassium ion $(20 \mathrm{ppm})$ in the waste suppressed ${ }^{90} \mathrm{Sr}$ removal. Therefore, at present, treatment of this waste stream by CST will not remove ${ }^{90} \mathrm{Sr}$ to levels that will allow for treatment of the wastewater in a more cost-effective manner.

The driver for additional treatment at CNF appears to be defined by the source of waste burned at the TSCA incinerator. If the waste is derived from ORNL research projects, TSCA blowdown may contain sufficient ${ }^{90} \mathrm{Sr}$ and ${ }^{137} \mathrm{Cs}$ to require an additional decontamination operation at $\mathrm{CNF}$ for these nuclides. 
Because of the high salt content of CNF wastewater, earlier column studies using chabazite and clinoptilolite zeolite were not suitable for the removal of ${ }^{90} \mathrm{Sr}$ or ${ }^{137} \mathrm{Cs}$ directly from the stream. Due to the limited funding level and available floor space at CNF, preferred treatment options will be those that take advantage of presently available mixing tank equipment. Therefore, the addition of loose, powdered sorbent to the waste tank for batch operation will be preferred over column technology. If column parameters match those of an existing activated-carbon column located downstream from the mixing tank, an engineered form of a sorbent might be suitable.

To address this possible need, an actual sample of CNF waste-water was spiked with strontium and cesium and was used to determine the decontamination achievable with various sorbents. The sorbents used in these batch tests included (a) Ionsiv ${ }^{\circledR E}$ IE 11 and IE-910 (engineered and powdered CST); (b) SrTreat ${ }^{\circledR}$ powder, (c) CsTreat ${ }^{\circledR}$ powder; and (d) the baseline sorbent, chabazite zeolite. CsTreat ${ }^{\circledR}$, followed closely by Ionsiv ${ }^{\circledR}$ IE-911, has the highest capacity for cesium in the waste. Zeolite did not compete satisfactorily against the other sorbents for removal of either cesium or strontium. Ionsiv ${ }^{\otimes}$ IE-910 removed the strontium much more effectively than either the SrTreat ${ }^{\circledR}$ or the zeolite. Strontium is expected to be present in solid particulates in the TSCA blowdown water and, therefore, could be removed primarily by physical means. It is the cesium, present as a soluble cation, that must be removed chemically from CNF waste. At the cesium concentrations tested here, a minimum DF of 1000 would be necessary to reduce the cesium in the wastewater to an acceptable level. The DFs in Table 7 show that the zeolite would not meet the minimum requirements for cesium removal at CNF, whereas Ionsiv ${ }^{\$}$ IE-911 and IE-910 and CsTreat ${ }^{\circledR}$ would exhibit satisfactory performance in this regard.

Figures 24 and 25 show the relative selectivities for strontium and cesium over competing cations in the high salt waste. CST sorbs $\mathrm{K}, \mathrm{Mg}$, and $\mathrm{Ca}$, in addition to $\mathrm{Sr}$ and $\mathrm{Cs}$; both $\mathrm{Na}$ and $\mathrm{H}+$ were exchanged. 
SrTreat ${ }^{\circledR}$ behaved similarly to Ionsiv ${ }^{\circledR}$ IE-910, although selectivity for Sr over competing alkaline earth metals was not as great as with CST. Cesium exchanged with both sodium and potassium forms of the cobalt hexacyannoferrate, CsTreat ${ }^{\circledR}$. The CsTreat ${ }^{\otimes}$ does not sorb primary wastewater cations and therefore has a greater selectivity for ${ }^{137} \mathrm{Cs}$ than Ionsiv ${ }^{\circledR}$ IE-9 10 . However, if strontium must be removed also, the CsTreat ${ }^{\mathbb{1}}$ should be used in conjunction with a strontium-selective sorbent.

CNF batch processing time at CNF places an additional demand on the sorbent selected for waste treatment. Sixteen thousand gallons of waste are currently processed within a 2 -h period. Therefore, sorbent efficiency must actually be based on a 2 -h contact time. In the review of the above sorbents, it appears that equilibration times are more a function of the radionuclide than of the sorbent. Only $50 \%$ of maximum cesium removal is achieved in $2 \mathrm{~h}$ relative to the $24-\mathrm{h}$ equilibration time on either Ionsiv ${ }^{\circledR}$ IE910 or CsTreat ${ }^{\otimes}$. Less than $20 \%$ strontium is removed at $2 \mathrm{~h}$ as compared with that removed at an equilibration time approaching $100 \mathrm{~h}$. Under this time constraint, it may be advisable to post-process the CNF waste using column technology.

\subsection{COLUMN TESTS}

Tables 13 and 14 summarize CST and zeolite column performance for the various feed streams tested. There are four figures of merit in the comparison of the data. The first notable observation is the relative differences in the $50 \%$ breakthrough points for the competing cations and the radionuclides (Figs. 8-22). The order of cation elution is similar on both sorbents, corresponding to the relative ease for which individual cations shed waters of hydration prior to bonding with the sorbent. However, with the exception of potassium, there is a much greater distance between the position of competing cation and incipient radionuclide breakthrough on CST. Under identical feed composition and column operating 
parameters, the positions of cation breakthrough on each sorbent are directly related to the selectivity of that sorbent for the radionuclides over competing cations. This difference corresponds to a greater selectivity for strontium and cesium on CST than on zeolite in low-ionic-strength, near-neutral-pH applications. The breakthrough profiles also demonstrate the strong competition between potassium and radionuclides for sorption on either sorbent, although competition is smallest on CST. The enhanced selectivity demonstrated by CST reflects the relatively smaller dependence of wastewater remediation efforts on matrix composition as compared to zeolite treatment.

Sorbent selectivity also plays a major role in terms of retaining radionuclides on the column once the column has been loaded. As seen in the treatment of Seep D water, strontium is desorbed from the zeolite column with continuous operation. There is an indication of slight strontium desorption from gamma scan data, but no evidence of desorption from CST was observed in data based on column effluent results over a much longer column operating time. Desorption of ${ }^{90} \mathrm{Sr}$ will have a significant impact on the way ion exchange on zeolite can be used to treat wastewater streams. The gamma scans indicate that multiple zeolite columns can be used in a carousel arrangement only if the upstream zeolite column is removed from the series before it is fully loaded with strontium. Otherwise, the strontium will be desorbed and transferred to the downstream zeolite columns. Additionally, if zeolite is used as the sorbent in underground, permeable barriers, such as in a french drain system, the sorbent will have to be exhumed prior to full loading with strontium. If left in place, the strontium will be desorbed to contaminate the groundwater at a higher level than influent ${ }^{90} \mathrm{Sr}$ activity.

The relative size of the radionuclide $K_{d}$ on each sorbent is a second distinguishing feature of the column data. The strontium and cesium coefficients on CST are $6 \times 10^{5}$ and $8 \times 10^{6} \mathrm{~L} / \mathrm{kg}$, respectively, or 30 and 
100 times greater than zeolite. Therefore, on the basis of cation selectivity and column capacity, Ionsiv ${ }^{\circledR}$ IE-911 outperforms the chabazite zeolite for treatment of PWTP simulant.

Thirdly, the sorption process on CST is much slower than on zeolite. The long mass transfer zone for strontium sorption on CST (Fig. 26) can be explained in terms of film mass-transfer coefficients, $k_{f}$ Theoretical predictions of the cation breakthrough curves for the two sorbents were performed using several empirical approaches. The calculated breakthrough curves presented an opportunity to evaluate the cationic film mass-transfer coefficients, $\mathrm{k}_{f}$, and, ultimately, allowed for mass-transfer rate comparisons. The relative differences in the calculated (and fitted, in some cases) $\mathrm{k}_{f}$ values were somewhat larger than those found by fitting the breakthrough curves to the Rosen solution. Cationic film mass-transfer coefficients determined by conventional empirical models for the zeolite columns generally fit the experimental column breakthrough data quite well, whereas in some cases, the $k_{f} s$ were reduced by a factor of 4 in order to fit the experimental CST data. The overprediction of the $k_{f} s$ for the CST columns suggest that the surface mechanism for sorption of the cations is slower than that for the zeolite. This supposition is supported by the multisite model of CST exchange presented by Zheng. ${ }^{10}$ Slower mass transfer rates, in general, are less desirable when time is an issue (i.e., batch operation). However, in the actual operation of columns, this can be an advantage because breakthrough occurs on a much more gradual scale, thus allowing more time for sorbent sluicing and removal from columns.

Fourth, CST is a multi-functional ion exchanger, and as such, breakthrough profiles on this sorbent are uneven in comparison to the zeolite, where a single ion exchange reaction predominates. Multiple ion exchange reactions result in an extended mass transfer zone that is actually a composite of several reaction zones. It is also because of the complex chemistry that the loading capacity for strontium on CST is approximately a factor of 10 higher than on zeolite for a given wastewater. As yet, no sorption 
model has been developed for strontium sorption on CST that incorporates the multiple functionality of the sorbent. Therefore, application of CST for the treatment of other waste streams is difficult to predict and must be based on small column testing.

Operational parameters such as material handling and sorbent costs also play a role in sorbent selection. Although fines must be removed from both as-received sorbents, only the zeolite continues to break down during column operation and eventually limits the lifetime of the column. The main detraction for the use of CST in wastewater treatment is the relatively high initial cost of the sorbent. It is hoped that as the market for the product enlarges, the bulk rate for the engineered form of CST will decrease, making it more economically viable. 


\section{REFERENCES}

1. D. T. Bostick, W. D. Arnold, Jr., P. A. Taylor, D. R. McTaggart, M. W. Burgess, and B. Guo, Evaluation of Improved Techniques for the Removal of ${ }^{90} \mathrm{Sr}$ and ${ }^{137} \mathrm{Cs}$ from Process Wastewater and Groundwater: Chabazile Zeolite Baseline Study, ORNL/TM-12903, Oak Ridge National Laboratory, Oak Ridge, Tenn., April 1995.

2. D. T. Bostick, W. D. Arnold, Jr., B. Guo, M. W. Burgess, D. R. McTaggart, and

P. A. Taylor, Evaluation of Improved Techniques for the Removal of ${ }^{90} \mathrm{Sr}$ and ${ }^{137} \mathrm{Cs}$ from Process Wastewater and Groundwater: FY 1995 Status, ORNL/TM-13099, Oak Ridge National Laboratory, Oak Ridge, Tenn., 1997.

3. D. T. Bostick and B. Guo, Evaluation of Improved Techniques for the Removal of Fission Products from Process Wastewater and Groundwater: FY 1996 Status, ORNL/TM-13306, Oak Ridge National Laboratory, Oak Ridge, Tenn., 1997.

4. D. T. Bostick, W. D. Arnold, B. Guo, and M. W. Burgess, "The Evaluation of Sodium-Modified Chabazite Zeolite and Resorcinol-Formaldehyde Resin for the Treatment of Contaminated Process Wastewater," Sep. Sci. Technol. 32, 793-811 (1997).

5. D. T. Bostick, S. M. DePaoli, and B. Guo, Evaluation of Improved Techniques for the Removal of Fission Products from Process Wastewater and Groundwater: FY 1997 Status, ORNL/TM-13497, Oak Ridge National Laboratory, Oak Ridge, Tenn, 1997.

6. S. M. DePaoli and D. T. Bostick, "Process Wastewater Treatment with Hydrogen-Form CST and Chabazite Zeolite," Proceedings of Spectrum '98, Denver, Colo., American Nuclear Society, LaGrange Park, Ill., 2, 1003-1009 (1998).

7. Practical Handbook of Environmental Control, ed. Conrad P. Staub, CRC Press, Boca Raton, Fla., 1989.

8. J. F. Relyea, "Theoretical and Experimental Considerations for Use of the Column Method for Determining Retardation Factors," Radioact. Waste Manage. Nucl. Fuel Cycle 3, 151-6 (1982).

9. H. L. Bonn, B. L. McNeal, and G. A. O'Conner, Soil Chemistry, John Wiley \& Sons, New York, 1985.

10. Z. Zheng, R. G. Anthony, and J. E. Miller, "Modeling Multicomponent Ion Exchange Equilibrium Utilizing Hydrous Crystalline Silicotitanates by a Multiple Interactive Ion Exchange Model," Ind. Eng. Chem. Res. 36, 2427-34, (1997).

11. Risto Harjula, IVO, Finland, private communication, Sept. 1, 1998. 
12. A. C. Coroneos, P. A. Taylor, W. D. Arnold, Jr., D. A. Bostick, and J. J. Perona, Bench-Scale Treatability Studies for Simulated Incinerator Scrubber Blowdown Containing Radioactive Cesium and Strontium, ORNL/TM-12823, December 1994.

13. J. B. Rosen, "Kinetics of a Fixed Bed System for Solid Diffusion into Spherical Particles," J. Chem. Phys., 20 (3), March 1932.

14. J. J. Perona, A. C. Coroneos, T. E. Kent, and S. A. Richardson, "A Sample Model for Strontium Breakthrough on Zeolite Columns," Presented at the $8^{\text {th }}$ Symposium on Separation Science and Technology, Gatlinburg, Tenn., Oct. 21-233, 1997.

15. M. E. Huckman and R. G. Anthony, presented at the $12^{\text {th }}$ Symposium on Separation Science and Technology, Gatlinburg, Tenn., Oct.. 21-23, 1997.

16. S. M. Robinson, W. D. Arnold, Jr., and C. W. Byers, Multicomponent Liquid Ion Exchange with Chabazite Zeolites, ORNL/TM-12403, October 1993.

17. R. H. Perry and C. H. Chilton, Eds., Chemical Engineers' Handbook, $5^{\text {th }}$ ed., McGrawHill Book Co., New York, 1973.

18 R. A. Robinson and R. H. Stokes, Electrolyte Solutions, $2^{\text {nd }}$ ed., Butterworths, London, 1959.

19. A. L. Hines and R. N. Maddox, Mass Transfer Fundamentals and Applications, PrenticeHall, Inc., Englewood Cliffs, N.J., 1985. 
Table 1. Composition of Process Waste Treatment Plant (PWTP) actual and simulant wastewater, Seep D water, and groundwater from Core Hole 8 sump

\begin{tabular}{|c|c|c|c|c|}
\hline \multirow{2}{*}{ Component } & \multicolumn{4}{|c|}{ Concentration $(\mathrm{mg} / \mathrm{L})$} \\
\hline & PWTP, actual & PWTP, simulant & Seep D water ${ }^{a}$ & Groundwater, $\mathrm{CH} 8^{a . b}$ \\
\hline $\mathrm{Ca}^{2+}$ & $35-40$ & 45 & 76 & 85 \\
\hline${ }^{137} \mathrm{Cs}^{+}$ & $\begin{array}{l}9.4 \times 10^{-8} \\
\left(3.0 \times 10^{2} \mathrm{~Bq} / \mathrm{L}\right)\end{array}$ & $\begin{array}{l}3.4 \times 10^{-4} \\
\left(1.12 \times 10^{6} \mathrm{~Bq} / \mathrm{L}\right)\end{array}$ & $\begin{array}{l}3.4 \times 10^{-4} \\
\left(1.12 \times 10^{6} \mathrm{~Bq} / \mathrm{L}\right)\end{array}$ & $\begin{array}{l}3.4 \times 10^{-4} \\
\left(1.12 \times 10^{6} \mathrm{~Bq} / \mathrm{L}\right)\end{array}$ \\
\hline $\mathrm{K}^{+}$ & $1-3$ & 1.2 & 1.6 & 1 \\
\hline $\mathrm{Mg}^{2+}$ & $7-8$ & 8.8 & 9.1 & 8 \\
\hline $\mathrm{Na}^{+}$ & $14-30$ & 18.3 & 8.7 & 8 \\
\hline $\begin{array}{l}\mathrm{Sr}^{2+} \text { (total) } \\
\mathrm{Sr}^{2+} \text { (rad.) }\end{array}$ & $\begin{array}{l}0.1 \\
5.3 \times 10^{-8} \text { as }{ }^{90} \mathrm{Sr} \\
\left(2.70 \times 10^{2} \mathrm{~Bq} / \mathrm{L}\right)\end{array}$ & $\begin{array}{l}0.1 \\
1.14 \times 10^{-6} \text { as }{ }^{85} \mathrm{Sr} \\
\left(1.0 \times 10^{6} \mathrm{~Bq} / \mathrm{L}\right)\end{array}$ & $\begin{array}{l}0.1 \\
5.33 \times 10^{-6} \text { as }{ }^{90} \mathrm{Sr} \\
\left(2.7 \times 10^{4} \mathrm{~Bq} / \mathrm{L}\right)\end{array}$ & $\begin{array}{l}0.1 \\
3 \times 10^{-8} \text { as }{ }^{90} \mathrm{Sr} \\
\left(1.50 \times 10^{2} \mathrm{~Bq} / \mathrm{L}\right)\end{array}$ \\
\hline $\mathrm{pH}$ & $6.7-9$ & $7-8$ & 8 & \\
\hline
\end{tabular}

${ }^{a}$ Cesium added to these waste waters in tracer levels.

${ }^{b}$ Core Hole 8 water collected from Bldg. 2016 sump.

Table 2. Actual compositions of wastewaters used in batch studies

\begin{tabular}{lcc}
\hline & \multicolumn{2}{c}{ Concentration (mg/L) } \\
\cline { 2 - 3 } Component & $\begin{array}{c}\text { Central Neutralization Facility } \\
(\mathrm{CNF}) \text { wastewater }\end{array}$ & $\begin{array}{c}\text { Gunite Tank (GAAT) } \\
\text { wastewater }\end{array}$ \\
\hline $\mathrm{Ca}^{2+}$ & 72 & 20 \\
$\mathrm{~K}^{+}$ & 8 & 18 \\
$\mathrm{Mg}^{2+}$ & 21 & 11 \\
$\mathrm{Na}^{+}$ & 219 & 400 \\
$\mathrm{Sr}^{2+}$ (total) & $0.1^{a}$ & 0.1 \\
$\mathrm{Sr}^{2+}$ (radioactive) & & $7.7 \times 10^{5} \mathrm{~Bq} / \mathrm{L}$ \\
${ }^{137} \mathrm{Cs}^{+}$ & $3.4 \times 10^{-4}$ & $3.0 \times 10^{-5}$ \\
& $\left(1.12 \times 10^{6} \mathrm{~Bq} / \mathrm{L}\right)^{a}$ & $9.8 \times 10^{4} \mathrm{~Bq} / \mathrm{L}$ \\
\hline
\end{tabular}

${ }^{a} \mathrm{CNF}$ wastewater was traced with strontium and cesium. 
Table 3. Atomic parameters of wastewater cations ${ }^{a}$

\begin{tabular}{cccc}
\hline Cation & $\begin{array}{c}\text { Dehydrated radius } \\
(\mathrm{nm})\end{array}$ & $\begin{array}{c}\text { Hydrated radius } \\
(\mathrm{nm})\end{array}$ & $\begin{array}{c}\text { Hydration energy } \\
(\mathrm{kcal} / \mathrm{mol})\end{array}$ \\
\hline $\mathrm{Ca}^{2+}$ & 0.099 & 0.412 & -377 \\
$\mathrm{~K}^{+}$ & 1.33 & 0.331 & -75 \\
$\mathrm{Mg}^{2+}$ & 0.65 & 0.428 & -456 \\
$\mathrm{Na}^{+}$ & 0.95 & 0.358 & -95 \\
$\mathrm{Sr}^{2+}$ & 1.12 & 0.412 & -345 \\
$\mathrm{Cs}^{+}$ & 1.69 & 0.329 & -61 \\
\hline
\end{tabular}

${ }^{a}$ H. L. Bonn, B. L. McNeal, and G. A. O'Conner, Soil Chemistry, John Wiley \& Sons, New York, 1985. 
Table 4. Physical and chemical parameters of sorbents

\begin{tabular}{|c|c|c|c|c|}
\hline & Chabazite zeolite & SrTreat $^{k}$ & CsTreat $^{(3)}$ & Crystalline silicotitanate ${ }^{a}$ \\
\hline Source & GSA Resources, Inc. & Selion OY, Finland & Selion OY, Finland & UOP molecular sieves \\
\hline Form & Naturally occurring, inorganic zeolite & Titanium dioxide & $\begin{array}{l}\text { Potassium cobalt } \\
\text { hexacyanoferrate }\end{array}$ & $\begin{array}{l}\text { Inorganic, engineered pellets or powder; } \\
\text { framework of aluminosilicate }\end{array}$ \\
\hline Exchangeable cation & Sodium & Sodium & Potassium & Sodium and hydrogen \\
\hline Cost & $\$ 50 / \mathrm{ft}^{3}$ & & & $\$ 7200 / \mathrm{ft}^{3}$ \\
\hline Bulk density, $\mathrm{g} / \mathrm{cm}^{3}$ & 0.7 & & & 1.0 \\
\hline Particle density, $\mathrm{g} / \mathrm{cm}^{3}$ & 1.73 & $5.6^{\mathrm{b}}$ & $2.8^{b}$ & 2.0 \\
\hline Average particle size, $\mu \mathrm{m}$ & $480 \pm 220$ & $0.15-0.30^{b}$ & $0.15-0.25^{b}$ & $410 \pm 110$ \\
\hline Moisture content, $\%$ & 7.71 & 8.77 & 2.97 & $5.85(6.07 \%$ for IONSIV IE-910) \\
\hline $\begin{array}{l}\text { Order of selectivity in process } \\
\text { waste simulant }\end{array}$ & $\mathrm{Na}<\mathrm{Mg}<\mathrm{Ca}<\mathrm{Sr}<\mathrm{Cs}$ & $\mathrm{ND} c$ & $\mathrm{ND}^{c}$ & $\mathrm{Mg}<\mathrm{Ca}<\mathrm{Na}<\mathrm{K}<\mathrm{Sr}<\mathrm{Cs}$ \\
\hline $\begin{array}{l}\text { Column operating } \\
\text { characteristics }\end{array}$ & $\begin{array}{l}\text { Material is friable; tends to break } \\
\text { down prior to complete loading, } \\
\text { causing column plugging }\end{array}$ & $\mathrm{ND}_{\boldsymbol{\varepsilon}}$ & $\mathrm{ND}^{c}$ & $\begin{array}{l}\text { Material appears to be structurally stable; } \\
\text { in column test over } 10 \text { months, no } \\
\text { noticeable plugging or fines produced }\end{array}$ \\
\hline $\begin{array}{l}\text { Pretreatment for near-neutral- } \\
\text { pH waste treatment }\end{array}$ & $\begin{array}{l}\text { Sieve; wash with } 2 \mathrm{MNaCl} \text {; wash with } \\
\mathrm{H}_{2} \mathrm{O} \text {; air dry }\end{array}$ & As-received & As-received & $\begin{array}{l}\text { Sieve, wash with } \mathrm{H}_{2} \mathrm{O} \text {; wash with } 0.1 \mathrm{M} \\
\mathrm{HCl}\end{array}$ \\
\hline Ion-exchange capacity, meq/g & 2.2 & $5.0^{b}$ & $0.35^{b}$ & 2.5 \\
\hline
\end{tabular}

${ }^{a}$ Information in table is for engineered form of CST.

${ }^{b}$ IVO data: SrTreat ${ }^{\text {b }}$ lot 10; CsTreat $^{\mathfrak{w}}$ lot 14/20; IVO Material Safety Data Safety Sheet and private communication.

$\mathrm{ND}=$ not determined. 
Table 5. Cationic compositions of tested sorbents

\begin{tabular}{|c|c|c|c|c|c|}
\hline Parameter & $\begin{array}{c}\text { Sodium } \\
\text { chabazite } \\
\text { zeolite }\end{array}$ & $\begin{array}{l}\text { Hydrogen 1- } \\
\text { CST pellets }\end{array}$ & $\begin{array}{l}\text { Hydrogen2- } \\
\text { CST pellets }\end{array}$ & $\begin{array}{c}\text { Ionsiv }^{\circledR} \\
\text { IE-910 } \\
\text { (as-received) }\end{array}$ & $\begin{array}{c}\text { SrTreat }^{\Phi} \\
\text { (as-received) }\end{array}$ \\
\hline$\% \mathrm{Na}$ & 5.1 & 0.02 & ND & 9.9 & 8.6 \\
\hline$\% \mathrm{~K}$ & 0.3 & $\mathrm{ND}^{\mathrm{a}}$ & trace & trace & 0.03 \\
\hline$\% \mathrm{Mg}$ & 0.2 & ND & 0.18 & trace & 0.02 \\
\hline$\% \mathrm{Ca}$ & 0.5 & ND & $\mathrm{ND}$ & 0.03 & 0.01 \\
\hline
\end{tabular}


Table 6. Comparison of strontium and cesium removal by Ionsiv $^{\mathbb{Q}}$ IE-911 in different wastewaters ${ }^{a}$

\begin{tabular}{|c|c|c|c|c|}
\hline \multirow{2}{*}{$\begin{array}{l}\text { Wastewater } \\
\text { source }\end{array}$} & \multicolumn{2}{|c|}{$\begin{array}{c}\text { Strontium } \\
\text { (at } 0.0023 \mathrm{meq} / \mathrm{L} \mathrm{Sr} \text { ) }\end{array}$} & \multicolumn{2}{|c|}{$\begin{array}{c}\text { Cesium } \\
\left.\text { (at } 3.2 \times 10^{-6} \mathrm{meq} / \mathrm{L} \mathrm{Cs}\right) \\
\end{array}$} \\
\hline & $\mathrm{L}_{\mathrm{c}}(\mathrm{meq} / \mathrm{kg})$ & $\mathrm{K}_{\mathrm{d}}(\mathrm{L} / \mathrm{kg})$ & $\mathrm{L}_{\mathrm{c}}(\mathrm{meq} / \mathrm{kg})$ & $\mathrm{K}_{\mathrm{d}}(\mathrm{L} / \mathrm{kg})$ \\
\hline PWTP simulant & 1050 & $6 \times 10^{5}$ & 26 & $8 \times 10^{6}$ \\
\hline CNF & 79 & $3 \times 10^{4}$ & 6.3 & $3 \times 10^{6}$ \\
\hline GAAT & 0.25 & $2 \times 10^{2}$ & 0.8 & $3.6 \times 10^{5}$ \\
\hline GAAT simulant & 3.2 & $1.5 \times 10^{3}$ & 5 & $1.3 \times 10^{6}$ \\
\hline
\end{tabular}

${ }^{a}$ Hydrogen 1-CST preparation of IONSIV ${ }^{\otimes}$ IE-911. 
Table 7. Decontamination factors and predicted distribution coefficients from batch isotherm studies in CNF wastewater

\begin{tabular}{|c|c|c|c|c|}
\hline \multirow{2}{*}{$\begin{array}{l}\text { Sorbent } \\
(\mathrm{mg})\end{array}$} & \multicolumn{4}{|c|}{ Decontamination factors, DFs } \\
\hline & Ionsiv ${ }^{\circledast}$ IE-910 & SrTreat & CsTreat $^{\star}$ & Chabazite zeolite \\
\hline & \multicolumn{4}{|c|}{ Strontium } \\
\hline 5 & 130 & 10 & $-\cdots$ & 2 \\
\hline 10 & 670 & 70 & $-\cdots$ & 3 \\
\hline 20 & 4,200 & 3,400 & --- & 6 \\
\hline 50 & 12,200 & 61,400 & $-\cdots$ & 20 \\
\hline 100 & 3,900 & 5,200 & $\cdots-$ & 50 \\
\hline \multirow[t]{2}{*}{$\begin{array}{l}\text { Prediction of distribution } \\
\text { coefficient }\left(\mathrm{K}_{\mathrm{d}}, \mathrm{L} / \mathrm{kg}\right)\end{array}$} & $K_{d}=219,500^{\prime \prime}$ & $\mathrm{K}_{\mathrm{d}}=8,300^{a}$ & $-\cdots$ & $K d={\frac{174}{[\mathrm{Sr}]_{l}^{0.345}}}^{b}$ \\
\hline & \multicolumn{4}{|c|}{ Cesium } \\
\hline 5 & 1,200 & $\cdots$ & 3,600 & 10 \\
\hline 10 & 2,000 & $-\cdots$ & 3,900 & 30 \\
\hline 20 & 5,100 & --- & 4,200 & 60 \\
\hline 50 & 5,800 & $\cdots$ & 5,900 & 190 \\
\hline 100 & 2,400 & $\cdots$ & 29,100 & 370 \\
\hline $\begin{array}{l}\text { Prediction of distribution } \\
\text { coefficient }\left(\mathrm{K}_{\mathrm{d}}, \mathrm{L} / \mathrm{kg}\right)\end{array}$ & $\mathrm{K}_{\mathrm{d}}=1,958,000^{\prime \prime}$ & $\ldots$ & $6,021,000^{a}$ & $K d=\frac{1318}{[\mathrm{Cs}]_{l}^{0.185}} b$ \\
\hline
\end{tabular}

${ }^{a}$ Linear fit to isotherm data.

${ }^{b}$ Freundlich fit to isotherm data. 
Table 8. Cation $K_{d}$ values $(\mathrm{L} / \mathrm{kg})$ in actual CNF wastewater

\begin{tabular}{lcccccc}
\hline & \multicolumn{6}{c}{ Cation $_{\mathrm{d}}(\mathrm{L} / \mathrm{kg})^{a}$} \\
\cline { 2 - 7 } Sorbent & $\mathrm{Sr}$ & $\mathrm{Cs}$ & $\mathrm{Na}$ & $\mathrm{K}$ & $\mathrm{Ca}$ & $\mathrm{Mg}$ \\
\hline Ionsiv $^{\otimes}$ IE-910 & $3.0 \times 10^{5}$ & $3.0 \times 10^{6}$ & Exchanged & $1.4 \times 10^{2}$ & $2.6 \times 10^{3}$ & Not sorbed \\
SrTreat $^{\otimes}$ & $1.0 \times 10^{5}$ & $1.5 \times 10^{3}$ & Exchanged & $1.3 \times 10^{2}$ & $5.2 \times 10^{3}$ & $4.2 \times 10^{2}$ \\
CsTreat $^{\otimes}$ & - & $8.0 \times 10^{6}$ & Exchanged & Exchanged & Not sorbed & Not sorbed \\
Zeolite & $2.0 \times 10^{3}$ & $2.0 \times 10^{4}$ & Exchanged & $5.3 \times 10^{1}$ & $1.2 \times 10^{3}$ & $3.6 \times 10^{1}$ \\
& & & & & & \\
\hline
\end{tabular}

${ }^{a}$ Actual CNF waste $(10 \mathrm{~mL})$ treated with $5 \mathrm{mg}$ of sorbent; equilibration times, selected for optimal removal of the radionuclides, were $24 \mathrm{~h}$ for IONSIV $^{\circledR}$ IE-910 and CsTreat ${ }^{\circledR}$ and $100 \mathrm{~h}$ for SrTreat ${ }^{\circledR}$.

Table 9. Selectivity factors in actual CNF wastewater

\begin{tabular}{|c|c|c|c|c|c|c|}
\hline \multirow[b]{2}{*}{ Sorbent } & \multicolumn{6}{|c|}{ Selectivity factors (cation ${ }_{1} \mathrm{~K}_{\mathrm{d}}$ cation $\left._{2} \mathrm{~K}_{\mathrm{d}}\right)^{a}$} \\
\hline & $\mathrm{Sr} / \mathrm{Ca}$ & $\mathrm{Sr} / \mathrm{Mg}$ & $\mathrm{Sr} / \mathrm{K}$ & $\mathrm{Cs} / \mathrm{Ca}$ & $\mathrm{Cs} / \mathrm{Mg}$ & $\mathrm{Cs} / \mathrm{K}$ \\
\hline IONSIV $^{\circledR}$ IE-910 & 1.1 & 1800 & 200 & 1100 & 17,000 & 2000 \\
\hline SrTreat ${ }^{\circledR}$ & 2.5 & 32 & -- & - & -- & $\ldots$ \\
\hline CsTreat $^{\circledR}$ & --- & -- & - & 17,000 & $\mathrm{Mg}$ not sorbed & $\mathrm{TBD}$ \\
\hline Zeolite & 1.5 & 48 & 33 & 18 & 570 & 40 \\
\hline
\end{tabular}

${ }^{a}$ Actual CNF waste $(10 \mathrm{~mL})$ treated with $5 \mathrm{mg}$ of sorbent; equilibration times, selected for optimal removal of the radionuclides, were $24 \mathrm{~h}$ for IONSIV ${ }^{\circledR}$ IE-910 and CsTreat ${ }^{\circledR}$ and $100 \mathrm{~h}$ for SrTreat ${ }^{\circledR}$. 
Table 10. Summary of variables in column experiments

\begin{tabular}{|c|c|c|c|c|c|}
\hline \multirow[t]{2}{*}{ Variable } & \multicolumn{2}{|c|}{ PWTP simulant feed } & \multicolumn{2}{|c|}{ Seep D feed } & \multirow{2}{*}{$\begin{array}{c}\begin{array}{c}\text { Core Hole } 8 \\
\text { groundwater feed }\end{array} \\
\text { Hydrogen2-CST }\end{array}$} \\
\hline & Chabazite zeolite & Hydrogen1-CST & Chabazite zeolite & Hydrogen2-CST & \\
\hline Exchanger weight, $\mathrm{g}$ & 2.13 & 3.81 & 2.30 & 3.85 & 3.89 \\
\hline Particle diameter, $\mu \mathrm{m}$ & 484 & 420 & 484 & 420 & 420 \\
\hline Column diameter, $\mathrm{cm}$ & 1.0 & 1.0 & 1.0 & 1.0 & 1.0 \\
\hline Bed length, $\mathrm{cm}$ & 4.9 & 4.85 & 4.8 & 5.2 & 5.2 \\
\hline Bed volume, $\mathrm{mL}$ & 3.85 & 3.81 & 3.77 & 4.08 & 4.08 \\
\hline Flow rate, $\mathrm{mL} / \mathrm{min}$ & 1.28 & 1.21 & 1.25 & 1.2 & 1.11 \\
\hline Column void fraction, $\varepsilon$ & 0.48 & 0.47 & 0.48 & 0.47 & 0.47 \\
\hline
\end{tabular}


Table 11. Film mass-transfer coefficients calculated for column breakthrough curve predictions

\begin{tabular}{|c|c|c|c|c|c|c|}
\hline & \multirow{3}{*}{ Cation } & \multicolumn{5}{|c|}{ Film mass-transfer coefficients $\left(k_{f} \times 10^{-3}, \mathrm{~cm}^{2} / \mathrm{s}\right)$} \\
\hline & & \multicolumn{2}{|c|}{ PWTP simulant feed stream } & \multicolumn{2}{|c|}{ Seep D feed stream } & \multirow{2}{*}{$\begin{array}{c}\begin{array}{c}\text { Core Hole } 8 \\
\text { feed stream }\end{array} \\
\text { Hydrogen2-CST }\end{array}$} \\
\hline & & Chabazite zeolite & Hydrogen 1-CST & Chabazite zeolite & Hydrogen2-CST & \\
\hline \multirow{6}{*}{ 㟔 } & $\mathrm{Ca}^{2+}$ & 1.74 & 1.82 & 1.64 & 0.4 & 0.1 \\
\hline & $\mathrm{Cs}^{+}$ & 1.26 & 1.28 & 1.68 & 1.23 & 1.79 \\
\hline & $\mathrm{K}^{+}$ & --- & 2.19 & 0.95 & 1.22 & 1.2 \\
\hline & $\mathrm{Mg}^{2+}$ & 1.69 & 1.77 & 1.6 & 0.2 & 1.69 \\
\hline & $\mathrm{Na}^{+}$ & 1.93 & 1.18 & 1.82 & 0.5 & 0.5 \\
\hline & $\mathrm{Sr}^{2+}$ & 0.5 & 0.35 & 0.7 & 0.35 & \\
\hline
\end{tabular}


Table 12. Liquid diffusivities calculated by the Nernst equation.

\begin{tabular}{cc}
\hline Cation & Liquid diffusivity, $D_{f}, \mathrm{~cm} / \mathrm{s}$ \\
\hline $\mathrm{Ca}^{2+}$ & $1.02 \times 10^{-5}$ \\
$\mathrm{Cs}^{+}$ & $1.5 \times 10^{-5}$ \\
$\mathrm{~K}^{+}$ & $1.48 \times 10^{-5}$ \\
$\mathrm{Mg}^{2+}$ & $9.66 \times 10^{-6}$ \\
$\mathrm{Na}^{+}$ & $1.25 \times 10^{-5}$ \\
$\mathrm{Sr}^{2+}$ & $1.02 \times 10^{-5}$ \\
\hline
\end{tabular}


Table 13. Distribution coefficients $\left(K_{d}\right)$ at $50 \%$ breakthrough for cations during column testing

\begin{tabular}{|c|c|c|c|c|c|}
\hline \multirow{3}{*}{ Cation } & \multicolumn{5}{|c|}{$\mathrm{K}_{d}(\mathrm{~L} / \mathrm{kg})$ at $50 \%$ breakthrough } \\
\hline & \multicolumn{2}{|c|}{ PWTP simulant } & \multicolumn{2}{|c|}{ Seep D water } & \multirow{2}{*}{$\begin{array}{l}\text { Core Hole } 8 \\
\text { groundwater } \\
\text { Ionsiv }{ }^{\circledR} \text { IE-911 }\end{array}$} \\
\hline & IONSIV ${ }^{\otimes}$ IE-911 & Chabazite zeolite & IONSIV ${ }^{\otimes}$ IE-911 & Chabazite zeolite & \\
\hline $\mathrm{Ca}^{2+}$ & 800 & 1100 & 440 & 560 & 410 \\
\hline $\mathrm{Cs}^{+}$ & $* 850,000$ & 90,200 & $* 150,000$ & $* 50,000$ & $>64,000$ \\
\hline $\mathrm{K}^{+}$ & 15,400 & ND & 19,700 & 10,900 & 14,000 \\
\hline $\mathrm{Mg}^{2+}$ & 200 & 660 & 140 & 325 & 65 \\
\hline $\mathrm{Na}^{+}$ & 1200 & 40 & 860 & 0.34 & 905 \\
\hline $\mathrm{Sr}^{2+}$ & 169,000 & 27,600 & 40,000 & 16,000 & 89,000 \\
\hline
\end{tabular}

*Calculations based on gamma scan of loaded column. 
Table 14. Selectivity factors among competing cations for CST and zeolite

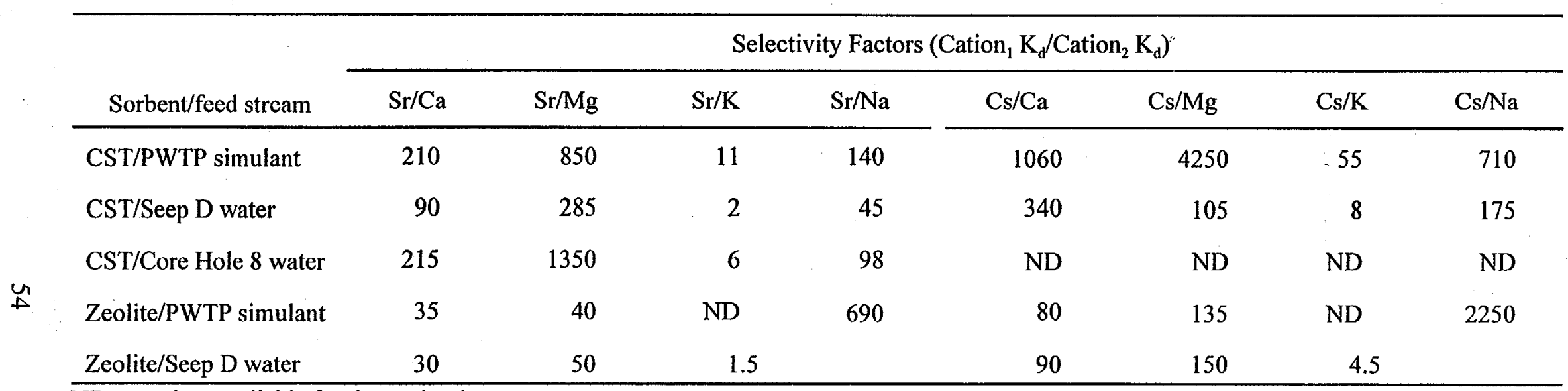

$\mathrm{ND}=$ no data available for determination 


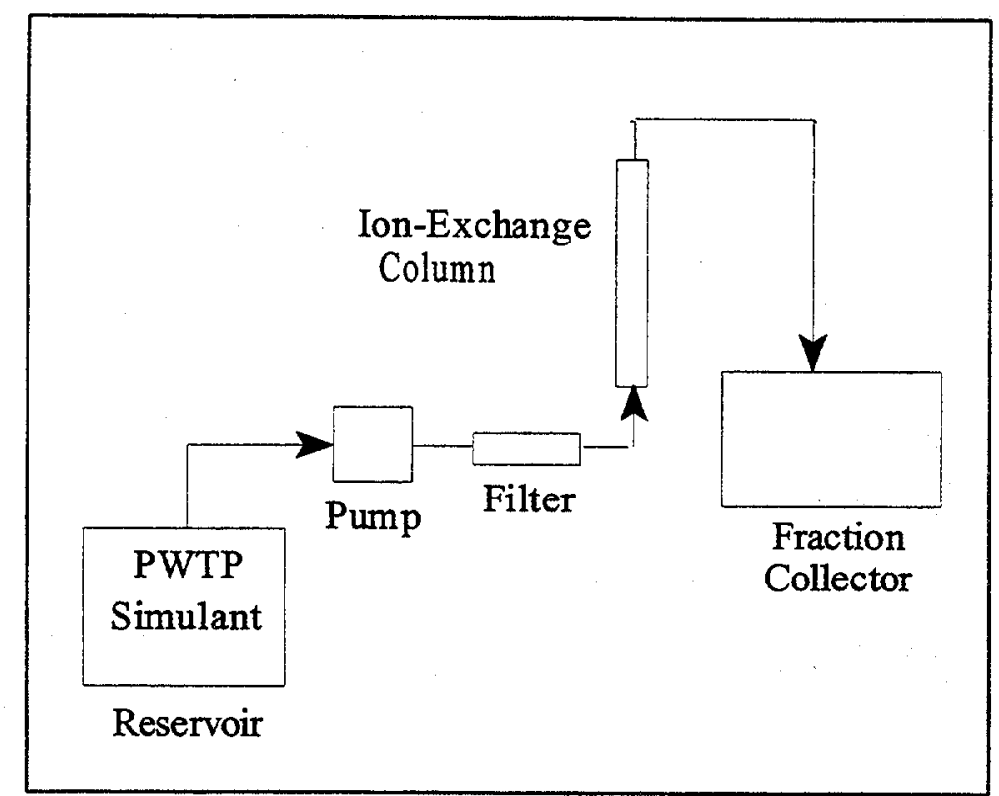

Fig. 1. Flow diagram of column test equipment. 
ORNL DWG 98C-378
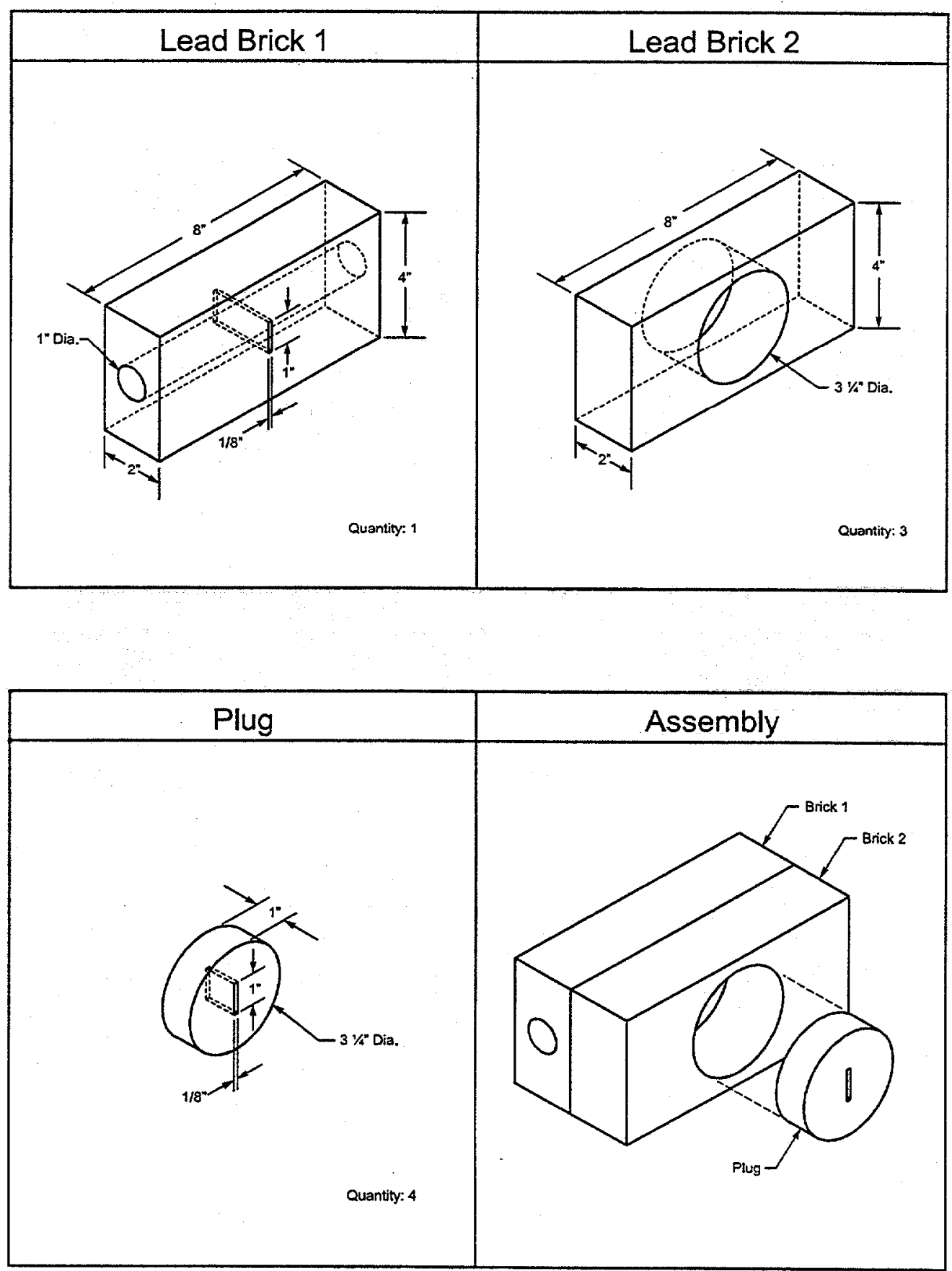

Fig. 2. Schematic of gamma scan shielding configuration. 


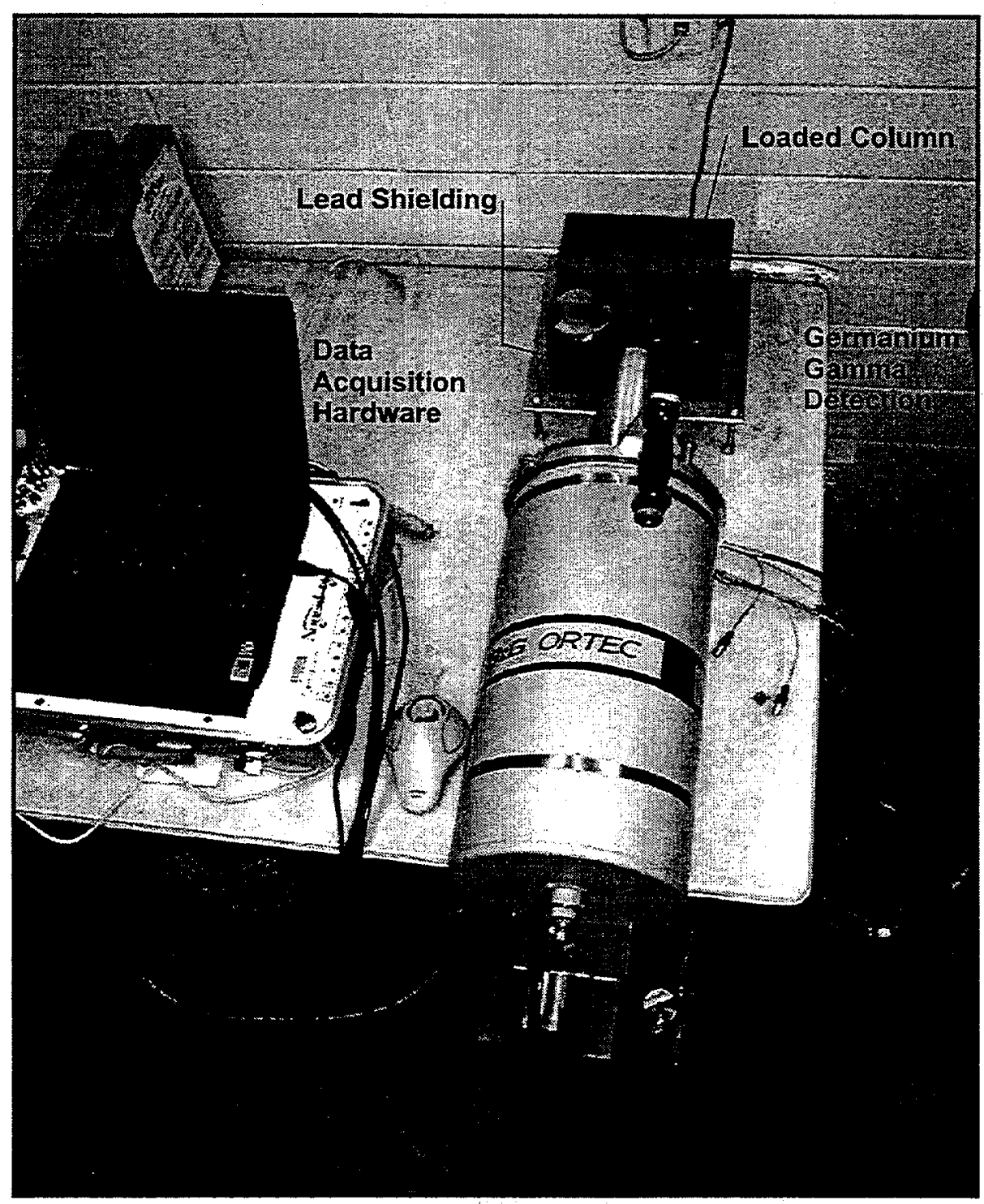

Fig. 3. Photo of gamma scanning equipment. 


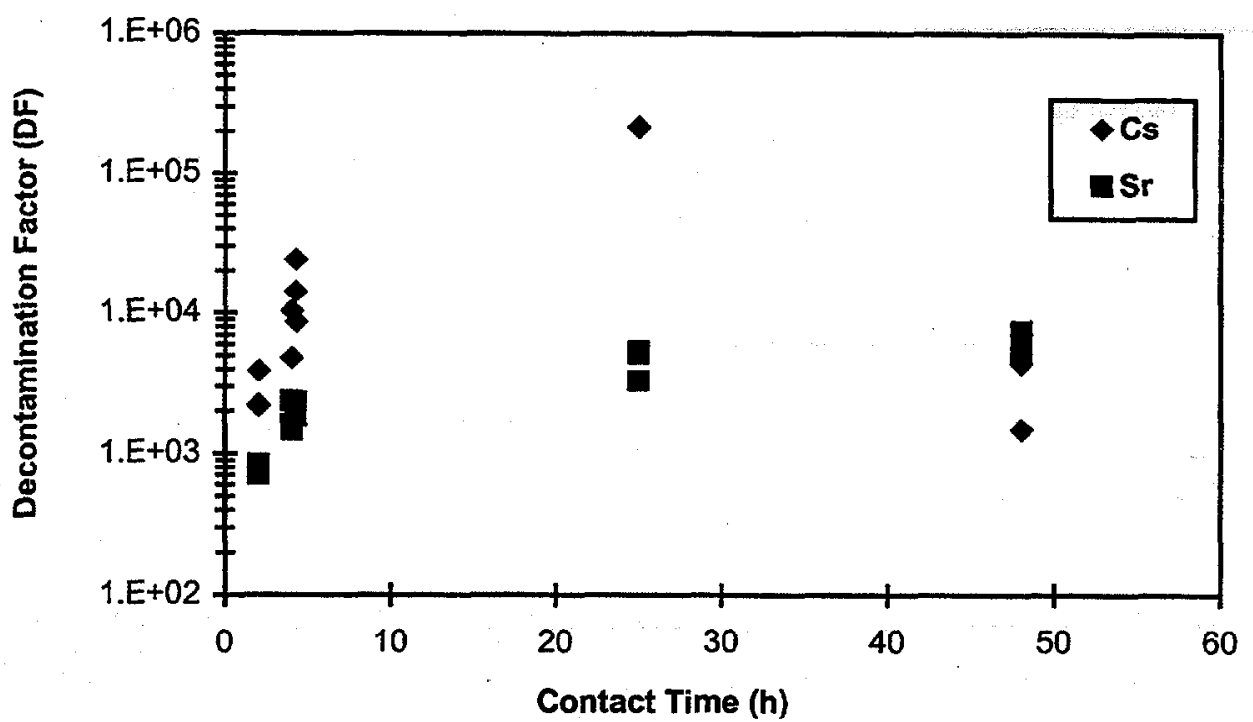

Figure 4. Equilibrium time for strontium and cesium removal from actual CNF wastewater by IONSIV IE-910. Test conditions: $20 \mathrm{mg}$ IONSTV IE-910 in $10 \mathrm{~mL}$ of CNF.

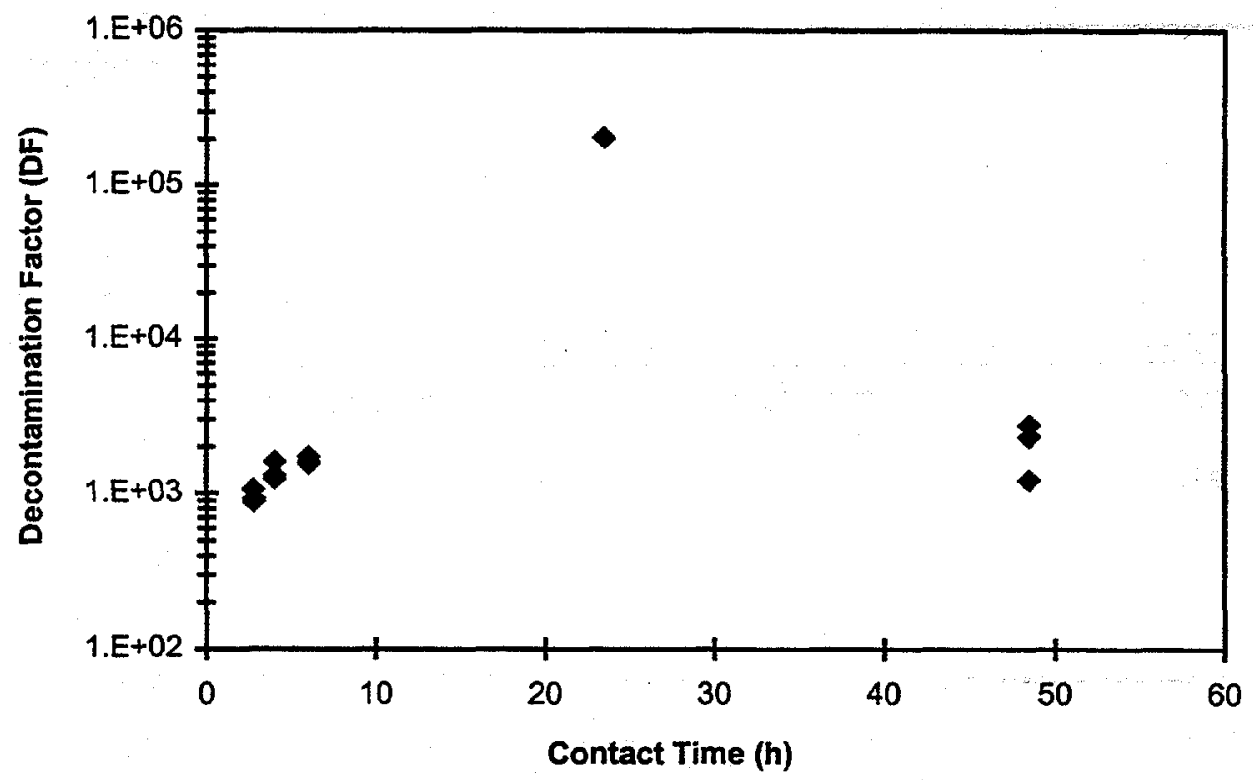

Figure 5. Equilibrium time for cesium removal from actual CNF wastewater by CsTreat. Test conditions: $20 \mathrm{mg}$ CsTreat in $10 \mathrm{~mL}$ of CNF. 


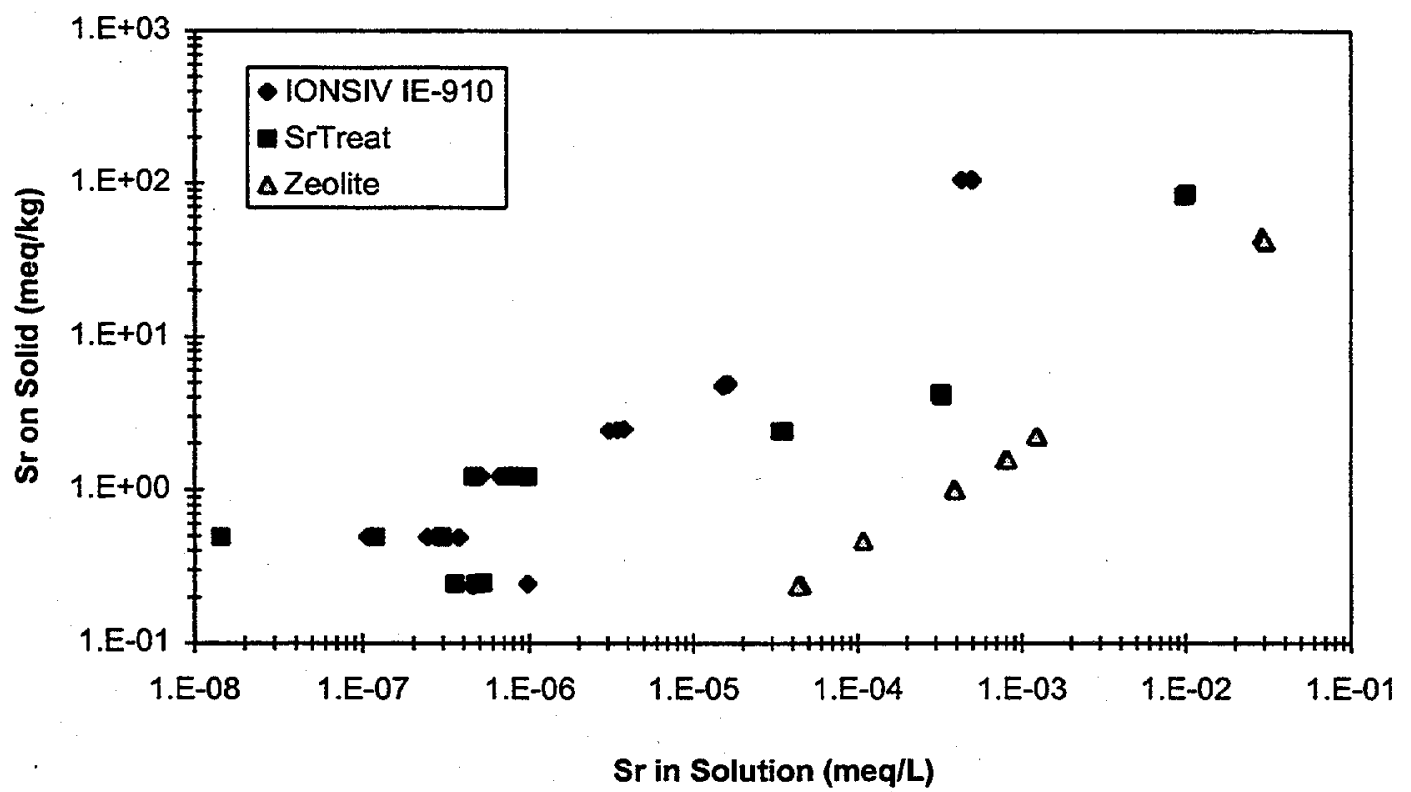

Figure 6. Sorption isotherms for strontium removal from CNF wastewater by various exchangers. Test conditions: Sorbent in $5-100 \mathrm{mg}$ amounts equilibrated with $10 \mathrm{~mL}$ of CNF wastewater.

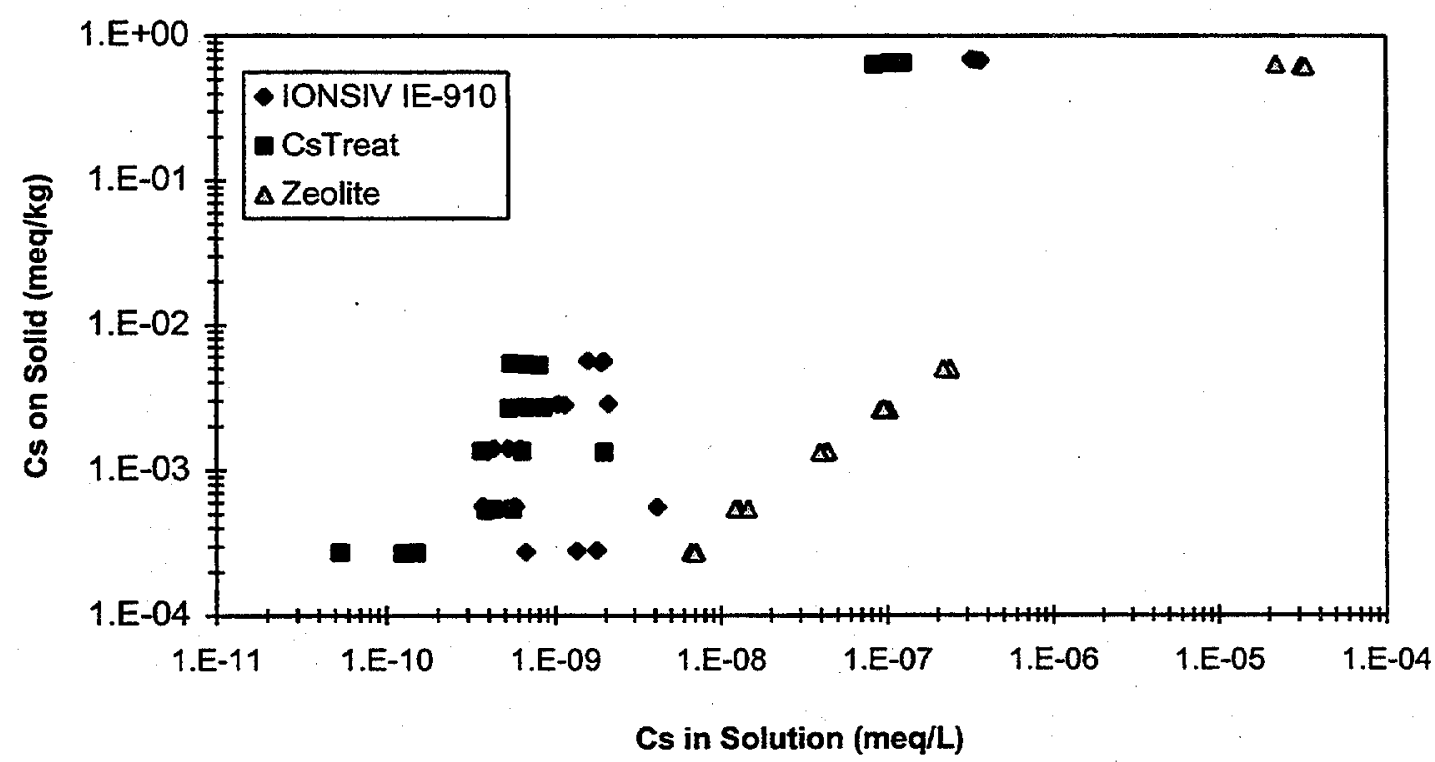

Figure 7. Sorption isotherms for cesium removal from CNF wastewater by various exchangers. Test conditions: Sorbent in 5-100 mg amounts equilibrated with $10 \mathrm{~mL}$ of CNF wastewater. 
(a)

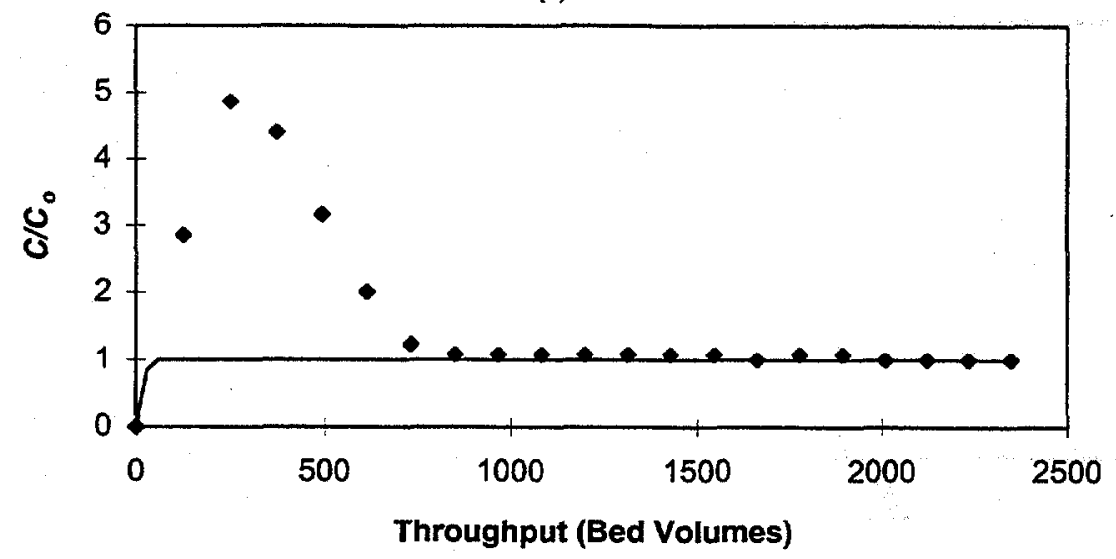

(b)

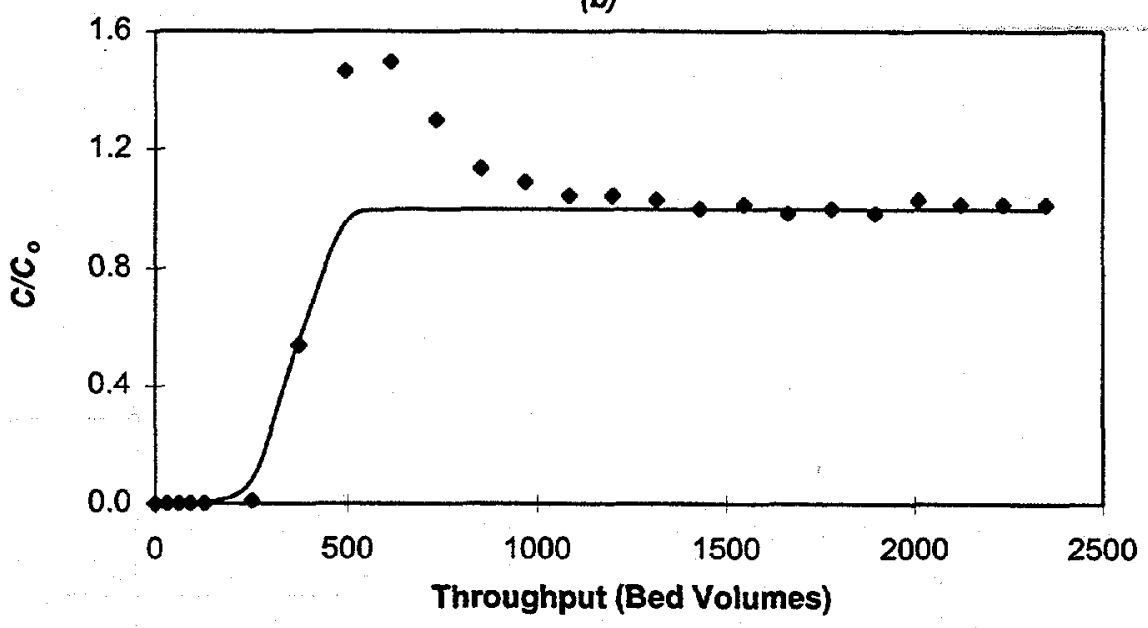

(c)

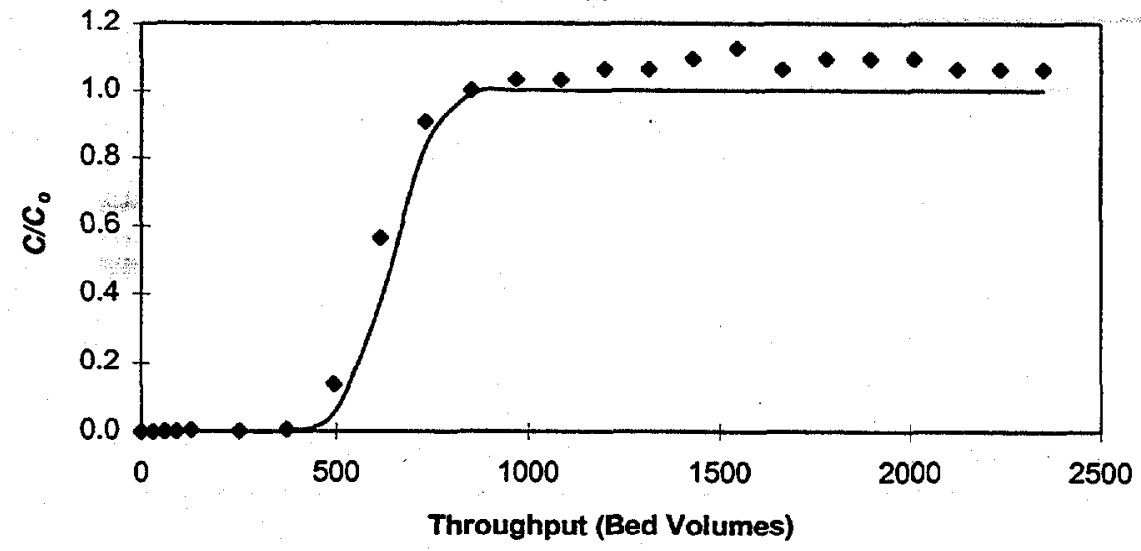

Figure 8. Experimental and theoretical breakthrough curves for (a) sodium, (b) magnesium, and (c) calcium on chabazite zeolite in PWTP simulant. Test conditions: $2.13 \mathrm{~g}$ chabazite zeolite, $1-\mathrm{cm}-\mathrm{ID}$ colum bed length $4.9 \mathrm{~cm}$. Process wastewater simulant flow rate was $1.25 \mathrm{~mL} / \mathrm{min}$. 


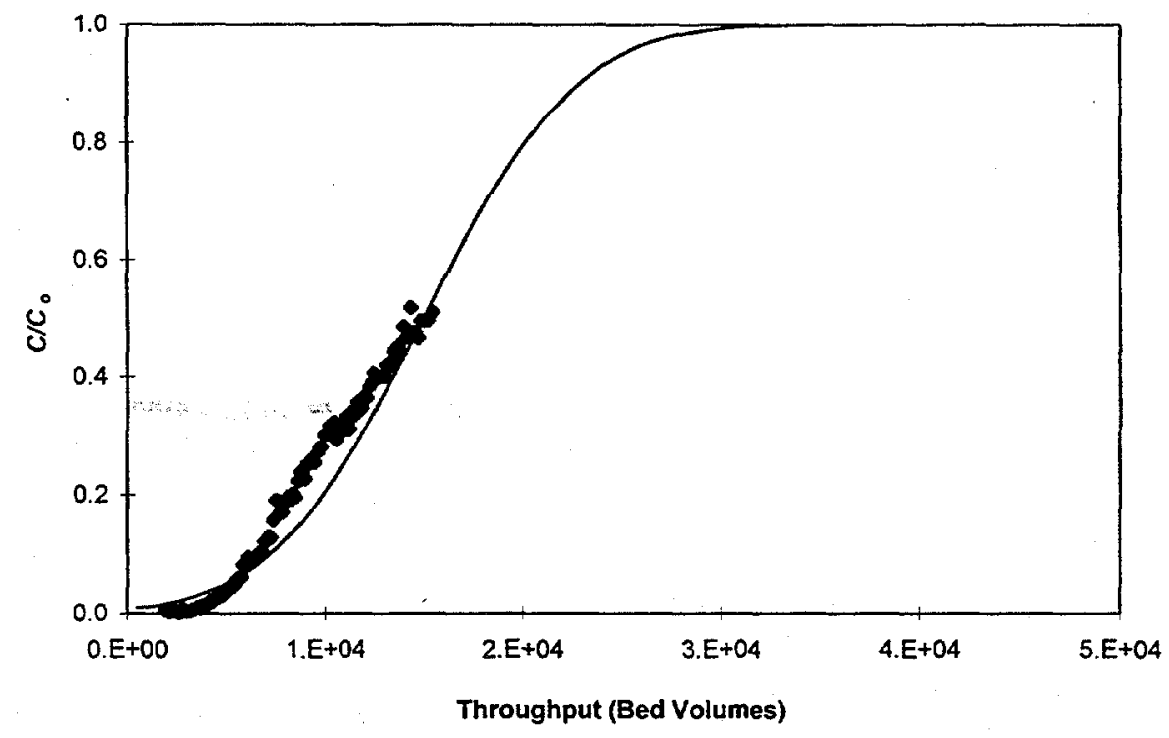

Figure 9. Experimental and theoretical breakthrough of strontium on chabazite zeolite in PWTP simulant. Test conditions: $2.13 \mathrm{~g}$ chabazite zeolite, $1-\mathrm{cm}-\mathrm{ID}$ column, bed length of $4.9 \mathrm{~cm}$. Process wastewater simulant flow rate was $1.25 \mathrm{~mL} / \mathrm{min}$.

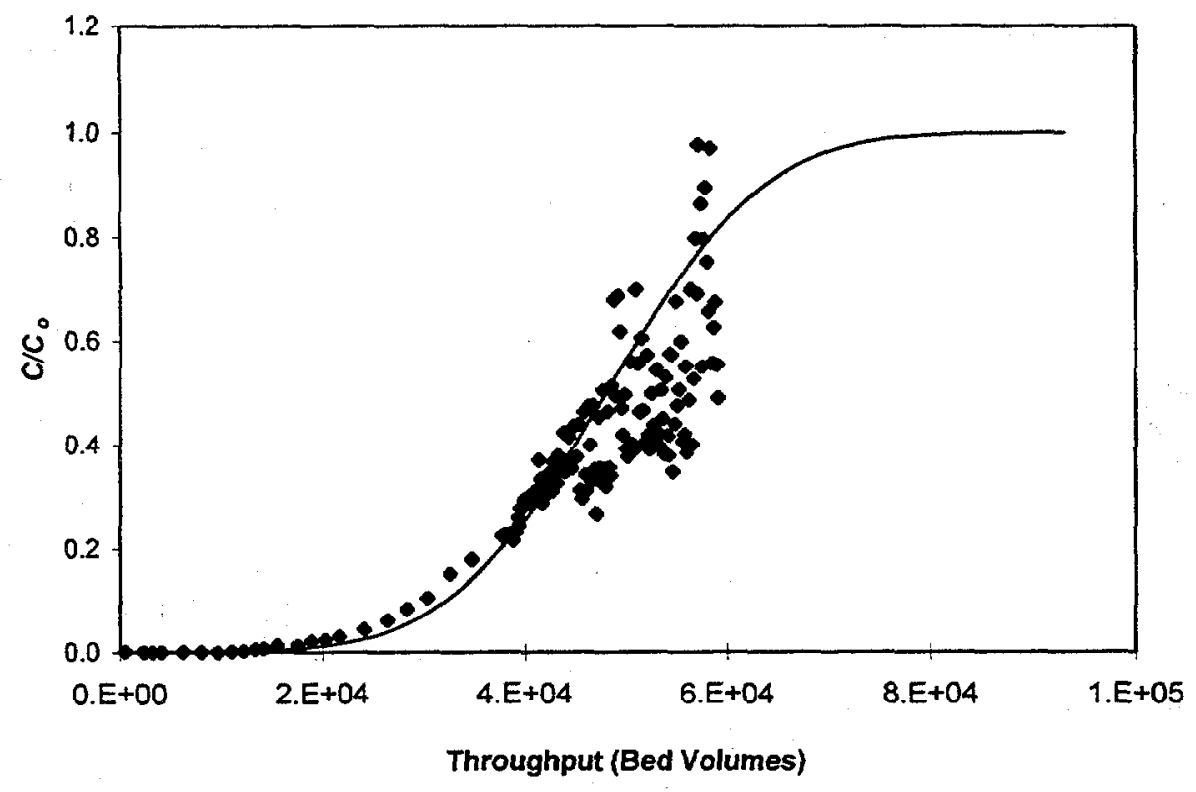

Figure 10. Experimental and theoretical breakthrough of cesium on chabazite zeolite in PWTP simulant. Test conditions: $2.13 \mathrm{~g}$ chabazite zeolite, $1-\mathrm{cm}-\mathrm{ID}$ column, bed length of $4.9 \mathrm{~cm}$. Process wastewater simulant flow rate was $1.25 \mathrm{~mL} / \mathrm{min}$. 


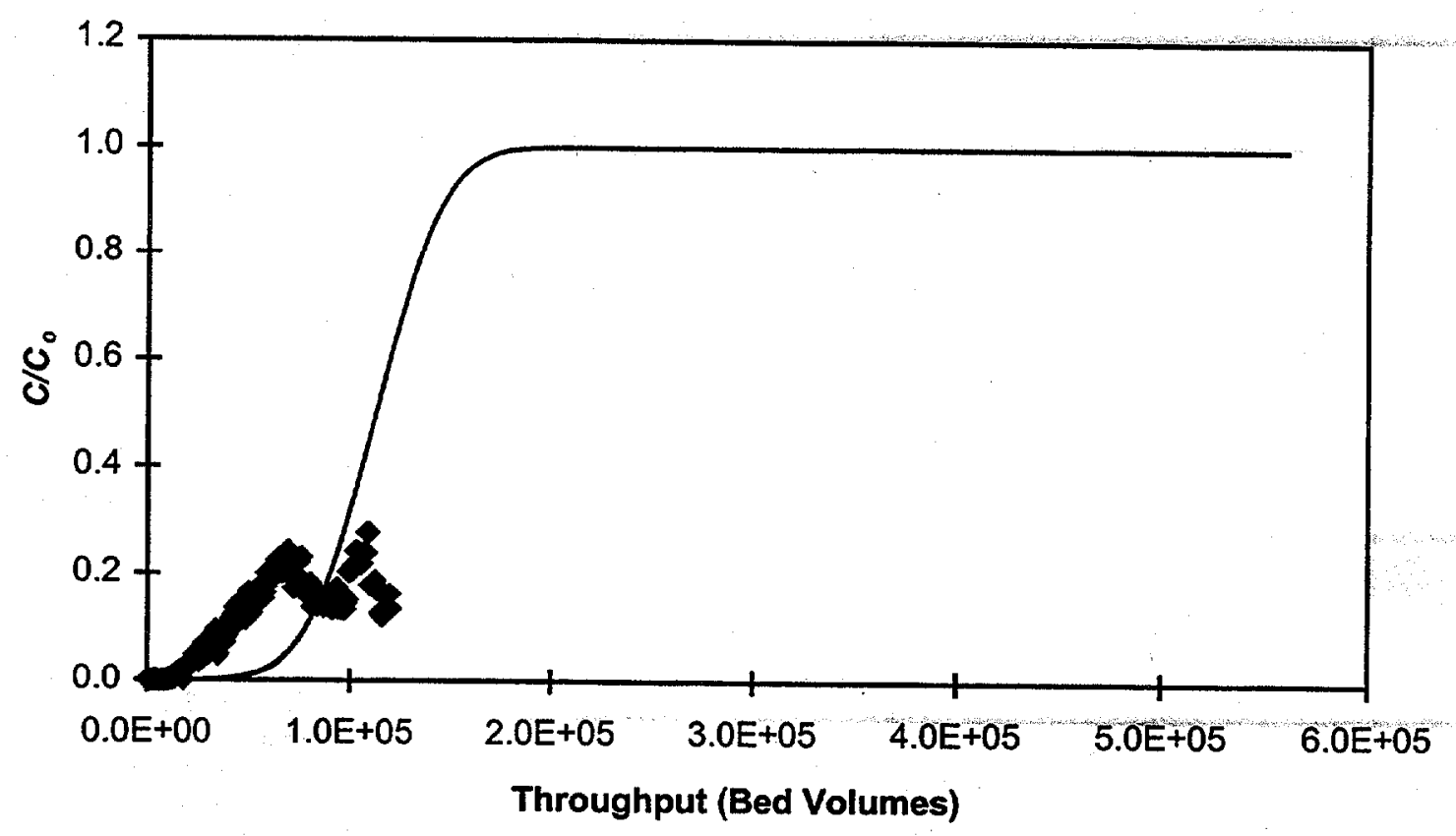

Figure 12. Experimental and theoretical breakthrough of strontium on Hydrogen1-CST in PWTP simulant. Test conditions: $3.81 \mathrm{~g}$ Hydrogen-CST, $1-\mathrm{cm}-\mathrm{ID}$ column, bed length $4.85 \mathrm{~cm}$. Process wastewater simulant flow rate was $1.2 \mathrm{~mL} / \mathrm{min}$.

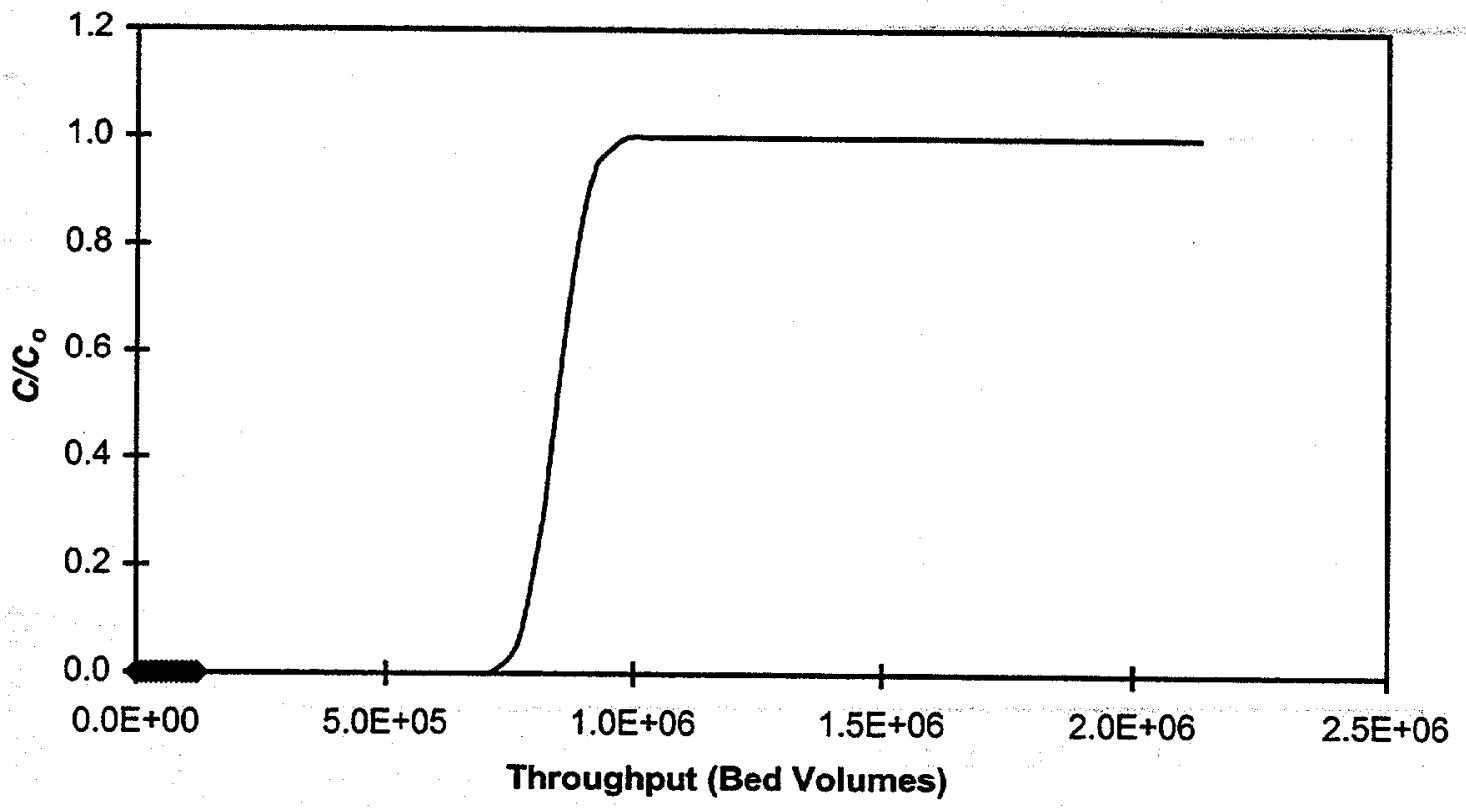

Figure 13. Experimental and theoretical breakthrough of cesium on Hydrogen1-CST in PWTP simulant. Test conditions: $3.81 \mathrm{~g}$ Hydrogen-CST, 1-cm-ID column, bed length $4.85 \mathrm{~cm}$. Process wastewater simulant flow rate was $1.2 \mathrm{~mL} / \mathrm{min}$. 

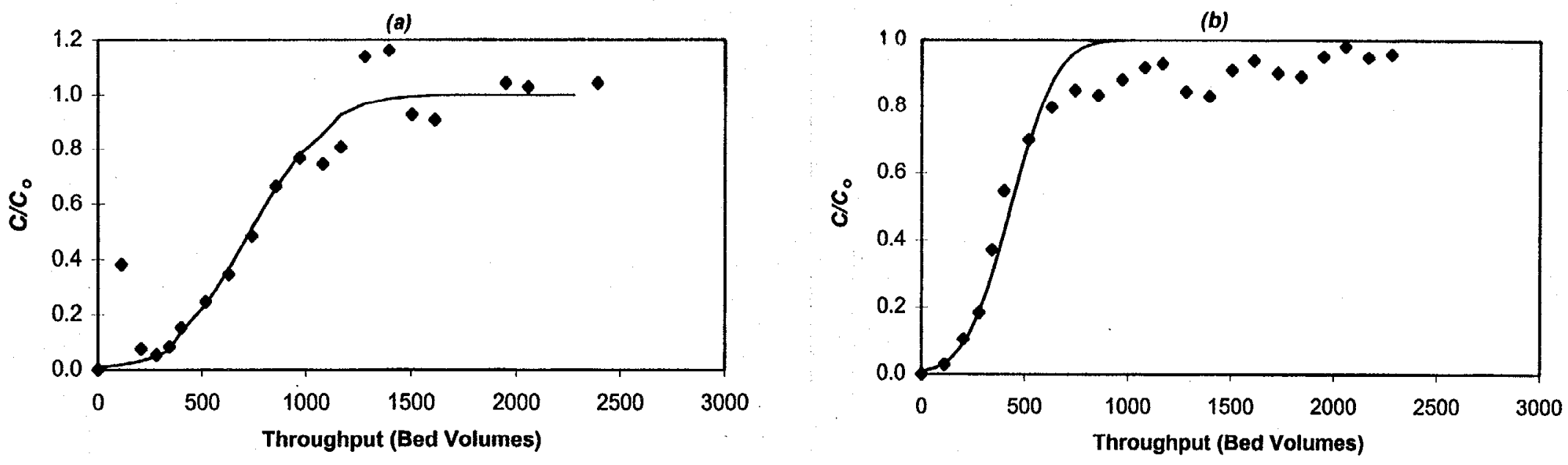

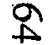
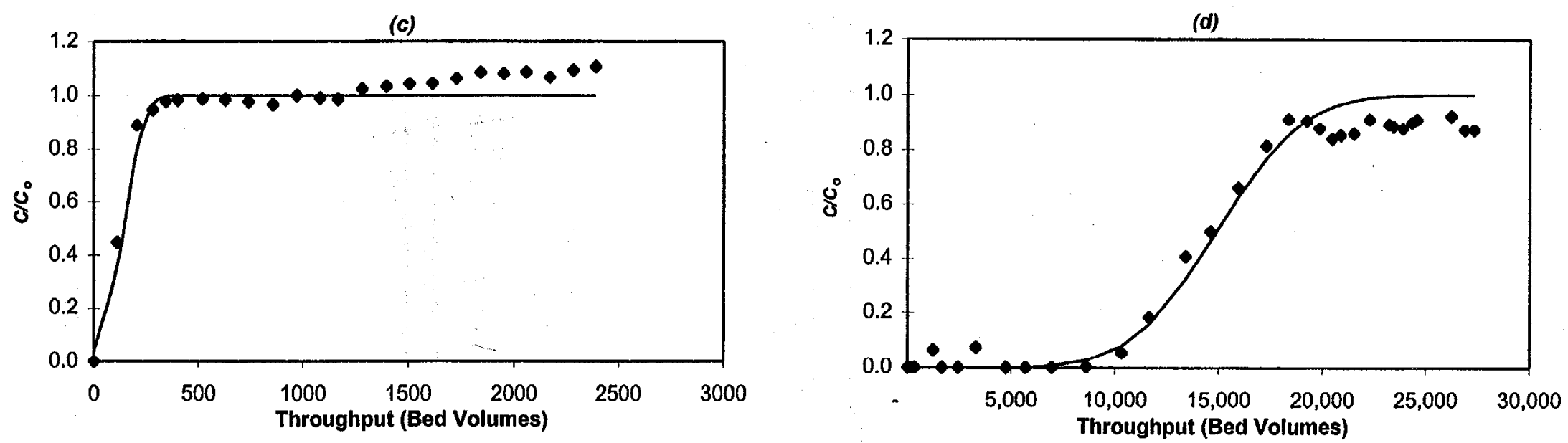

Figure 14. Experimental and theoretical breakthrough curves for (a) sodium, (b) calcium, (c) magnesium, and (d) potassium on Hydrogen2-CST in Seep D water. Test conditions: $3.35 \mathrm{~g}$ of Hydrogen-CST, 1-cm-ID column, $4.9 \mathrm{~cm}$ bed length, feed flow rate was $1.2 \mathrm{~mL} / \mathrm{min}$. 


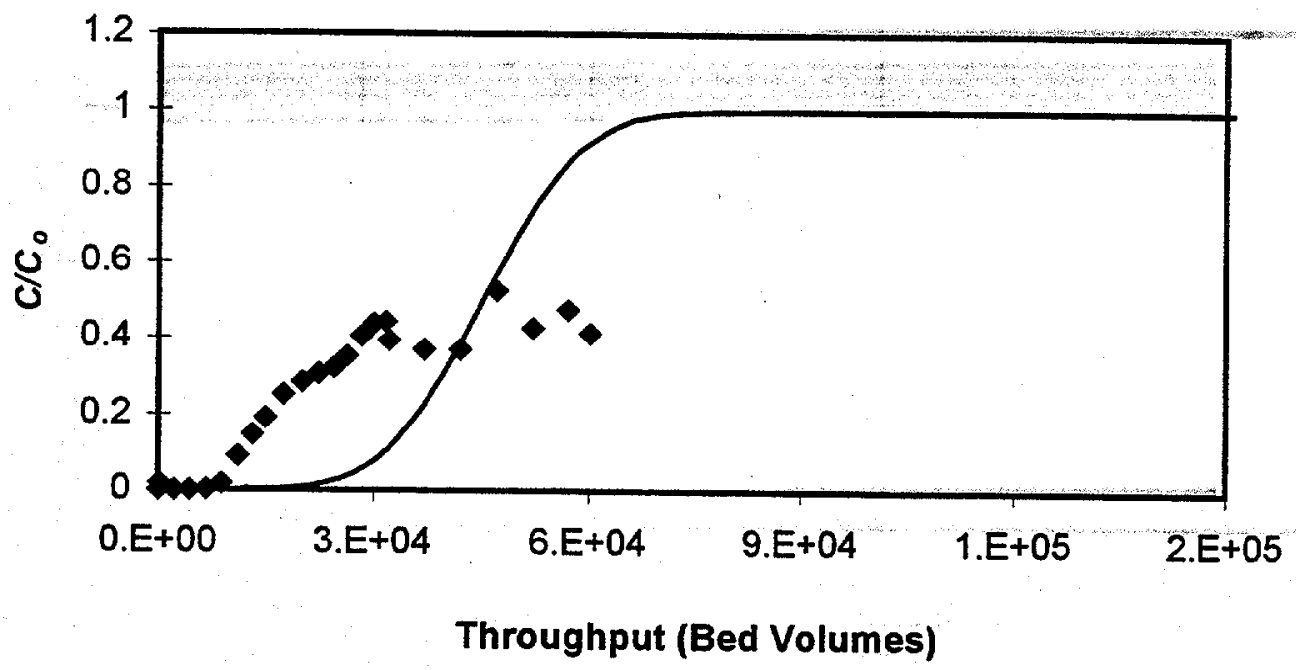

Figure 15. Experimental and theoretical breakthrough of strontium on Hydrogen2-CST in Seep D water. Test conditions: $3.35 \mathrm{~g}$ of Hydrogen-CST, $1-\mathrm{cm}-\mathrm{ID}$ column, $4.9 \mathrm{~cm}$ bed length, feed flow rate was $1.2 \mathrm{~mL} / \mathrm{min}$.

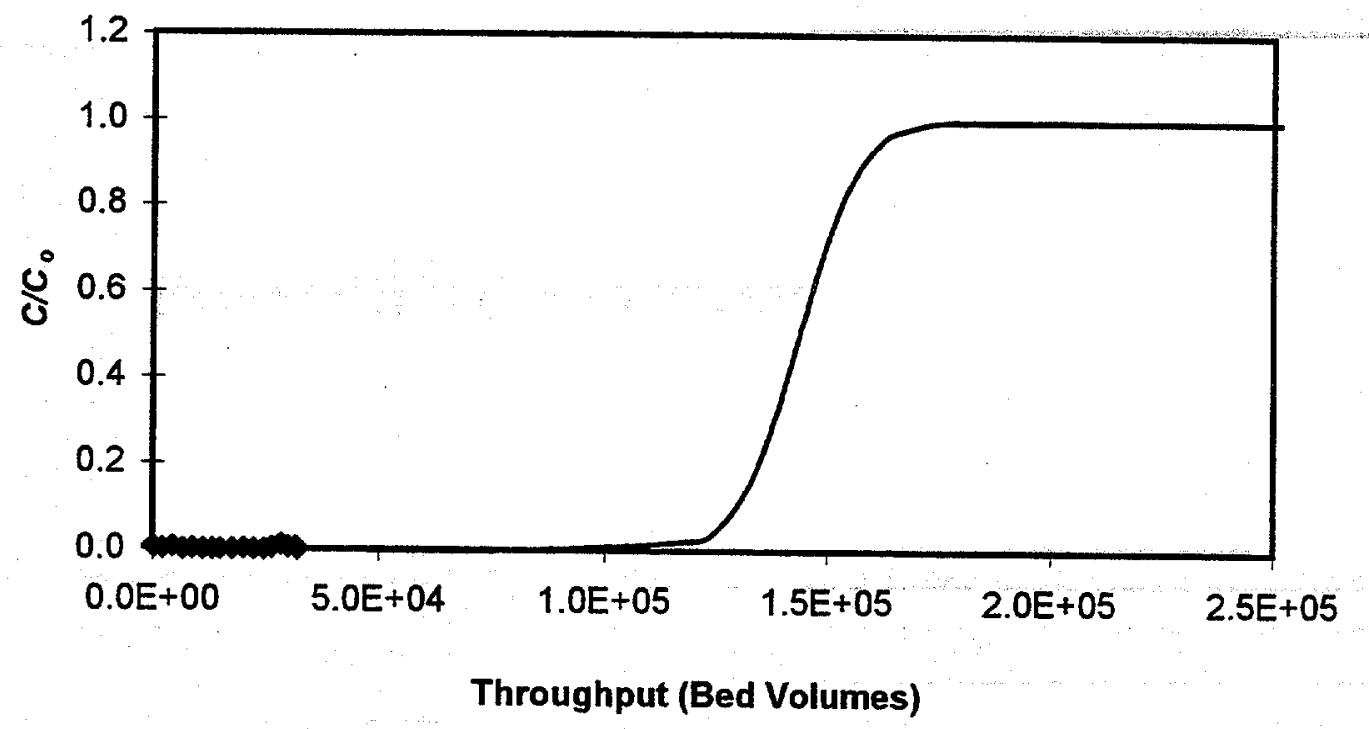

Figure 16. Experimental and theoretical breakthrough of cesium on Hydrogen2-CST in Seep D water. Test conditions: $3.35 \mathrm{~g}$ of Hydrogen-CST, 1-cm-ID column, $4.9 \mathrm{~cm}$ bed length, feed flow rate was $1.2 \mathrm{~mL} / \mathrm{min}$. 

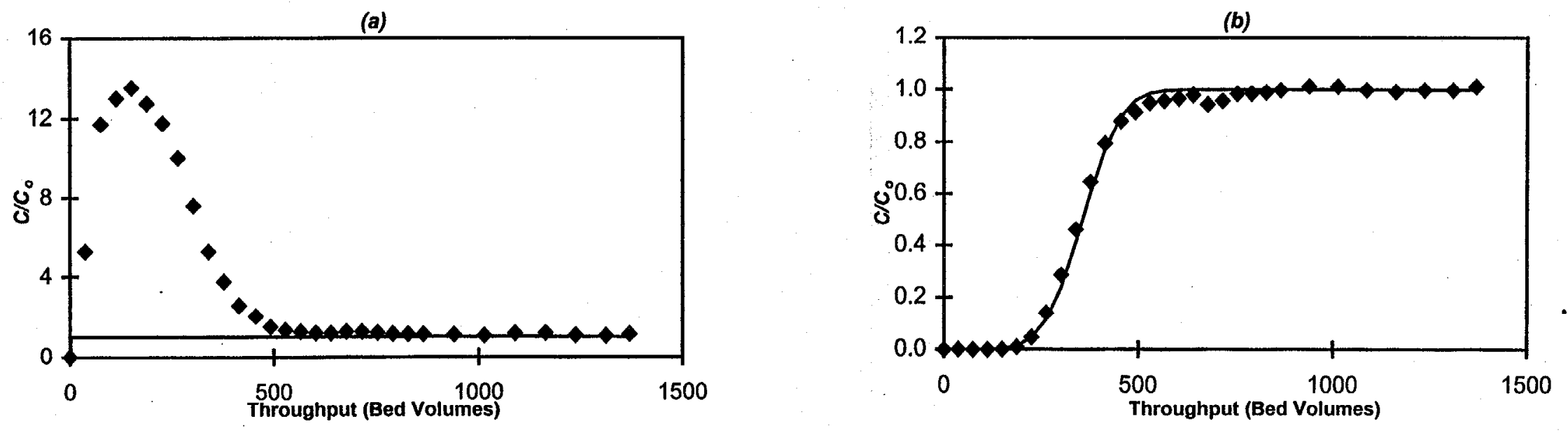

ร
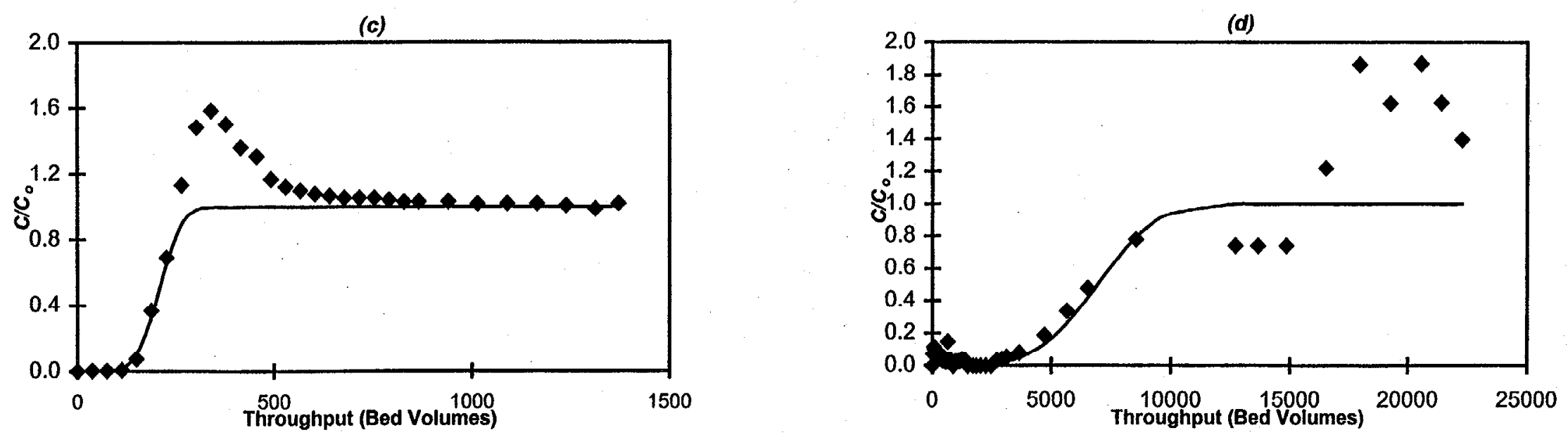

Figure 17. Experimental and theoretical breakthrough curves for (a) sodium, (b) calcium, (c) magnesium, and (d) potassium on chabazite zeolite in Seep D water. Test conditions: $2.30 \mathrm{~g}$ chabazite zeolite, $1-\mathrm{cm}-\mathrm{ID}$ column, bed length $4.8 \mathrm{~cm}$.

Feed flow rate was $1.2 \mathrm{~mL} / \mathrm{min}$. 


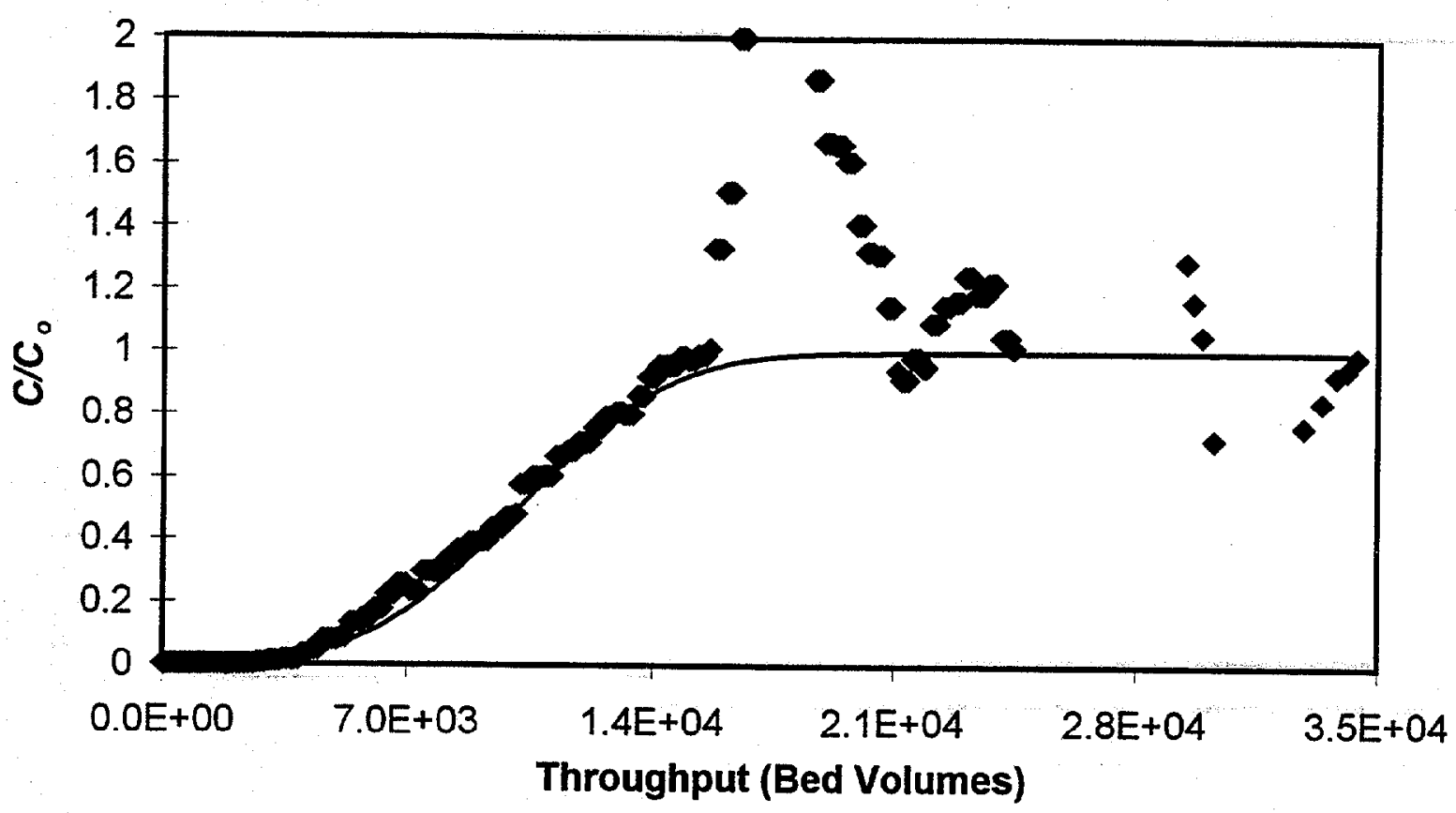

Figure 18. Experimental and theoretical breakthrough of strontium on chabazite zeolite in Seep D water. Test conditions: $2.30 \mathrm{~g}$ chabazite zeolite, $1-\mathrm{cm}-\mathrm{ID}$ column, bed length $4.8 \mathrm{~cm}$. Feed flow rate was $1.2 \mathrm{~mL} / \mathrm{min}$.

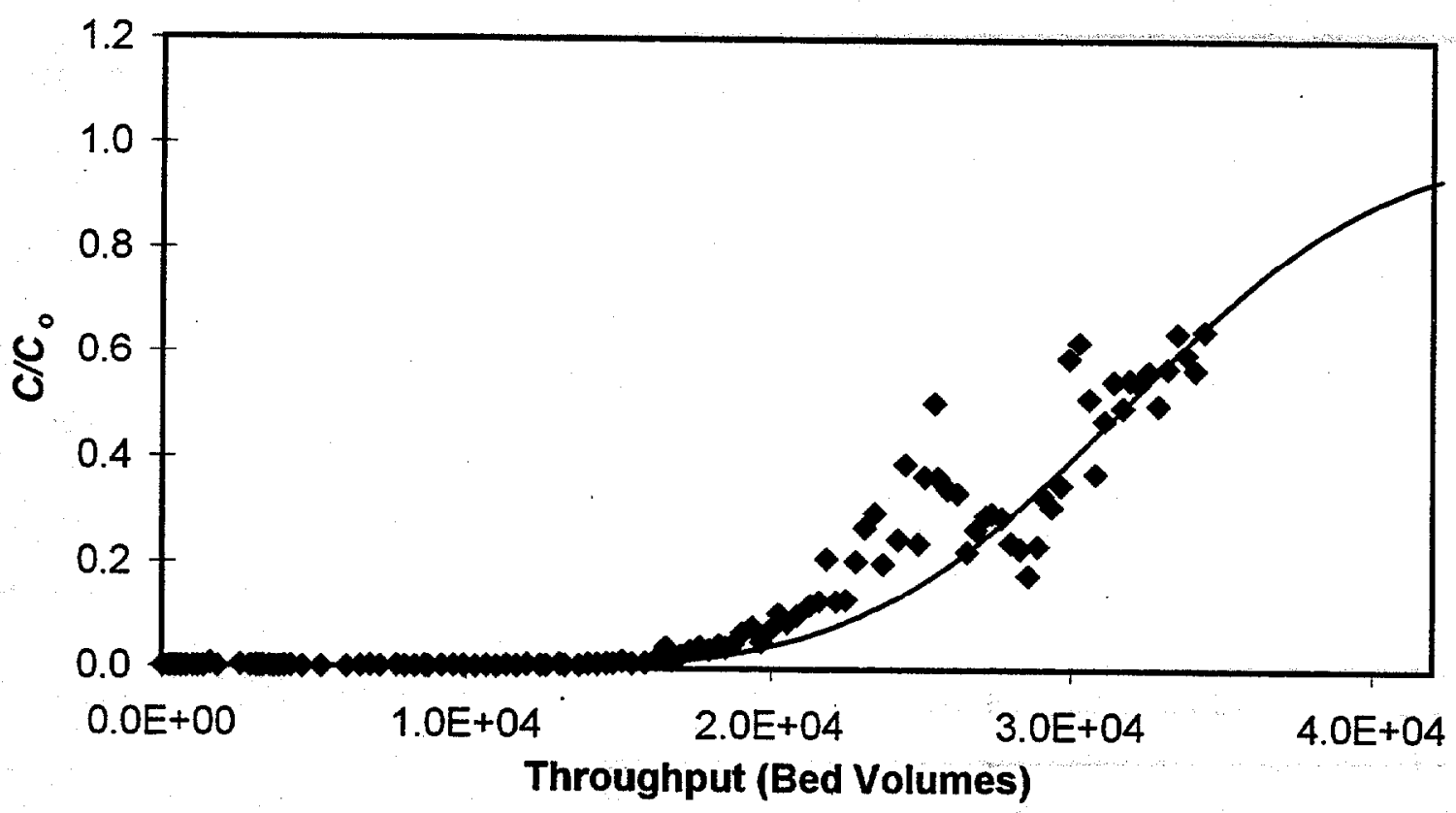

Figure 19. Experimental and theoretical breakthrough of cesium on chabazite zeolite in Seep D water. Test conditions: $2.30 \mathrm{~g}$ chabazite zeolite, $1-\mathrm{cm}-\mathrm{ID}$ column, bed length $4.8 \mathrm{~cm}$. Feed flow rate was $1.2 \mathrm{~mL} / \mathrm{min}$. 

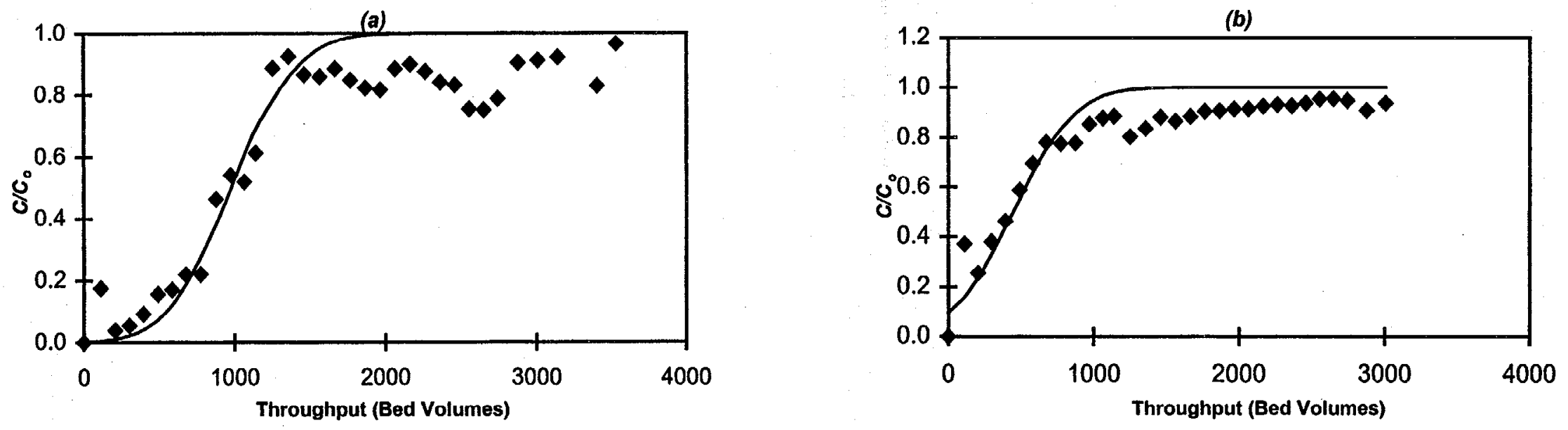

$\infty$
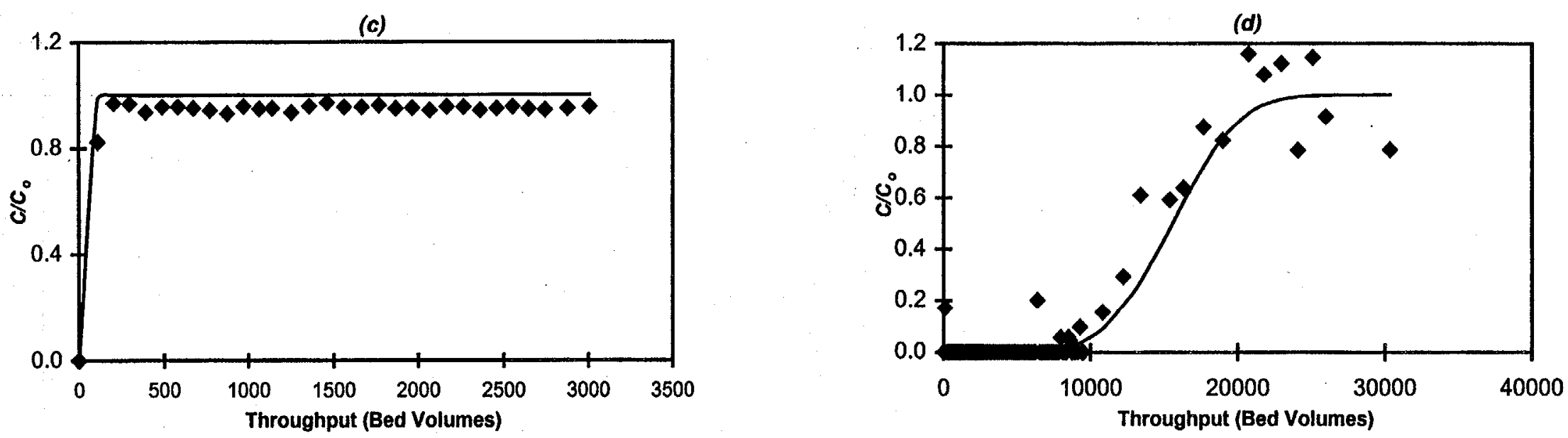

Figure 20. Experimental and theoretical breakthrough curves for (a) sodium, (b) calcium, (c) magnesium, and (d) potassium on CST in Core Hole 8 groundwater. Test conditions: $3.89 \mathrm{~g} \mathrm{CST,} 1-\mathrm{cm}-\mathrm{ID}$ column, bed length $4.8 \mathrm{~cm}$.

Feed flow rate was $1.1 \mathrm{~mL} / \mathrm{min}$. 


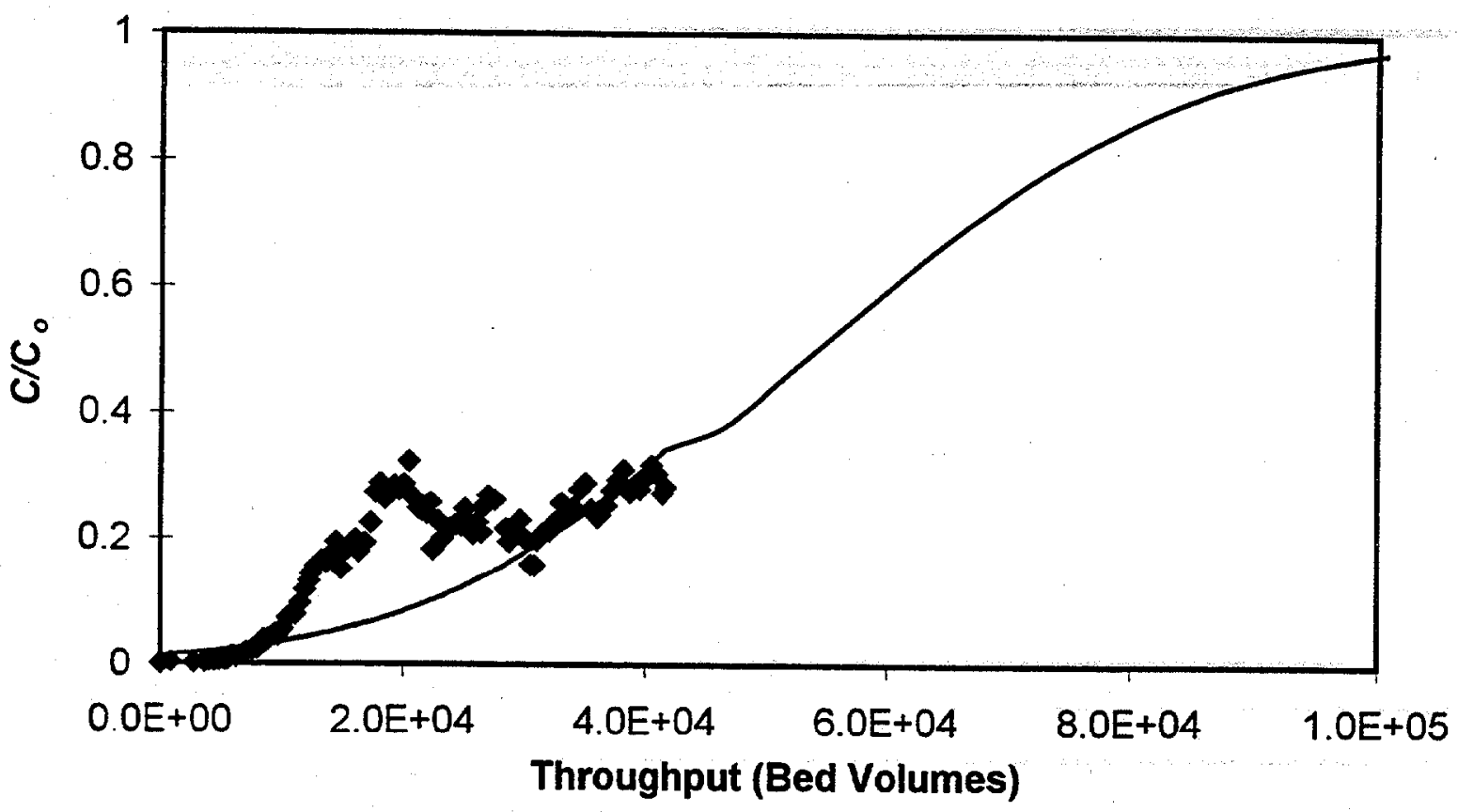

Figure 21. Experimental and theoretical breakthrough of strontium on CST in Core Hole 8 groundwater. Test conditions: $3.89 \mathrm{~g} \mathrm{CST}, 1-\mathrm{cm}-\mathrm{ID}$ column, bed length $4.8 \mathrm{~cm}$. Feed flow rate was $1.1 \mathrm{~mL} / \mathrm{min}$.

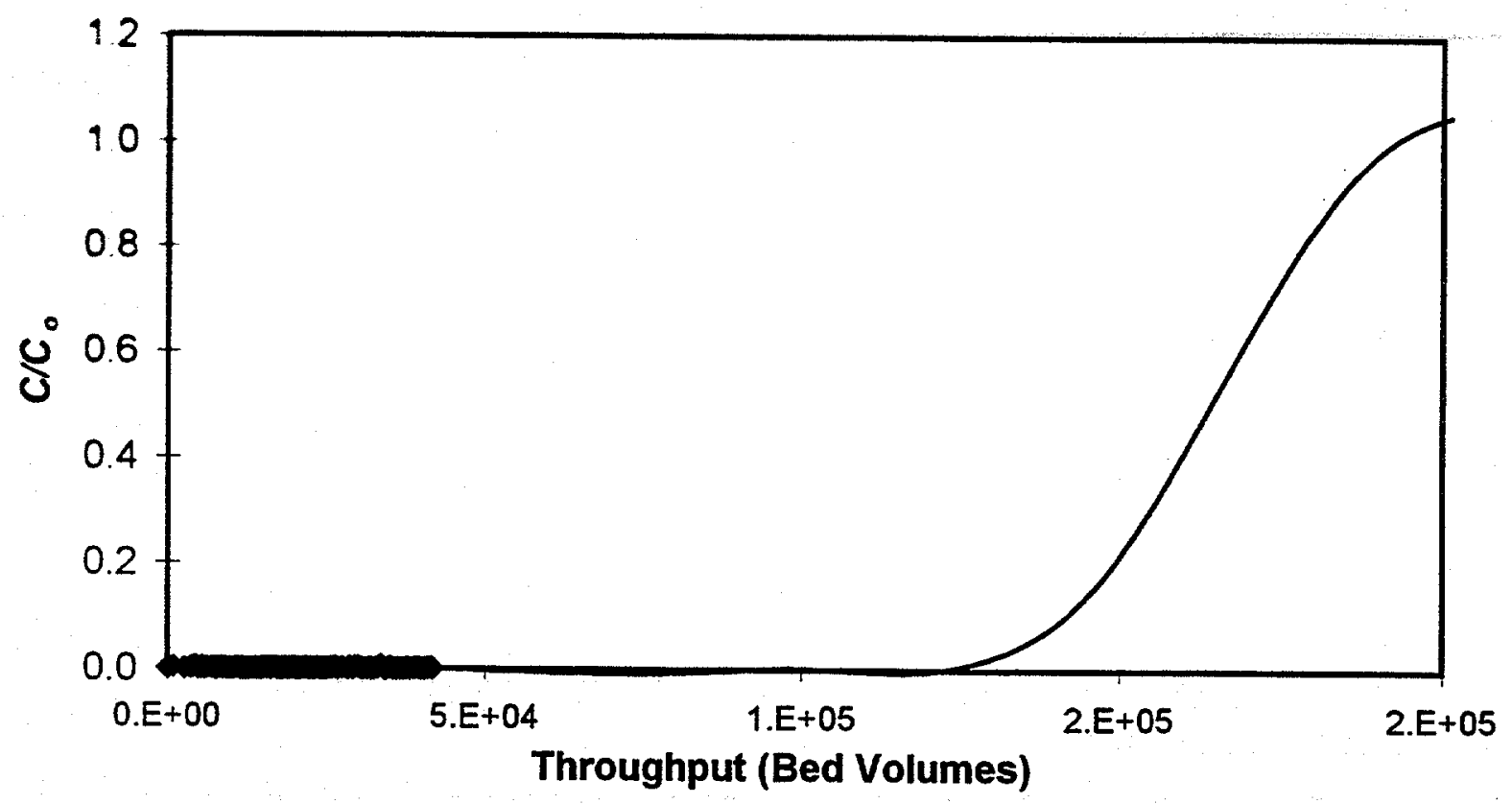

Figure 22. Experimental and theoretical breakthrough of cesium on CST in Core Hole 8 groundwater. Test conditions: $3.89 \mathrm{~g} \mathrm{CST,} 1-\mathrm{cm}-\mathrm{ID}$ column, bed length $4.8 \mathrm{~cm}$. Feed flow rate was $1.1 \mathrm{~mL} / \mathrm{min}$. 
(a)

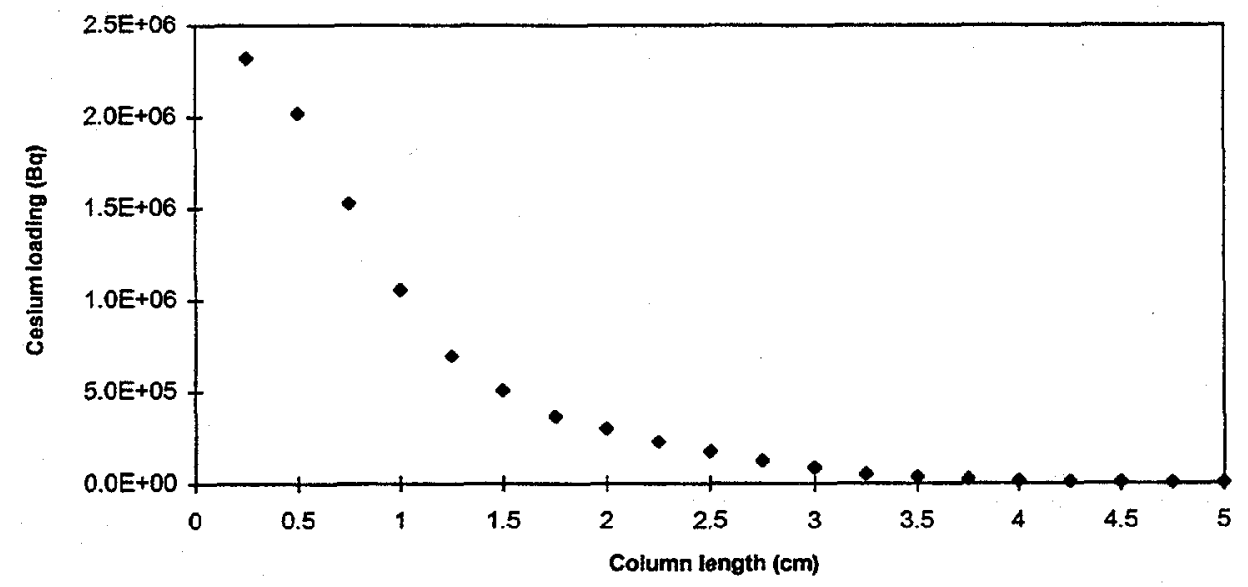

(b)

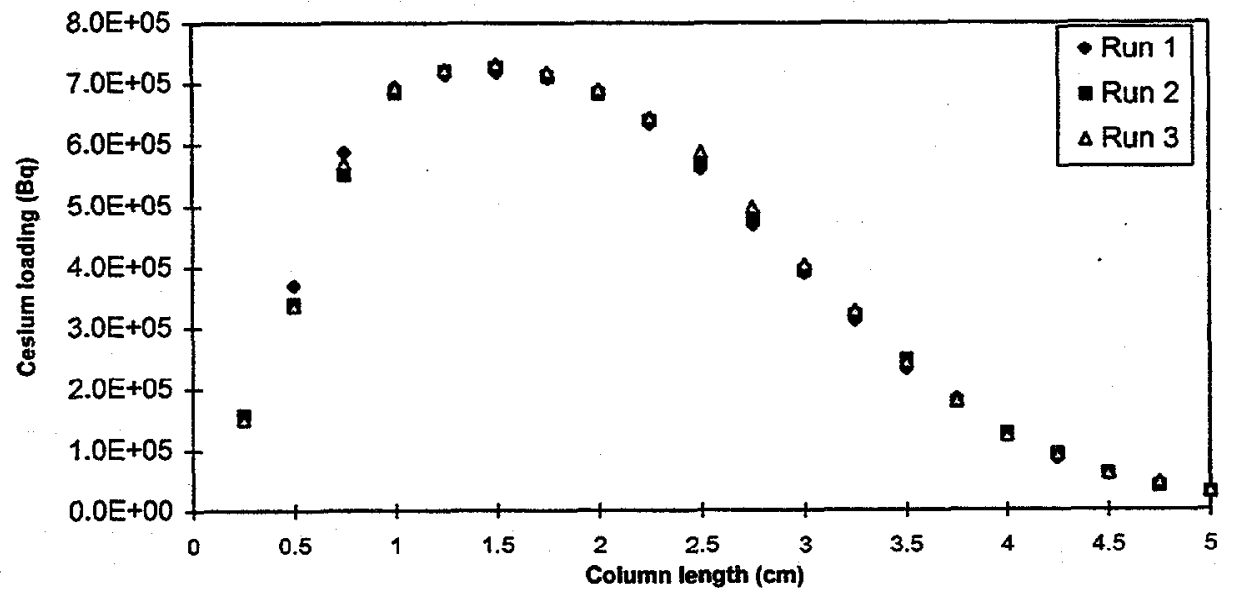

(c)

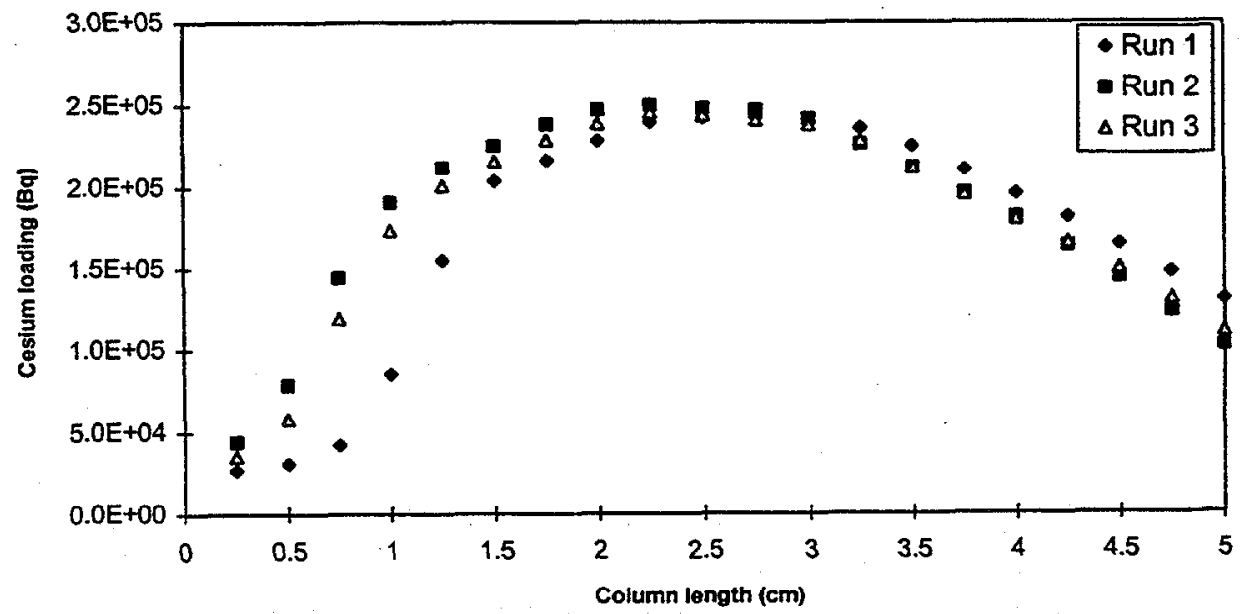

Figure 23. Gamma scan of columns showing cesium loading on (a) CST from PWTP simulant, (b) CST from Seep D water, and (c) chabazite zeolite from Seep D water. 

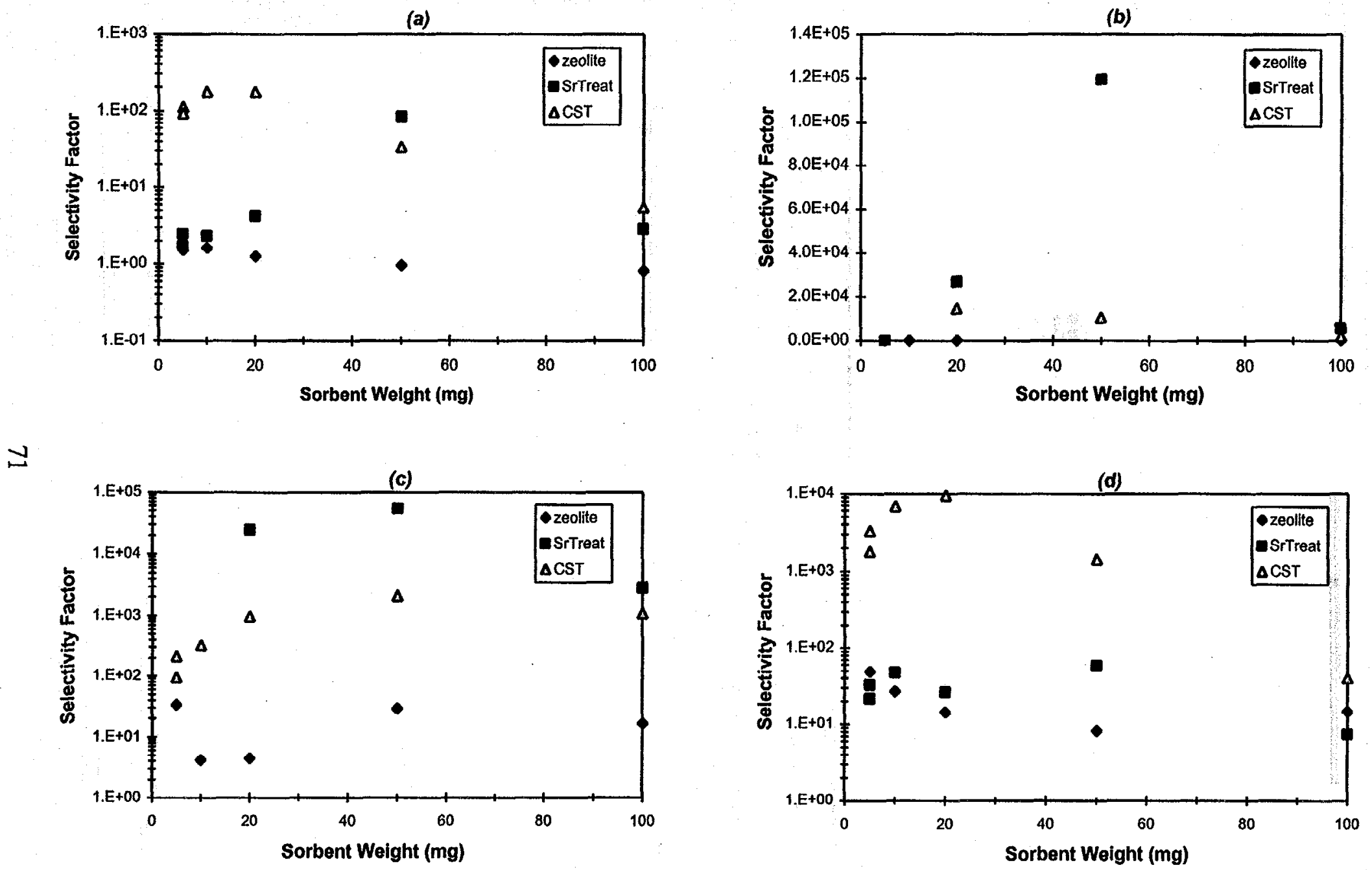

Figure 24. Selectivity coefficient ratios (selectivity factors) for strontium and competing cations on various sorbents in $10 \mathrm{~mL}$ of actual CNF wastewater: (a) strontium/calcium, (b) strontium/sodium, (c) strontium/potassium, and (d) strontium/magnesium. 

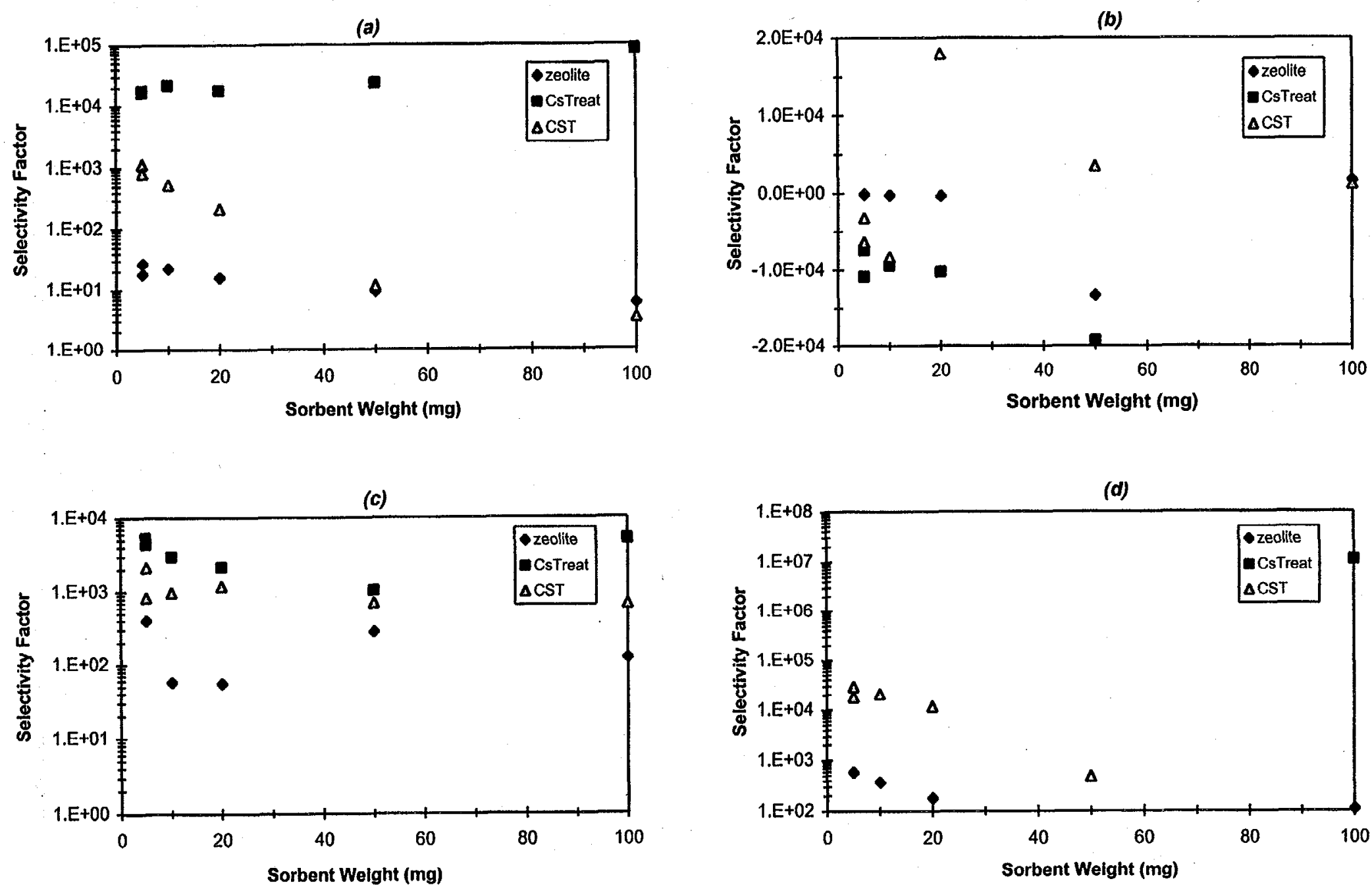

Figure 25. Selectivity coefficient ratios (selectivity factors) for cesium and competing cations on various sorbents in $10 \mathrm{~mL}$ of actual CNF wastewater: (a) cesium/calcium, (b) cesium/sodium, (c) cesium/potassium, and (d) cesium/magnesium. 
ORNL/TM-13689

\section{INTERNAL DISTRIBUTION}

$\begin{aligned} \text { 1-10. } & \text { D. A. Bostick } \\ \text { 11. } & \text { W. D. Bostick } \\ \text { 12. } & \text { J. L. Collins } \\ \text { 13. } & \text { A. G. Croff } \\ \text { 14. } & \text { S. M. DePaoli } \\ \text { 15. } & \text { T. O. Early } \\ \text { 16. } & \text { S. M. Gibson } \\ \text { 17. } & \text { R. H. Ketelle } \\ \text { 18. } & \text { C. M. Kendrick } \\ 19 . & \text { T. E. Kent } \\ 20 . & \text { K. T. Klasson } \\ 21 . & \text { B. E. Lewis } \\ 22 . & \text { C. P. McGinnis }\end{aligned}$

23. L. E. McNeese

24. B. A. Moyer

25. T. E. Myrick

26. S. M. Robinson

27. C. B. Scott

28. F. S. Smith

29. P. A. Taylor

30. J. S. Watson

31. Laboratory Records, RC

32-33. Laboratory Records, For OSTI

34. Central Research Library

\section{EXTERNAL DISTRIBUTION}

35. R. G. Anthony, Department of Chemical Engineering, Texas A\&M, College Station, TX 77843-3122

36. Abraham Clearfield, Director, Materials Science \& Engineering Program, Texas A\&M, College Station, TX 77843

37. N. H. Cutshall, Central Management Offices, U.S. DOE, 12800 Middlebrook Road, Suite 102 , Germantown, MD 20874

38. Dan Eyde, Resources, Inc., 7660N Business Park Drive, Tucson, AZ 85743

39. Dennis Fennelly, UOP, Molecular Sieves, 307 Fellowship Rd., Suite 207, Mt. Laurel, NJ 08054

40. K. Gerdes, Office of Science \& Technology, U.S. DOE, EM-53 CL, 19901 Germantown Rd, Germantown, MD 20874

41. J. Harness, Department of Energy, Oak Ridge Operations, P.O. Box 2001, Oak Ridge, TN 37831-8620

42. R. D. Korynta, Department of Energy, Oak Ridge Operations, P.O. Box 2001, Oak Ridge, TN 37831-8620

43. D. Lillian, Office of Science \& Technology, U.S. DOE, EM-53 CL, 19901 Germantown Road, Germantown, MD 20874

44. J. O. Moore, Oak Ridge Technical Program Officer, Department of Energy, Oak Ridge Operations, P.O. Box 2001, Oak Ridge, TN 37831-8620

45. I. Tasker, Waste Policy Institute, 555 Quince Orchard Road, Suite 600, Gaithersburg, MD 20878-1437

46. Major Thompson, Westinghouse Savannah River Co., Savannah River Technology Center, Building 773-A, Aiken, SC 29808 


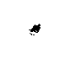

$=$

$=$

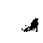

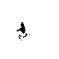

